\title{
Continuous catalytic process for the selective dehydration of glycerol over Cu-based mixed oxide
}

\author{
Jaime Mazarío ${ }^{a}$, Patricia Concepción ${ }^{a}$, María Ventura ${ }^{a}$, Marcelo E. Domine*a \\ a Instituto de Tecnología Química (UPV-CSIC). Universitat Politècnica de València. \\ Consejo Superior de Investigaciones Científicas. Avda. de los Naranjos s/n, 46022, \\ Valencia, Spain.
}

* mdomine@itq.upv.es

\section{Abstract}

The selective dehydration of glycerol to hydroxyacetone (acetol) was studied with $\mathrm{Cu}$ based mixed oxides derived from hydrotalcite as catalysts in a continuous flow fix-bed reactor. Catalysts were prepared by co-precipitation and characterized by ICP, $\mathrm{N}_{2}$ adsorption, $\mathrm{XRD}, \mathrm{NH}_{3}-\mathrm{TPD}, \mathrm{CO}_{2}-\mathrm{TPD}, \mathrm{TPR}$ and TEM. Different parameters were investigated to develop the most appropriate material as well as to determine the function of every metallic species. The optimized $\mathrm{Cu}-\mathrm{Mg}-\mathrm{AlO} \mathrm{O}_{\mathrm{x}}$ offered $\approx 60 \%$ acetol selectivity at $>90 \%$ glycerol conversion ( $\approx 80 \%$ liquid yield, up to TOS $=9 \mathrm{~h})$. The catalyst could be regenerated by calcination, achieving full activity recovery after five re-cycles. "In-situ" FTIR and XPS measurements evidenced that the presence of $\mathrm{Cu}$, specially the most active $\mathrm{Cu}^{1+}$ species, was essential to carry out the dehydration to acetol with high reaction rates, and to form the preferred intermediate (with $\mathrm{C}=\mathrm{O}$ group); although a minor contribution from $\mathrm{Cu}^{0}$ and $\mathrm{Cu}^{2+}$ species could not be discarded. 


\section{Keywords}

acetol, glycerol, glycerol dehydration, copper catalyst, mixed oxides 


\section{Introduction}

Nowadays, fossil fuels such as coal, petroleum and natural gas provide more than $75 \%$ of the total energy consumed in our planet and represent an essential source of raw materials for the chemical industry [1]. Nonetheless, the growing use of these resources has led to their depletion along with an increment in the levels of $\mathrm{CO}_{2}$ emissions to the atmosphere, which is considered as the main cause of the greenhouse gases (GHG) effect in the planet. Thus, the conversion of alternative, clean and renewable raw materials such as biomass into fuels and chemicals has become an interesting way of dealing with global warming and contributing to the diversity of energy sources [2-5].

In the last years, a wide variety of the so-called biofuels has appeared in the market: bioethanol, biobutanol, biodiesel, biogas or pyrolysis gases as promising renewable alternatives [6]. The common feature of these biofuels is the reduced amount of greenhouse gases generated while using them in different applications, thereby allowing to design processes without $\mathrm{CO}_{2}$ net emission provided that efficient crop methods are developed to produce the biomass of interest $[3,5]$.

Regarding the biodiesel, it is synthesized by means of a transesterification reaction using triglycerides (vegetable oils) and methanol or ethanol to produce the corresponding methyl or ethyl-esters. The raw materials being the source of triglycerides used to be colza, sunflower, soy or palm oil, whereas the biodiesel obtained can be used directly as a fuel or mixed with petro-diesel in different ratios [3]. However, in the last years, and due to the constrains derived from the use of agricultural suitable land and vegetables for fuel industry against food applications, biodiesel production coming from the transformation and upgrading of used oils derived from food industry, as well as from other residues and unconventional raw materials (i.e. animal fats, agricultural and domestic wastes, oil 
wastes, etc.) [7-9] started to be developed. Even in these novel cases, huge amounts of glycerol are also obtained as a by-product, which is supposed to be somehow used if the biorefinery wants the process to be profitable [10]. Consequently, the transformation and valorization of glycerol has been broadly studied by many research groups working in catalysis, and compiled in some interesting reviews [11-13]. This academic effort has resulted in glycerol integrating the list of the twelve more important platform molecules derived from biomass [14]. Many possibilities of valorization for this molecule by using heterogenous catalysis have been developed in the last years. Processes such as the synthesis of glycerol carbonate for solvent and polymer production with hydrotalcitederived oxides [15] or zeolites [16] as catalysts, the glycerol steam reforming to produce syn-gas using catalysts containing $\mathrm{Pt}$, Ru or Re supported on different inorganic matrix [17], as well as the manufacture of fuel additives by means of glycerol acetalization, etherification or esterification reactions [18] are among the most relevant catalytic strategies up to now reported.

The selective dehydration of glycerol to hydroxyacetone (or acetol) is of interest if the reactivity of this molecule, having a terminal hydroxyl group and a carbonyl group in the second carbon, is considered. These functional features give this molecule the possibility of taking part in different organic reactions such as the Mannich reaction [19] or some aldolic condensations [20]. Besides, acetol is a key intermediate in the production of 1,2propanediol or propylene glycol [21]. Therefore, a better understanding of this glycerol dehydration could also give an improvement on the yield to propylene glycol and on any product derived from it.

With respect to acetol production, Chiu et al. have studied the dehydration of glycerol to acetol with different heterogeneous catalysts in a reactive distillation system, the highest values of conversion and selectivity being reached with copper-chromite catalyst [22]. 
Nevertheless, copper-chromite cannot be considered as an environmentally friendly catalyst due to its toxicity and, additionally, the scale-up of a reactive distillation system is not straightforward from an industrial viewpoint. In this sense, continuous catalytic processes would be more suitable, although just a few articles can be found in the literature [23-25], most of them involving the use of hydrogen. In this regard, it would be very interesting to develop a continuous and sustainable process for the selective dehydration of glycerol to acetol by using an efficient heterogeneous catalyst.

Due to the considerable number of studies carried out to produce acrolein, the other possible dehydration product from glycerol, Brönsted acid centers are believed to present a higher selectivity to its formation. On the contrary, Lewis acid centers would in principle provide more selectivity towards acetol $[26,27]$. Nonetheless, it is worth noting that some contradictory opinions can be found in the literature about the reaction mechanism of this system. Some authors argue that the acetol formation could be favored by a certain ratio between acid and basic Lewis centers [28,29]. Following this idea, and to effectively carry out the selective dehydration of glycerol to acetol, it is reasonable to think that the combination of both acid and basic Lewis centers contained in metallic mixed oxides derived from hydrotalcites constitutes an excellent alternative to accomplish this target.

Hydrotalcite-type materials are Mg-Al lamellar double hydroxides with a structure derived from brucite $\left[\mathrm{Mg}(\mathrm{OH})_{2}\right]$. This structure is constituted by two dioctahedral sheets of magnesium hydroxide with water molecules in the interlaminar space. Hydrotalcites are the result of an isomorphic substitution of some $\mathrm{Mg}^{2+}$ by $\mathrm{Al}^{3+}$ thereby the sheet acquires a positive charge which allows several anions to be located beside the water molecules in the interlaminar space (in its natural state mainly $\mathrm{OH}^{-}$and $\mathrm{CO}_{3}{ }^{2-}$ ). This structure is common to many natural and synthetic materials having the same empirical formula [30-32]: $\mathrm{M}^{2+}{ }^{2+} \mathrm{b}^{3+}(\mathrm{OH})_{2 a+2 b}\left(\mathrm{X}^{-}\right)_{2 b} \cdot \mathrm{xH}_{2} \mathrm{O}$. During the calcination, the structure collapses and yields a 
low-crystalline mixed oxide with cationic vacancies produced due to the need of equilibrating the excess of positive charge introduced by replacing some $\mathrm{Mg}^{2+}$ by $\mathrm{Al}^{3+}$. Therefore, with respect to $\mathrm{MgO}$, the material exhibits some stronger Lewis basic sites, corresponding to unsaturated $\mathrm{O}^{2-}$, and some weak acid sites, corresponding to $\mathrm{Al}^{3+}[32-$ 34].

Among their many advantages, hydrotalcite-type materials have an easy and low-cost synthesis procedure; they are non-toxic and possess the capacity of easily modifying their physicochemical properties by means of controlling their composition. Thus, amount and strength of both basic and acid sites can be adapted to the catalytic process needs just by changing the $\mathrm{M}^{2+} / \mathrm{M}^{3+}$ molar ratio. In addition, different metals (others than $\mathrm{Mg}$ and $\mathrm{Al}$ ) can also be incorporated in the hydrotalcite precursor either during the synthesis or in postsynthesis steps, thus extending the versatility of these materials.

In light of all the above-mentioned, in this work an efficient continuous catalytic process for the selective dehydration of glycerol to acetol (see Scheme 1) in a fixed bed reactor by using transition metal hydrotalcite-derived materials as catalysts and without introducing hydrogen in the reactor is designed and optimized. Concretely, Mg/Al hydrotalcite-type materials with different amounts of $\mathrm{Cu}, \mathrm{Ni}$, or Co were prepared, since these transition metals have been reported to help to produce acetol as an intermediate during glycerol reforming $[35,36]$. Their hydrotalcite-derived metallic mixed oxides were evaluated in the production of the desired acetol from glycerol. Special attention is paid to the role of copper in the formation of acetol and the influence of its oxidation state in that process, as it appears to be a key point to generate the dehydration product, as it was observed during glycerol hydrogenolysis process $[37,38]$. 


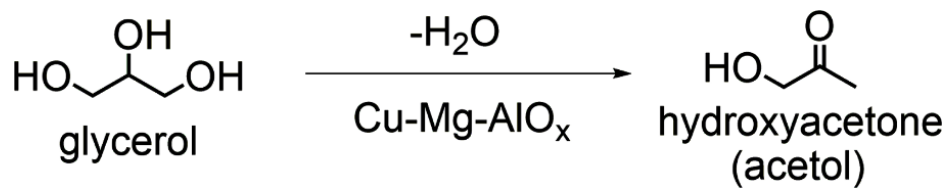

Scheme 1. Selective dehydration of glycerol to acetol over Cu-Mg-Al mixed oxide.

\section{Experimental}

\subsection{Materials}

Glycerol (Sigma-Aldrich, 99.5\%) was used as reagent in the dehydration reaction. For the analysis of the reaction products acetol (90\%), methyl glycolate $(99 \%)$, methyl lactate (98\%), acetoin (98\%), methyl pyruvate (98\%), acetic acid (99\%), propionic acid $(99.5 \%)$, 1,2-propanediol 99.5\%), 1,3-propanediol (98\%), methyl acetate (98\%), methyl formiate (99\%) and chlorobenzene (internal standard, 99\%) were purchased from Sigma-Aldrich and used as received. Acrolein (Merck, 95\%) and dihydroxyacetone (Merck, 98\%) were also used. Methanol (reagent grade $99.9 \%$ ) supplied by Scharlau and water (Milli-Q quality, Millipore) were used as solvents. Hydrotalcite-type materials were prepared by using in each case the suitable metallic precursors bought from Sigma-Aldrich: $\mathrm{Mg}\left(\mathrm{NO}_{3}\right)_{2} \cdot 6 \mathrm{H}_{2} \mathrm{O}(99 \%), \mathrm{Al}\left(\mathrm{NO}_{3}\right)_{3} \cdot 9 \mathrm{H}_{2} \mathrm{O}(98 \%), \mathrm{Cu}\left(\mathrm{NO}_{3}\right)_{2} \cdot 2.5 \mathrm{H}_{2} \mathrm{O}(98 \%), \mathrm{Ni}\left(\mathrm{NO}_{3}\right)_{2} \cdot 6 \mathrm{H}_{2} \mathrm{O}$ (98.5\%) and $\mathrm{Co}\left(\mathrm{NO}_{3}\right)_{2} \cdot 6 \mathrm{H}_{2} \mathrm{O}(98 \%)$. In addition, $\mathrm{Na}_{2} \mathrm{CO}_{3}$ (Fisher Chemical, 99.7\%), $\mathrm{NaOH}$ (Sigma-Aldrich, 98.0\%) and $\mathrm{H}_{2} \mathrm{O}$ (milliQ, Millipore) were also used for their synthesis. For comparative purposes $\mathrm{MgO}$ and $\mathrm{Al}_{2} \mathrm{O}_{3}$ (Sigma-Aldrich) were also tested in the reaction. Hydrogen (99.999\%) was purchased from Abelló Linde S.A.

\subsection{Catalyst preparation}

Hydrotalcite-type materials were prepared by the co-precipitation method under well optimized synthesis (and aging) conditions, following the procedure described in refs. 
$[15,39]$ and starting from two different solutions. Solution A, containing the metallic species (Al, $\mathrm{Mg}$ and $\mathrm{Cu} / \mathrm{Ni} / \mathrm{Co}$ ) in the desired molar ratios as nitrates and not exceeding 1.5 of total cationic concentration; and solution B, containing sodium hydroxide and sodium carbonate in adequate amounts to accomplish a $\mathrm{CO}_{3}{ }^{2-}$ / (total cationic number) ratio always equal to 0.66. These solutions were added at the same rate $(20 \mathrm{ml} / \mathrm{h})$ to an empty plastic beaker with continuous stirring at $200 \mathrm{rpm}$. The precipitates were aged at $60^{\circ} \mathrm{C}$ overnight in a thermostatic bath. The resulting products were filtered and washed thoroughly with deionized water until $\mathrm{pH}=7$. Depending on the transition metal to be incorporated in the hydrotalcite, the corresponding $\mathrm{Cu}\left[\mathrm{Cu}\left(\mathrm{NO}_{3}\right)_{2} \cdot 2.5 \mathrm{H}_{2} \mathrm{O}\right], \mathrm{Ni}\left[\mathrm{Ni}\left(\mathrm{NO}_{3}\right)_{2} \cdot 6 \mathrm{H}_{2} \mathrm{O}\right]$ or $\mathrm{Co}$ $\left[\mathrm{Co}\left(\mathrm{NO}_{3}\right)_{2} \cdot 6 \mathrm{H}_{2} \mathrm{O}\right]$ precursors were used. The hydrotalcites were calcined at $550{ }^{\circ} \mathrm{C}$ during $6 \mathrm{~h}$ in air to yield the corresponding metal-based mixed oxides used in the catalytic tests. Additionally, and in the case of Cu-based samples, one material was reduced under $\mathrm{H}_{2}$ flow $(100 \mathrm{~mL} / \mathrm{min})$ at $450{ }^{\circ} \mathrm{C}$ during $3 \mathrm{~h}$, and another amount of the same material was partially reduced at $200{ }^{\circ} \mathrm{C}$ during $3 \mathrm{~h}$, prior to their use in the catalytic experiments.

\subsection{Catalyst characterization}

Hydrotalcite-type and metal mixed oxides materials were characterized by ICP (inductively coupled plasma), with a Varian 715-ES ICP-Optical Emission spectrometer, after solid dissolution in $\mathrm{HNO}_{3} / \mathrm{HCl}$ aqueous solution. Phase purity of the catalysts was determined by X-ray diffraction (XRD) in a Philips X'Pert MPD diffractometer equipped with a PW3050 goniometer (CuKa radiation, graphite monochromator), provided with a variable divergence slit and working in the fixed irradiated area mode. The obtained diffractograms were compared with those found at the PDF2 database (codes in parenthesis). Surface areas of the solid samples $(200 \mathrm{mg}$ ) were calculated by applying the BET method to the $\mathrm{N}_{2}$ adsorption isotherms obtained by carrying out liquid nitrogen adsorption experiments at $77 \mathrm{~K}$, in a Micromeritics flowsorb apparatus. 
The reduction behavior of copper in these materials was studied by temperatureprogrammed reduction (TPR) analysis carried out in a Micromeritics Autochem 2910 equipment. About $30 \mathrm{mg}$ of sample were initially flushed with $30 \mathrm{~cm}^{3} / \mathrm{min}$ of $\mathrm{Ar}$ at room temperature for $30 \mathrm{~min}$, and then a mixture of 10 vol\% of $\mathrm{H}_{2}$ in Ar was passed through the catalyst at a total flow rate of $50 \mathrm{~cm}^{3} / \mathrm{min}$, while the temperature was increased up to 1273 $\mathrm{K}$ at a heating rate of $10 \mathrm{~K} / \mathrm{min}$. The $\mathrm{H}_{2}$ consumption rate was monitored in a thermal conductivity detector (TCD) previously calibrated using the reduction of $\mathrm{CuO}$ as reference. In addition, X-ray photoelectron spectroscopy (XPS) was used to determine the oxidation states of copper species at the catalyst surface. XPS data were collected on a SPECS spectrometer equipped with a 150-MCD-9 detector and using a non-monochromatic Mg $\mathrm{Ka}(1253.6 \mathrm{eV}) \mathrm{X}$-ray source. Spectra were recorded at $25^{\circ} \mathrm{C}$, using an analyzer pass energy of $30 \mathrm{eV}$, an X-ray power of $50 \mathrm{~W}$ (to avoid photo-reduction) and under an operating pressure of $10^{-9}$ mbar. During data processing of the XPS spectra, binding energy (BE) values were referenced to the $\mathrm{Al} 2 \mathrm{p}$ peak settled at $73.5 \mathrm{eV}$. Spectra treatment was performed using the CASA software.

Acid and basic centers present in our materials were determined by temperature programmed desorption of ammonia ( $\left.\mathrm{NH}_{3}-\mathrm{TPD}\right)$ and carbon dioxide ( $\left.\mathrm{CO}_{2}-\mathrm{TPD}\right)$, respectively, carried out on a TPD/2900 apparatus from Micromeritics. Approximately, $0.100 \mathrm{~g}$ of sample were pre-treated in an Ar stream at $300{ }^{\circ} \mathrm{C}$ during $1 \mathrm{~h}$. Ammonia was chemisorbed by pulses at $100^{\circ} \mathrm{C}$ until equilibrium was reached, while carbon dioxide was chemisorbed in the same way at room temperature. Then, the sample was fluxed with helium stream during $15 \mathrm{~min}$, prior to increase the temperature up to either $500{ }^{\circ} \mathrm{C}\left(\mathrm{NH}_{3}\right)$ or $650{ }^{\circ} \mathrm{C}\left(\mathrm{CO}_{2}\right)$ in a helium stream of $100 \mathrm{ml} / \mathrm{min}$ and using a heating rate of $10^{\circ} \mathrm{C} / \mathrm{min}$. Gas adsorption was monitored with a calibrated thermal conductivity detector (TCD), representing a quantitative value. On the other hand, a non-calibrated mass-spectrometer 
(MS) was used to follow ammonia desorption, providing us with a qualitative information about the strength distribution of acid sites.

FT-IR spectrometry studies were recorded with a Bruker 70V spectrometer using a DTGS detector and acquiring at $4 \mathrm{~cm}^{-1}$ resolution. An IR cell allowing "in situ" treatments in controlled atmospheres and temperatures from $25^{\circ} \mathrm{C}$ to $500{ }^{\circ} \mathrm{C}$ was connected to a vacuum system with gas/liquid dosing facility. For IR studies the samples were pressed into self-supported wafers and treated at $300^{\circ} \mathrm{C}$ in Nitrogen flow $\left(20 \mathrm{ml} \cdot \mathrm{min}^{-1}\right)$ during $1 \mathrm{~h}$ followed by evacuation at $10^{-4}$ mbar at $100^{\circ} \mathrm{C}$ during $1 \mathrm{~h}$, except in the ex situ $\mathrm{H}_{2}$ reduced sample which was activated in vacuum at $100^{\circ} \mathrm{C}$ for $1 \mathrm{~h}$. After activation the samples were cooled down to $25^{\circ} \mathrm{C}$ under dynamic vacuum conditions and exposed to $1.5 \mathrm{mbar}$ of $1,2-$ propanediol and/or hydroxyacetone followed by evacuation at $25^{\circ} \mathrm{C}$ during $5 \mathrm{~min}$. In the case of 1,2-propanediol the temperature was risen under static vacuum conditions to 80 ${ }^{\circ} \mathrm{C}$ and $160^{\circ} \mathrm{C}$ acquiring IR spectra at $45 \mathrm{~min}$ of each temperature. Once achieved $45 \mathrm{~min}$ at $160{ }^{\circ} \mathrm{C}$, the sample was evacuated and cooled down to $25^{\circ} \mathrm{C}$ where 10 mbar $\mathrm{CO}$ has been adsorbed for surface titration. In order to avoid surface reduction by CO, IR spectra was immediately collected. IR spectra were processed using the Origin software. For NO adsorption studies, after activation the samples were cooled down to $-156^{\circ} \mathrm{C}$ under dynamic vacuum conditions followed by NO dosing at increasing pressure $(0.05-0.60$ mbar). IR spectra were recorded after each dosage. After maximum NO dosing, the samples were evacuated under dynamic vacuum conditions at $10^{-5} \mathrm{mbar}$ and IR spectra acquired at controlled times.

High-resolution transmission electron microscopy (HR-TEM) was done using a Jeol JEM$2100 \mathrm{~F}$ operating at $200 \mathrm{kV}$. The microscope was also equipped with a high-angle annular dark-field (HAADF) detector and an EDS X-Max 80 detector. HR micrograph analysis, lattice spacing, First Fourier Transform (FFT) and phase interpretation, were done with 
the Gatan Digital Micrograph software (Gatan Inc.). Besides, thanks to the EDS detector, with a resolution of $127 \mathrm{eV}$, maps with different colours depending on the element were obtained. Jeol JSM6300 operating at $20 \mathrm{kV}$ and equipped with an energy-dispersive X-ray spectrometer (EDX) was used to obtain Screen Electron Microscopy (SEM) images and compositional mappings.

Thermogravimetric analyses (TG) were carried out in a Mettler Toledo TGA/SDTA 851 apparatus, using a heating rate of $10^{\circ} \mathrm{C} / \mathrm{min}$ in an air stream until $800{ }^{\circ} \mathrm{C}$ was reached. Elemental analysis (EA) was carried out in a Fisons EA1108CHN-S apparatus. These two techniques (TG and EA) together with ICP, $\mathrm{N}_{2}$ adsorption and $\mathrm{XRD}$ measurements were applied to determine and evaluate the organic content, the metal leaching, and the stability of metal mixed oxide structures, respectively, after several consecutive uses of the catalysts under reaction conditions.

\subsection{Catalytic tests}

Catalytic experiments were performed in a stainless-steel tubular fixed-bed reactor (length $=25 \mathrm{~cm}$ and diameter $=0.5 \mathrm{~cm}$ ), with the catalyst pelletized in particles $0.4-0.6 \mathrm{~mm}$ in size and diluted with $\mathrm{SiC}(0.6-0.8 \mathrm{~mm})$. Typically, catalytic tests were carried out by feeding the reactor with a liquid mixture of glycerol $(\mathrm{GLY})$ and methanol $(\mathrm{MeOH})$ (10:90 weight ratio) at temperatures between 220 and $280^{\circ} \mathrm{C}$ during $9 \mathrm{~h}$. For each experiment, cumulative fractions corresponding to $0-1 \mathrm{~h}, 1-2 \mathrm{~h}, 2-3 \mathrm{~h}$, etc. were collected in a glass recipient submerged in an ice bath, and then analyzed by HPLC (Shimadzu Nexera LC-20 AD XR, reverse phase, Hi-Plex H Column 300x7.7 mm, and PL Hi-Plex Guard Column 50x7.7 $\mathrm{mm}$ ), and also by GC (Varian CP-3800, CARBOWAX Column $15 \mathrm{~m} \times 3.2 \mathrm{~mm}$ ). Product identification was done by GC-MS (Agilent 6890N GC System coupled with an Agilent $5973 \mathrm{~N}$ mass detector). 
With the aim of calculating conversions and, taking into account that some few amounts of glycerol are retained on the catalytic surface and part of it could be later transformed into coke, the total yield to products was considered as the actual conversion, as it gives more information about the "effective activity" of our materials:

$X_{\text {glycerol }}(\%)=\frac{\sum n_{\text {product }_{i}}^{f} a_{i}}{n_{\text {glycerol }}^{0}} \cdot 100$

Being $a_{i}$ the stoichiometric correction factor for the product ${ }_{i}$.

Selectivity to acetol (and to the different products) was also calculated as a function of the total amount of products as follows:

$S_{\text {acetol }}(\%)=\frac{n_{\text {acetol }}^{f}}{n_{\text {total products }}^{f}} \cdot 100$

Finally, gaseous products mainly derived from methanol conversion in some specific pretreatment experiments were analyzed at the exit of the reactor. The gas composition was determined using a GC fitted with 3 detection lines: i) one for $\mathrm{H}_{2}$ separated on a $5 \mathrm{~A}$ molecular sieve column (with Ar as carrier) and quantified on a TCD, ii) a second one for $\mathrm{N}_{2}$ separated on a $13 \mathrm{X}$ molecular sieve column (with He as carrier) and quantified on a second TCD, and iii) a third one equipped with Al-plot column (with He as carrier) and a FID detector for hydrocarbons quantification. This, together, with the TG analysis (see section 2.3) allowed us to calculate the carbon balance of the reaction with respect to the total amount of glycerol fed into the reactor.

$C B_{\text {glycerol }}(\%)=\frac{\sum n_{\text {product }_{i}}^{f} \cdot x_{i} \text { C atoms }}{n_{\text {glycerol }^{0}} \cdot 3 \text { C atoms }} \cdot 100$

Being $x_{i}$ the number of carbon atoms in the product $_{i}$ coming from glycerol reaction. 


\subsection{Re-usability tests}

After the reaction, the solid catalyst was washed with $20 \mathrm{~mL}$ of methanol $(2 \mathrm{~mL} / \mathrm{min})$ in the same reactor, and then calcined at $550{ }^{\circ} \mathrm{C}$ during $6 \mathrm{~h}$ in air. The catalytic experiments together with the analytics corresponding to the re-usability tests were performed in the same way as the common experiments already described at the beginning of section 2.4.

\section{Results and discussions}

\subsection{Catalysts characterization}

A series of hydrotalcite-type (HTs) materials with different molar ratio $\mathrm{M}^{2+} / \mathrm{M}^{3+}$, copper loading close to $5 \mathrm{wt} \%$, and surface areas of around $200 \mathrm{~m}^{2} / \mathrm{g}$ were firstly synthesized and well characterized. Table 1 shows the main physicochemical and textural properties of $\mathrm{Cu}$ based hydrotalcite-derived materials after calcination.

The structural characteristics of the Cu-based hydrotalcite-type materials were analyzed by XRD measurements. For the non-calcined Cu-HTs samples, the X-ray diffractograms of Figure 1 show that a common Mg/Al layered hydrotalcite structure is obtained in practically all samples. Only in the case of $5.0 \% \mathrm{Cu}-\mathrm{HT}-1$ sample, several diffraction peaks from aluminum hydroxide are observed. This is probably due to the large amount of $\mathrm{Al}^{3+}$ present in the initial solution, precipitated apart from the Cu-Mg-Al hydrotalcite and unable to enter inside the hydrotalcite structure during the co-precipitation process.

After the calcination of the Cu-based HT-precursors, the corresponding Cu-Mg-Al mixed oxides were attained, and their XRD patterns are drawn in Figure 1b. For Cu-based mixed oxides the desired phase with poorly crystalline $\mathrm{MgO}$ structure containing the cationic 
species in the appropriate proportions has been obtained in practically all the measured materials, being necessary to emphasize the greater level of crystallization when increasing the $\mathrm{Mg}$ content. In the case of $5.0 \% \mathrm{Cu}-\mathrm{HT}-1$ calcined sample, its X-ray diffractogram exhibits some peaks corresponding to aluminum oxide, as expected after analyzing the diffractogram belonging to the hydrotalcite precursor. It seems that after the calcination process some $\mathrm{Al}^{3+}$ from bayerite became part of the crystal lattice but other remained apart, giving rise to this aluminum oxide.

Table 1. Main physicochemical and textural properties of Cu-based HT-derived calcined materials with different $\mathrm{M}^{\prime \prime} / \mathrm{M}^{\prime \prime \prime}$ ratios.

\begin{tabular}{|c|c|c|c|}
\hline Catalyst & $\begin{array}{c}\text { Cu content } \\
(w t \%)^{a}\end{array}$ & $\begin{array}{l}\mathrm{M}^{\mathrm{II}} / \mathrm{M}^{\mathrm{III}} \text { molar } \\
\text { ratio }^{\mathrm{a}}\end{array}$ & $\begin{array}{c}\text { Surface area }\left(\mathrm{m}^{2} / \mathrm{g}\right)^{\mathrm{b}} \\
\text { [BET method] }\end{array}$ \\
\hline $5.0 \% \mathrm{Cu}-\mathrm{HT}-1$ & 4.9 & 1.0 & 218 \\
\hline $5.0 \% \mathrm{Cu}-\mathrm{HT}-2$ & 4.6 & 2.3 & 245 \\
\hline $5.0 \% \mathrm{Cu}-\mathrm{HT}-3$ & 4.9 & 3.3 & 212 \\
\hline $5.0 \% \mathrm{Cu}-\mathrm{HT}-4$ & 4.9 & 4.1 & 205 \\
\hline $5.0 \% \mathrm{Cu}-\mathrm{HT}-5$ & 5.1 & 5.5 & 224 \\
\hline $5.0 \% \mathrm{Cu}-\mathrm{HT}-6$ & 4.8 & 6.3 & 177 \\
\hline
\end{tabular}




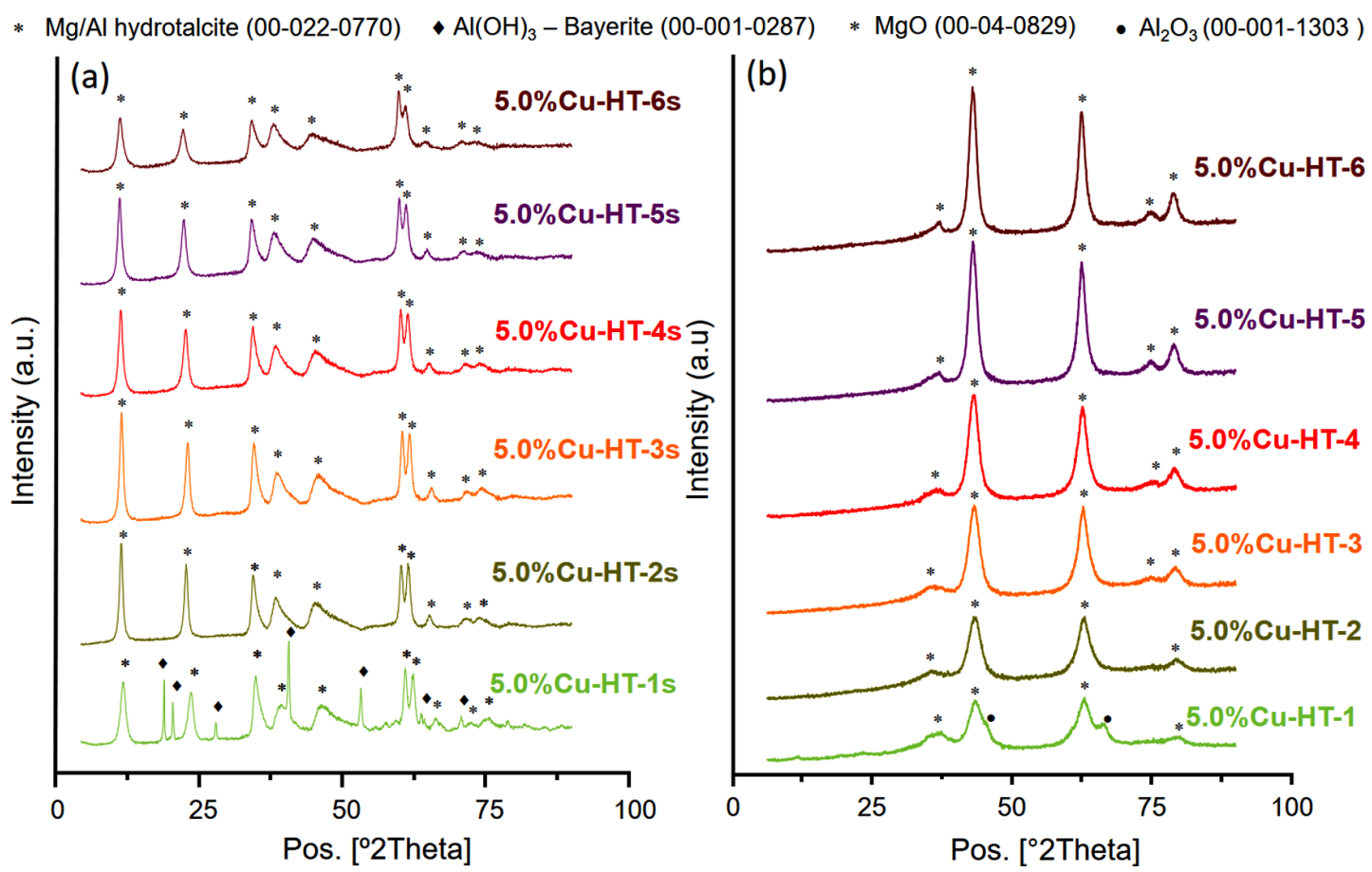

Figure 1. a) XRD patterns of as-synthesized Cu-based hydrotalcites with different $\mathrm{M}^{\prime \prime} / \mathrm{M}^{\prime \prime \prime}$ ratios (the "s" at the end of the name indicates a material analyzed just after the synthesis). b) XRD patterns of Cu-based hydrotalcite-derived mixed oxides with different $\mathrm{M}^{\prime \prime} / \mathrm{M}^{\mathrm{III}}$ ratios.

A second series of hydrotalcite-type materials having the same proportion $(5.0 \mathrm{wt} \%$ with respect to the calcined material) of different transition metals, such as $\mathrm{Cu}$, Co and $\mathrm{Ni}$, and by fixing the molar ratio $\mathrm{M}^{2+} / \mathrm{M}^{3+}$ equal to 4 were prepared and characterized. The main physicochemical and textural properties of $5.0 \% \mathrm{Cu}-\mathrm{HT}-4,5.0 \% \mathrm{Co}-\mathrm{HT}-4$, and $5.0 \% \mathrm{Ni}-\mathrm{HT}-$ 4 calcined samples are summarized in Table 2. Chemical composition of this series of materials is again very similar to the theoretical one, while the attained surface areas are close to $200 \mathrm{~m}^{2} / \mathrm{g}$ in the three cases. 
Table 2. Main physicochemical and textural properties of HT-derived calcined materials containing different transition metals.

\begin{tabular}{cccc}
\hline Catalyst & $\begin{array}{c}\text { Metal content } \\
(\mathbf{w t} \%)^{\mathrm{a}}\end{array}$ & $\begin{array}{c}\mathbf{M}^{\mathrm{I}} / \mathrm{M}^{\mathrm{III}} \text { molar } \\
\text { ratio }^{\mathrm{a}}\end{array}$ & $\begin{array}{c}\text { Surface area }\left(\mathbf{m}^{\mathbf{2}} / \mathbf{g}\right)^{\mathbf{b}} \\
\text { [BET method] }\end{array}$ \\
\hline $\mathbf{5 . 0 \% C u - H T - 4}$ & 4.9 & 4.1 & 205 \\
$\mathbf{5 . 0 \% \text { Co-HT-4 }}$ & 4.9 & 4.2 & 198 \\
$\mathbf{5 . 0 \% N i - H T - 4}$ & 5.1 & 4.2 & 190 \\
\hline
\end{tabular}

a Metal ( $\mathrm{Cu}$, Co or $\mathrm{Ni}$ ) content and chemical composition measured by ICP.- ${ }^{b}$ Values calculated from $\mathrm{N}_{2}$ adsorption isotherms by applying the BET method.-

As can be seen in Figure S1a (see SI), the XRD patterns of the three Cu-HT-4, Co-HT-4 and Ni-HT-4 as-prepared samples showed the characteristic peaks corresponding to the formation of well-crystallized layered double hydroxides of the hydrotalcite structure. Therefore, both the $5.0 \% \mathrm{Ni}-\mathrm{HT}-4$ and the $5.0 \% \mathrm{Co}-\mathrm{HT}-4$ samples contain the majority of either $\mathrm{Ni}^{2+}$ or $\mathrm{Co}^{3+}$ ions in the hydrotalcite structure partially substituting $\mathrm{Mg}^{2+}$ and $\mathrm{Al}^{3+}$ ions, respectively. In the case of $\mathrm{Ni}$ - and Co-based mixed oxides obtained after calcination of hydrotalcite precursors, the X-ray diffractograms of Figure S1b (see SI) only show the peaks corresponding to the formation of the $\mathrm{MgO}$ structure. This meaning that $\mathrm{Ni}^{2+}$ and $\mathrm{Co}^{3+}$ ions are well dispersed on the $\mathrm{Mg}-\mathrm{Al}-\mathrm{O}$ structure in both cases.

Finally, different hydrotalcite-type materials with a $\mathrm{M}^{\prime \prime} / \mathrm{M}^{\mathrm{II}}$ molar ratio of $\approx 4$ possessing different $\mathrm{Cu}$ loadings (from 1.0 to $12.8 \mathrm{wt} \%$ ) were synthesized and characterized. The main physicochemical and textural properties of these Cu-based HT-4 calcined samples are detailed in Table 3, showing that the $\mathrm{Cu}$ was incorporated in the expected amounts into the hydrotalcite precursors, which maintain a $\mathrm{M}^{11} / \mathrm{M}^{111}$ molar ratio around 4 and surface areas close to $200 \mathrm{~m}^{2} / \mathrm{g}$. 
Table 3. Main physicochemical and textural properties of Cu-based HT-derived calcined materials with different copper loadings.

\begin{tabular}{|c|c|c|c|}
\hline Catalyst & $\begin{array}{c}\text { Cu content } \\
(w t \%)^{a}\end{array}$ & $\begin{array}{l}M^{\prime \prime} / M^{1 I I} \text { molar } \\
\text { ratio }^{a}\end{array}$ & $\begin{array}{c}\text { Surface area }\left(\mathrm{m}^{2} / \mathrm{g}\right)^{\mathrm{b}} \\
\text { [BET method] }\end{array}$ \\
\hline HT-4 & - & 4.3 & 249 \\
\hline $1.0 \% \mathrm{Cu}-\mathrm{HT}-4$ & 1.0 & 4.4 & 196 \\
\hline $2.5 \% \mathrm{Cu}-\mathrm{HT}-4$ & 2.4 & 4.1 & 199 \\
\hline $5.0 \% \mathrm{Cu}-\mathrm{HT}-4$ & 4.9 & 4.1 & 205 \\
\hline $7.0 \% \mathrm{Cu}-\mathrm{HT}-4$ & 6.7 & 4.1 & 193 \\
\hline $10.0 \%$ Cu-HT-4 & 9.9 & 4.2 & 196 \\
\hline $12.0 \% \mathrm{Cu}-\mathrm{HT}-4$ & 12.8 & 4.1 & 186 \\
\hline
\end{tabular}

The XRD patterns of the Cu-based materials containing different $\mathrm{Cu}$ loadings before and after calcination treatment are depicted in Figure S2a and S2b (see SI), respectively. For these Cu-based series of samples, both the desired hydrotalcite phase and the mixed oxide phase with $\mathrm{MgO}$ structure are observed for the non-calcined and calcined material, respectively. Interestingly, even for the materials containing quantities of copper above $5.0 w t \%$ non-isolated copper species are noticed.

In good agreement with what has been observed by XRD, microscopy analyses (SEM and HR-TEM) of the materials $5.0 \% \mathrm{Cu}-\mathrm{HT}-4,10.0 \% \mathrm{Cu}-\mathrm{HT}-4$ and $12.0 \% \mathrm{Cu}-\mathrm{HT}-4$ (Figure 2, and Figures S6-8 in SI) confirm that the materials were, mostly, homogeneous, with a $\mathrm{MgO}$ structure, also showing a very high copper dispersion inside this crystalline structure. 
However, a very careful analysis by using HR-TEM allowed us to detect $\mathrm{CuO}_{\mathrm{x}}$ nanoparticles in $12.0 \% \mathrm{Cu}-\mathrm{HT}-4$ (Figure S16b). For materials containing lower copper loadings, those nanoparticles were not evident with this technique but, when using a more sensitive bulk technique such as $\mathrm{NO}$ adsorption (see Figure S9), again isolated $\mathrm{CuO}_{\mathrm{x}}$ species became visible. Nonetheless, the XRD data together with the microscopic measurements evidence that most of the copper integrates the crystalline lattice in materials containing less than $12.0 w t \%$ of $\mathrm{Cu}$.
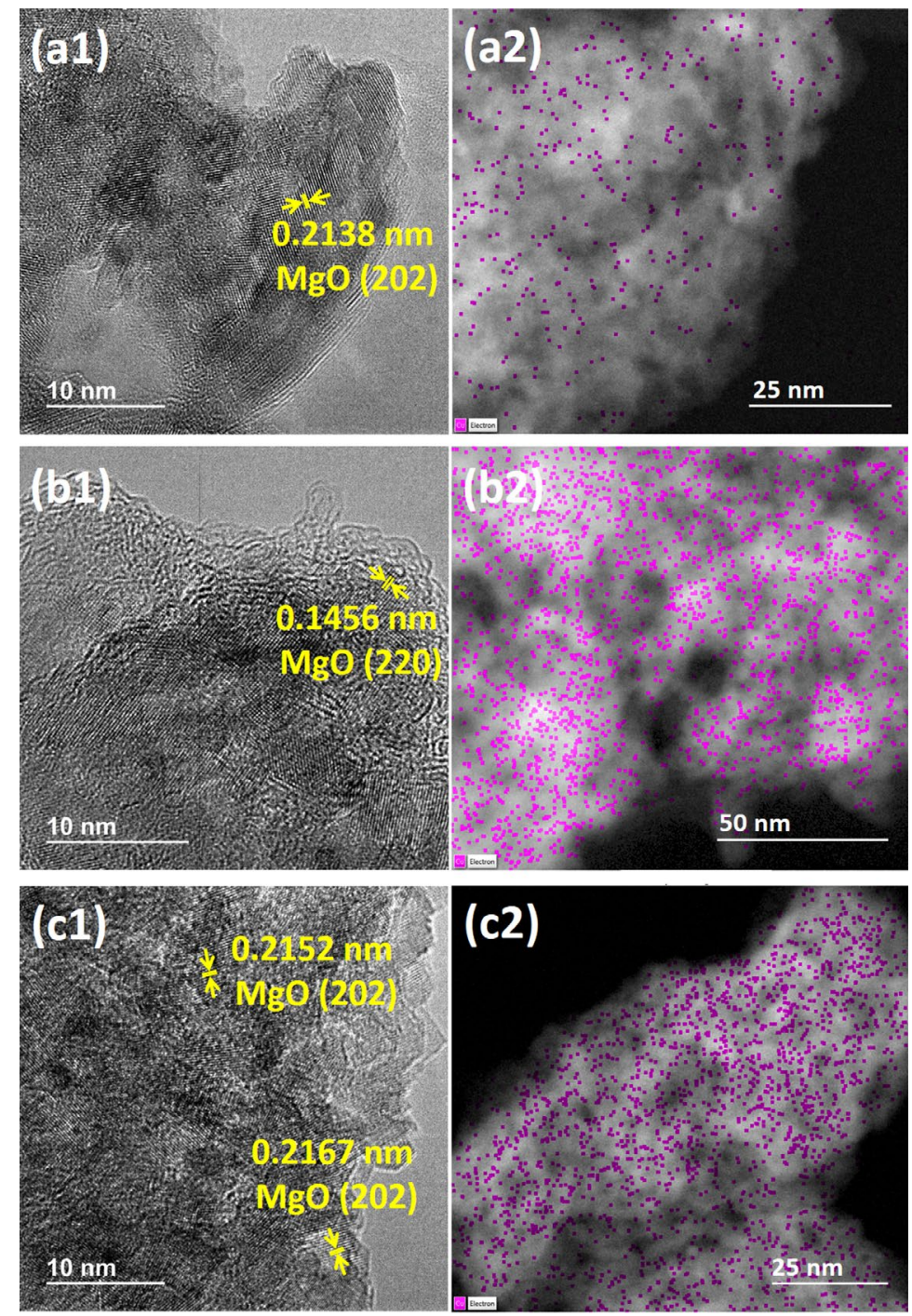

Figure 2. HR-TEM (1) and STEM (2) images of (a) 5.0\%Cu-HT-4, (b) $10.0 \% \mathrm{Cu}-\mathrm{HT}-4$, (c) 12.0\% Cu-HT-4. (') Copper detected by EDS mapping. 


\subsection{Catalytic results in continuous flow fixed-bed reactor}

Catalytic experiments for selective dehydration of glycerol (GLY) to acetol were carried out as described in Experimental section 2.4. In a first attempt aimed at optimizing the most important reaction conditions, different operational parameters, such as glycerol dilution and temperature, were varied by working always with $5.0 \% \mathrm{Cu}-\mathrm{HT}-4$ calcined material as catalyst. The attained results in terms of catalytic activity (i.e. glycerol conversion), stability (maintenance of conversion with TOS), and more importantly, selectivity to acetol, were evaluated, main data being summarized in Table S1 (see SI) together with its more relevant discussion. From these results, the mixture $\mathrm{MeOH} / \mathrm{GLY}=$ 90:10 (weight ratio) was selected as the optimal for further studies because it allows the system to work up to longer TOS with higher productivities of acetol, also maintaining a good catalyst stability. Once the optimum dilution degree of glycerol in methanol had been stablished, a series of experiments were done to figure out which temperature could improve both, glycerol conversion and selectivity to acetol. Tests of selective dehydration of glycerol over $5.0 \% \mathrm{Cu}-\mathrm{HT}-4$ catalyst were carried out by varying temperature from 220 to $280^{\circ} \mathrm{C}$, keeping constant all the other reaction parameters (feed: $\mathrm{MeOH} / \mathrm{GLY}=90 / 10$, flow $=2 \mathrm{~mL} / \mathrm{h}$, catalyst $=0.5 \mathrm{~g}, \mathrm{TOS}=9 \mathrm{~h}$ ). The attained results are depicted in Figure S3 in terms of average conversion (cumulative conversion of glycerol during all the experiment, TOS $=1-9 \mathrm{~h}$ ) and average selectivity to acetol (cumulative acetol selectivity during all reaction, TOS $=1-9 \mathrm{~h}$ ). The temperature of $240^{\circ} \mathrm{C}$ turned out to be the best by a small difference in terms of glycerol conversion and clearly better as far as selectivity to acetol is concerned during most part of the reaction. No great differences were noticed with respect to the catalyst stability.

Other important parameter to be considered is the particle size of the catalyst, which will determine whether we have our reaction being dominated by internal diffusion processes 
across the particle. We found that the internal diffusion controls the reaction when working with particle sizes above $0.600 \mathrm{~mm}$, being the value $0.425-0.600$ the smallest one to be chosen to avoid load losses and reactor seals (see Figure S4 in SI). In addition, some experiments varying the liquid feed flow (q) along with the catalyst loading (W) were accomplished to prove that the liquid flow corresponding to $2 \mathrm{~mL} / \mathrm{h}$ is in the area free of mass transfer limitations (see Figure S5 in SI). Thus, the set of experiments aimed to evaluate the catalytic performance of different hydrotalcite-derived mixed oxides can be carried out under these conditions $\left(240{ }^{\circ} \mathrm{C}, \mathrm{MeOH} / \mathrm{GLY}=90: 10\right.$ wt., particle size $=0.425-$ $0.600 \mathrm{~mm}, 2 \mathrm{~mL} / \mathrm{h}$ ). More information corresponding to these experiments can be found in the supporting information (SI).

The product distribution for the glycerol dehydration reaction under the aforementioned conditions and the reaction network proposed can be found in Figure 3 and Scheme 2 (appearing in color all the identified compounds), respectively. 

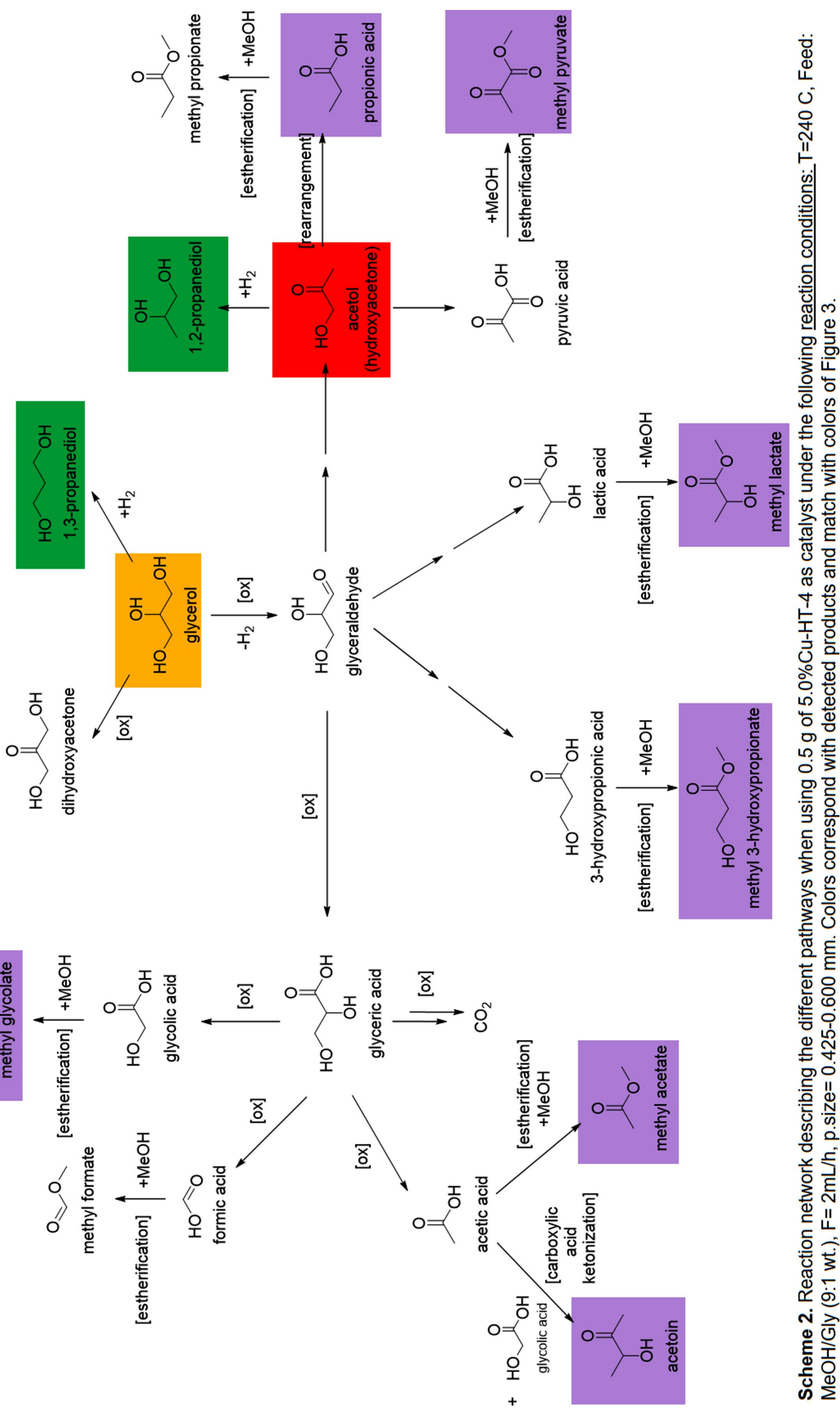
(a)

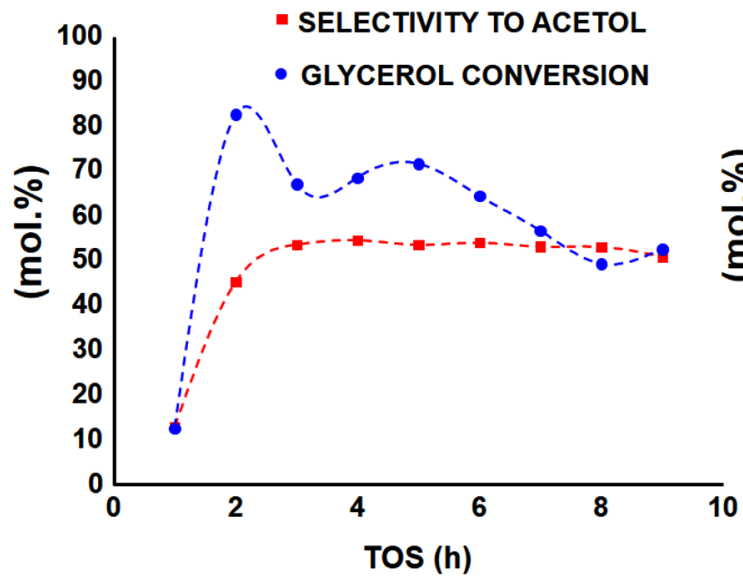

(b)

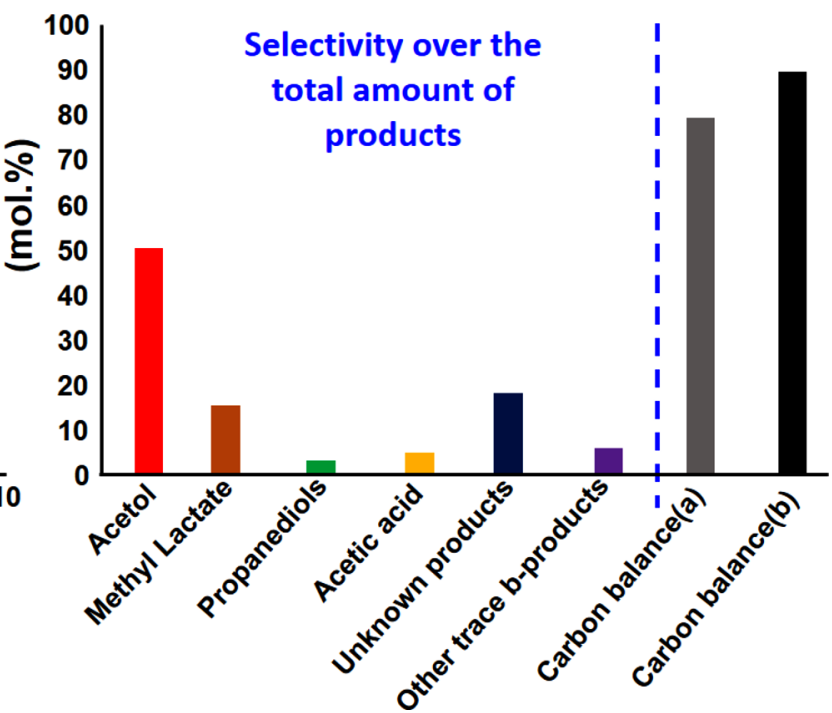

Figure 3. a) Glycerol conversion and selectivity to acetol with TOS under the optimal reaction conditions over the $5.0 \% \mathrm{Cu}-\mathrm{HT}-4$ catalyst b) Product distribution and carbon balance: ${ }^{a}$ Carbon balance calculated with the total amount of products quantified during reaction, and ${ }^{b}$ Carbon balance calculated including also the carbonaceous matter deposited on catalytic surface and the gas products coming from glycerol. (Reaction conditions: feed: $\mathrm{MeOH} / \mathrm{GLY}=90 / 10$ wt. flow $=2 \mathrm{~mL} / \mathrm{h}$, temperature $=240{ }^{\circ} \mathrm{C}$, catalyst $=$ $0.5 \mathrm{~g})$.

\subsection{Optimizing the $M^{\prime \prime} / M^{\prime \prime \prime}$ molar ratio in Cu-based catalysts}

As it has been already explained, thermal decomposition of Mg-Al hydrotalcite precursor yields a high surface area Mg-Al mixed oxide, which mainly exposes strong Lewis basic sites and some weak acid sites. The acid-base properties of these sites depend on the $\mathrm{M}^{\prime \prime} / \mathrm{M}^{\mathrm{III}}$ molar ratio, i.e. mainly the $\mathrm{Mg}-\mathrm{Al}$ ratio, in the hydrotalcite precursor [32-34]. With the aim of optimizing this $\mathrm{M}^{\prime \prime} / \mathrm{M}^{\prime \prime \prime}$ ratios in $\mathrm{Cu}-\mathrm{Mg}-\mathrm{Al}$ mixed oxides, hydrotalcites with $(\mathrm{Cu}+\mathrm{Mg}) / \mathrm{Al}$ ratios from 1 to 6 were prepared, calcined and tested in the selective dehydration of glycerol in continuous flow fixed-bed catalytic reactor. Catalytic results in terms of glycerol conversion and selectivity to acetol (at $240{ }^{\circ} \mathrm{C}$ and TOS $=4 \mathrm{~h}$ ) attained for $\mathrm{Cu}-\mathrm{Mg}-\mathrm{Al}$ mixed oxides $(5.0 \%-\mathrm{HTs})$ with different $(\mathrm{Cu}+\mathrm{Mg}) / \mathrm{Al}$ ratios are depicted in 
Figure 4 and compared with $\mathrm{CuO} / \mathrm{Al}_{2} \mathrm{O}_{3}$ and $\mathrm{CuO} / \mathrm{MgO}$ (with $5 \mathrm{wt} \% \mathrm{Cu}$ in both cases), as reference materials. In addition, the average both, glycerol conversion and acetol selectivity obtained for the different $\mathrm{Cu}-\mathrm{Mg}-\mathrm{Al}$ mixed oxides here studied during $9 \mathrm{~h}$ of reactor operation at $240{ }^{\circ} \mathrm{C}$ are also shown in Figure 5. As can be seen, $\mathrm{M}^{\prime \prime} / \mathrm{M}^{\prime \prime \prime}$ molar ratios around 4 in the catalysts offered the highest both glycerol conversion and acetol selectivity (highest yield of acetol) achieved. The glycerol conversion and, more importantly, the acetol selectivity reached with $5.0 \% \mathrm{Cu}-\mathrm{HTs}$ catalysts with $\mathrm{Mg} / \mathrm{Al}$ ratios from 3 to 5 are higher than the values achieved with $\mathrm{CuO} / \mathrm{Al}_{2} \mathrm{O}_{3}$ reference material, while $\mathrm{CuO} / \mathrm{MgO}$ material offered the worse results. However, the catalyst stability makes the difference between these values since $\mathrm{Cu}-\mathrm{Mg}-\mathrm{Al}$ materials with higher $\mathrm{M}^{\prime \prime} / \mathrm{M}^{\mathrm{III}}$ molar ratios $((\mathrm{Cu}+\mathrm{Mg}) / \mathrm{Al}$ ratios $\geq 4)$ are slightly more capable to keep the catalytic performance over at least 9 hours.

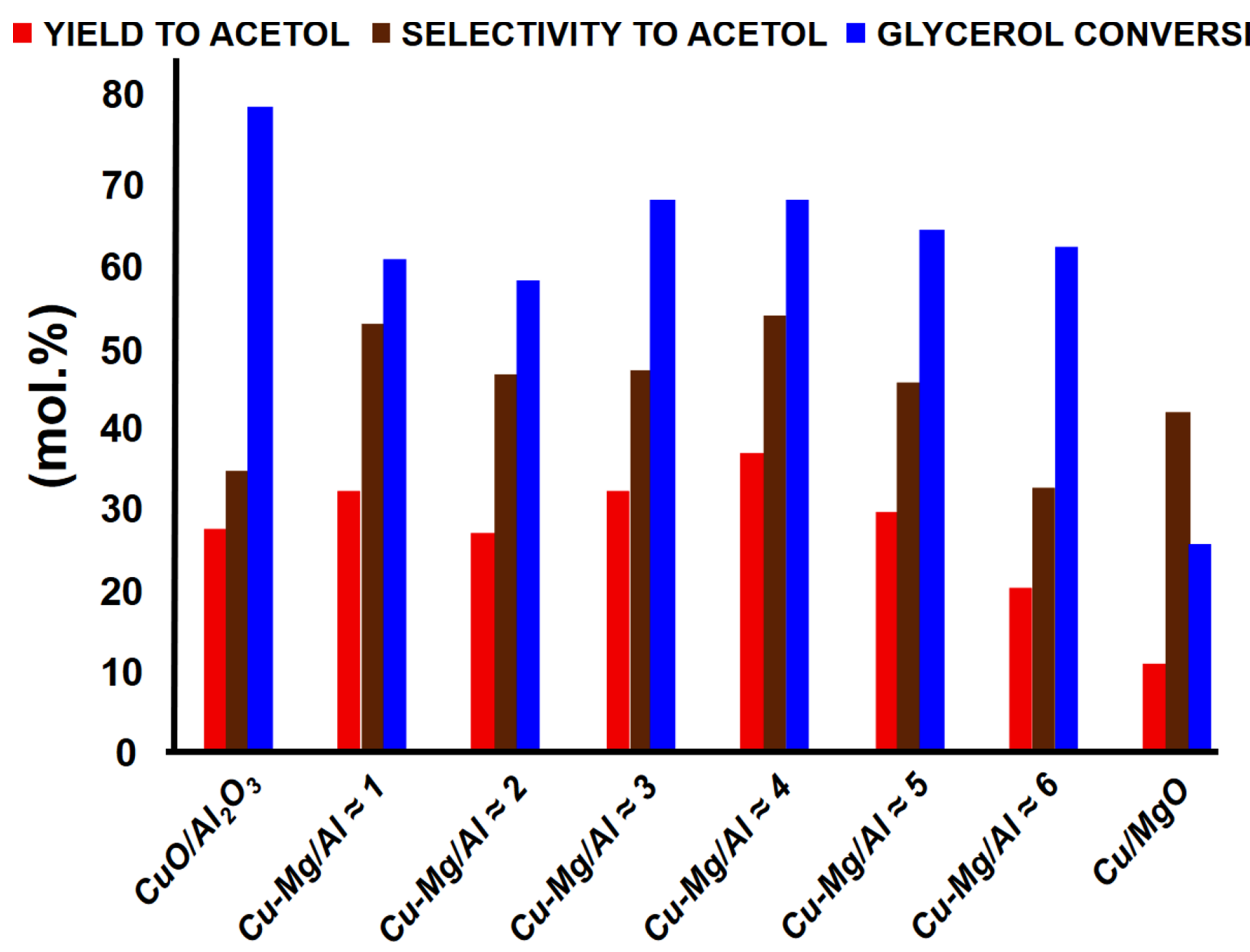

Figure 4. Glycerol conversion, selectivity and yield to acetol in the selective dehydration of glycerol over $5.0 \% \mathrm{Cu}-\mathrm{HT}$ catalysts with different $(\mathrm{Cu}+\mathrm{Mg}) / \mathrm{Al}$ molar ratios at TOS $=4 \mathrm{~h}$. 
(Reaction conditions: feed: $\mathrm{MeOH} / \mathrm{GLY}=90 / 10 \mathrm{wt}$, flow $=2 \mathrm{~mL} / \mathrm{h}$, temperature $=240{ }^{\circ} \mathrm{C}$, catalyst $=0.5 \mathrm{~g})$.

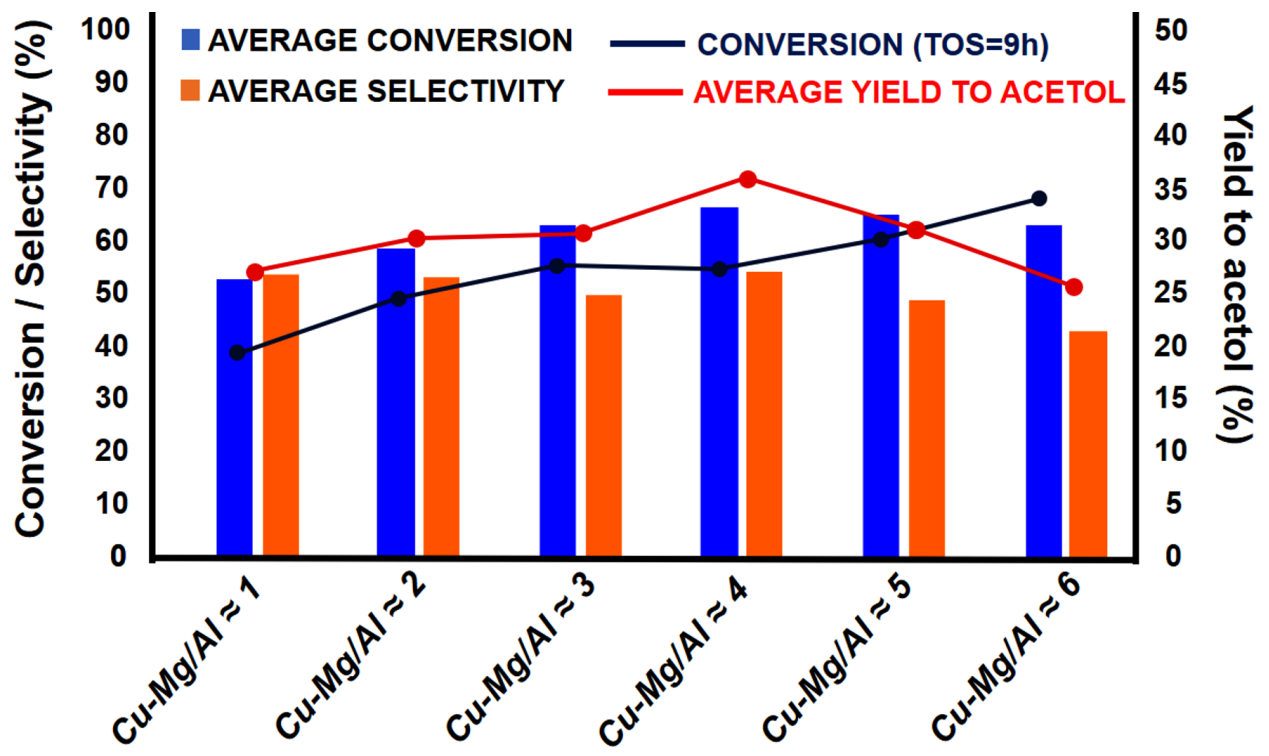

Figure 5. Average glycerol conversion and selectivity to acetol in the selective dehydration of glycerol over $5.0 \% \mathrm{Cu}-\mathrm{HT}$ catalysts with different $(\mathrm{Cu}+\mathrm{Mg}) / \mathrm{Al}$ molar ratios during TOS $=1-9$ h. (Reaction conditions: feed: $\mathrm{MeOH} / \mathrm{GLY}=90 / 10$ wt., flow $=2 \mathrm{~mL} / \mathrm{h}$, temperature $=$ $240^{\circ} \mathrm{C}$, catalyst $=0.5 \mathrm{~g}$ ).

Regarding the acid properties of the Cu-Mg-Al samples, looking at the $\mathrm{NH}_{3}$-TPD profiles (Figure 6a) two different peaks can be distinguished, the first one appearing at temperatures around $200{ }^{\circ} \mathrm{C}$, and the second at temperatures above $350^{\circ} \mathrm{C}$. As it has been reported for calcined hydrotalcites, the acidity in-between this range can be ascribed to weak and moderate Lewis acid sites corresponding mainly to different $\mathrm{Al}^{3+}$ species $[40,41]$, although a contribution of copper to the moderate acid sites cannot be discarded [42]. As far as the basic sites is concerned, the two peaks at lower temperatures appearing in Figure $6 \mathrm{~b}$ could be assigned to $\mathrm{MgO}$ (weak, physisorbed $\mathrm{CO}_{2}$ ) and $\mathrm{O}^{2-}$ unsaturated (moderate, chemisorbed $\mathrm{CO}_{2}$ ). Similar sites can be found in $\mathrm{MgO}$ [43]. 
Therefore, an explanation to the higher performance of these mixed oxides having $\mathrm{M}^{\prime \prime} / \mathrm{M}^{\prime \prime \prime}$ molar ratios between 3-4 could be found in the different distribution of active sites exhibited by each material, being more beneficial a material containing mainly weak Lewis acid sites and moderate Lewis basic sites. This adequate combination of Lewis acid and basic sites can be encountered in the aforementioned samples with $\mathrm{M}^{11 /} / \mathrm{M}^{\prime \prime \prime}$ molar ratios $\approx 3-4$ (see Figure 6 and Table 4). On the contrary, higher ratios make the material lose both total acidity (concretely weak centers) and basicity, the former because of the lower aluminum loading, the latter due to the decrease of the vacancies in the mixed oxide structure produced by the presence of aluminum [34]. Nevertheless, the MgAl mixed oxides possessing a combination of Lewis both basic and acid sites but without $\mathrm{Cu}$ in the structure are not capable to perform the selective dehydration of glycerol to acetol. Thus, the presence of $\mathrm{Cu}$ is essential to carry out this process.

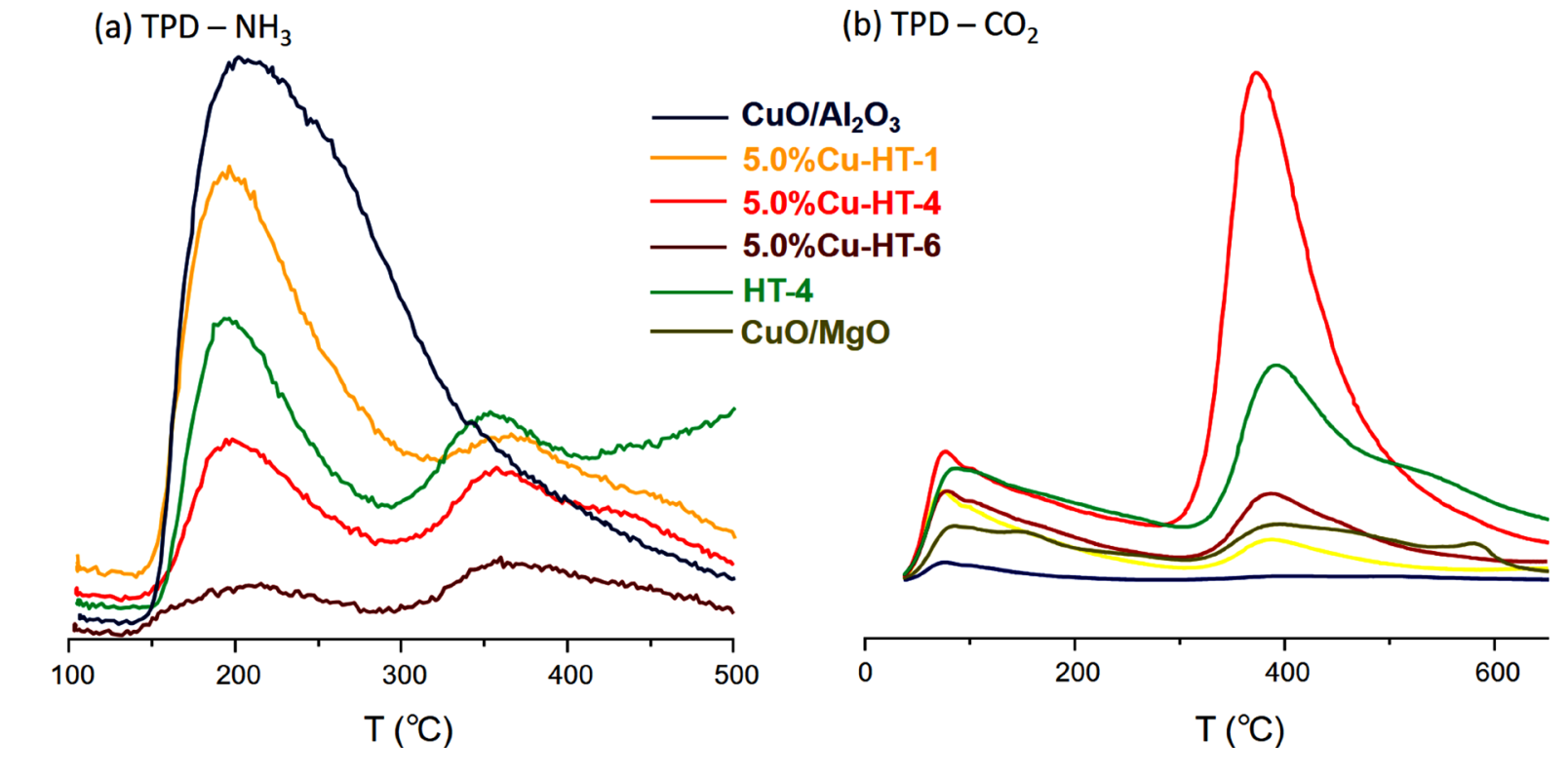

(b) $\mathrm{TPD}-\mathrm{CO}_{2}$

Figure 6. $\mathrm{NH}_{3}$-TPD (a) and $\mathrm{CO}_{2}$-TPD (b) profiles of Cu-Mg-Al hydrotalcite-derived mixed oxides with different $M^{\prime \prime} / M^{\prime \prime \prime}$ ratios. Note: Baseline drift in HT-4 sample due to $\mathrm{NO}_{x}$ formation $\left(T \geq 450^{\circ} \mathrm{C}\right)$. 
Table 4. Quantitative data for temperature programmed desorption $\left(\mathrm{NH}_{3}-\mathrm{TPD}\right.$ and $\mathrm{CO}_{2}$ TPD) of Cu-Mg-Al hydrotalcite-derived materials with different $\mathrm{M}^{\prime \prime} / \mathrm{M}^{\prime \prime \prime}$ molar ratios.

\begin{tabular}{|c|c|c|c|c|}
\hline Catalyst & $\begin{array}{c}\text { Acid site } \\
\text { density } \\
(\mu \mathrm{mol} / \mathrm{g})\end{array}$ & $\begin{array}{c}\text { Basic } \\
\text { site } \\
\text { density } \\
(\mu \mathrm{mol} / \mathrm{g})\end{array}$ & $\begin{array}{c}\text { Acid sites } \\
\text { (weak/medium) }\end{array}$ & $\begin{array}{c}\text { Basic sites } \\
\text { (weak/medium) }\end{array}$ \\
\hline $\mathrm{CuO} / \mathrm{Al}_{2} \mathrm{O}_{3}$ & 102 & 33 & 100 & $77: 23$ \\
\hline $5.0 \% \mathrm{Cu}-\mathrm{HT}-1$ & 122 & 111 & $68: 32$ & $66: 34$ \\
\hline $5.0 \% \mathrm{Cu}-\mathrm{HT}-4$ & 87 & 159 & $42: 58$ & $21: 79$ \\
\hline $5.0 \% \mathrm{Cu}-\mathrm{HT}-6$ & 63 & 153 & $37: 63$ & $44: 56$ \\
\hline $\mathrm{CuO} / \mathrm{MgO}$ & - & 111 & $-{ }^{a}$ & $39: 61$ \\
\hline
\end{tabular}

a $\mathrm{MgO}$ can be considered as having almost zero acidity [44].

The presence of $\mathrm{Cu}$ in the hydrotalcite-derived mixed oxide provokes a decrease in the acidity and also in the basicity of the samples compared to the MgAl mixed oxides (see Table 4). This behavior can be explained by different effects occurring simultaneously. When $\mathrm{Cu}^{2+}$ replacing $\mathrm{Mg}^{2+}$ in the mixed oxide structure is close to $\mathrm{Al}^{3+}$ sites, $\mathrm{Cu}$ acts as the base but the acid site related to the $\mathrm{Al}$ is less acid with respect to the corresponding site in the only presence of Mg. Thus, the acidity (mainly week acidity) of the Cu-HT material is lower with respect to the acidity observed in the analogous HT sample without $\mathrm{Cu}$ (see also Table 5). In addition, by replacing $\mathrm{Mg}^{2+}$ by $\mathrm{Cu}^{2+}$ in the mixed oxide structure the amount and strength of basic sites are diminished in the material, mainly because $\mathrm{CuO}$ species have lower basicity than MgO species (see Table 5). Summarizing, the presence of $\mathrm{Cu}$ in MgAl mixed oxides lead to a decrease in the acidity and the basicity of the materials, being this effect more pronounced in the case of the basic properties. It is also possible that the Lewis acidity of the $\mathrm{Cu}^{2+}$ species could contribute to the total acidity 
presented by the Cu-HT samples, but this contribution should be quite minor in comparison to the amount of Al contained in the samples. In that case, the effect could be more relevant only in the case of $\mathrm{Cu}-\mathrm{HT}$ samples with very low amount of Al (i.e. Cu-HT$6)$.

In summary, taking also into account the differences observed in Figures 4 to 6 , where the comparison between our $\mathrm{Cu}$-based materials and $\mathrm{CuO}$ supported on $\mathrm{Al}_{2} \mathrm{O}_{3}$ and $\mathrm{MgO}$, as well as with the pure MgAl mixed oxide $(\mathrm{HT}-4, \mathrm{Mg} / \mathrm{Al}=4)$ is shown, a $5.0 \% \mathrm{Cu}-\mathrm{HT}-4$ material having an adequate combination of weak acid and moderate basic sites presents a medium activity (in terms of glycerol conversion) between $\mathrm{Al}_{2} \mathrm{O}_{3}$-based (mainly acid) and MgO-based (basic) materials. With this $5.0 \% \mathrm{Cu}-\mathrm{HT}-4$ material the best catalytic results (maximum values of selectivity and yield to acetol) can be reached. Therefore, weak acid sites corresponding to $\mathrm{Al}^{3+}$ can be concluded as the main responsible of the glycerol conversion as they are almost the only one present on the most active material $\left(\mathrm{CuO} / \mathrm{Al}_{2} \mathrm{O}_{3}\right)$. This fact can be confirmed by the activity reached for $\mathrm{MgO}$, without any acid site that was the worst among all the materials tested. In this sense, a compromise between acid and basic centers present in the solid seems to be needed for obtaining a good yield to acetol. On one hand, low Mg/Al molar ratios in the catalyst do not offer the necessary basicity to perform the reaction with good selectivity. On the other hand, higher $\mathrm{Mg} / \mathrm{Al}$ ratios as well as pure $\mathrm{MgO}$ lack the acid site density needed to carry out the reaction with the desired acetol production.

Last but not least, and speaking about catalytic deactivation detected in these Cu-based catalysts, one possible explanation that fits in the tendency observed for these HT-derived materials would be the deactivation occurring on the weak acid sites, which ratio increases with decreasing of $(\mathrm{Cu}+\mathrm{Mg}) / \mathrm{Al}$ in the solids. However, with the handled data, the deactivation on the weak basic sites cannot be discarded either. Actually, it is impossible 
neither to distinguish between both options nor to discard any of them. Besides, there are literature reports making both acid and basic sites responsible for the catalytic deactivation in similar reactions, as coke formation would occur on acid sites, and polyglycerols or acetalization products of glycerol would be formed and remain adsorbed on basic sites [45].

Finally, as it was previously mentioned in this section, it is worth noting that the MgAl mixed oxide (HT-4), despite offering both weak acid and moderate basic centers, is not able to carry out the reaction in almost any extent (see Table 5), which unveils the need of having copper to interplay with glycerol through some interaction beyond a simple acid-base effect. This fact will be the subject of further discussions in next sections.

Table 5. Comparison of $\mathrm{NH}_{3}$-TPD and $\mathrm{CO}_{2}$-TPD quantitative data and catalytic activity of hydrotalcite-derived $\mathrm{Cu}-\mathrm{Mg}-\mathrm{Al}$ and $\mathrm{Mg}-\mathrm{Al}$ mixed oxides with the same $\mathrm{Mg} / \mathrm{Al}$ ratio.

\begin{tabular}{|c|c|c|c|c|}
\hline Catalyst & $\begin{array}{c}\text { Acid sites } \\
\text { ( } \mu \mathrm{mol} / \mathrm{g}) \\
\text { (weak:medium) }\end{array}$ & $\begin{array}{c}\text { Basic sites ( } \mu \mathrm{mol} / \mathrm{g}) \\
\text { (weak:medium) }\end{array}$ & $\begin{array}{c}\text { GLY } \\
\text { conversion }^{\mathrm{a}}\end{array}$ & $\begin{array}{l}\text { Selectivity } \\
\text { to acetol }\end{array}$ \\
\hline $5.0 \% \mathrm{Cu}-\mathrm{HT}-4$ & $87(42: 58)$ & $159(21: 79)$ & 64.1 & 52.2 \\
\hline HT-4 & $124(56: 44)$ & $245(31: 69)$ & 6.9 & 39.0 \\
\hline
\end{tabular}

a Average glycerol conversion and selectivity to acetol during TOS $=1-9 \mathrm{~h}$. (Reaction conditions: feed: $\mathrm{MeOH} / \mathrm{GLY}=90 / 10$ wt. flow $=2 \mathrm{~mL} / \mathrm{h}$, temperature $=240^{\circ} \mathrm{C}$, catalyst $=0.5 \mathrm{~g}$ ).

\subsection{The role of $\mathrm{Cu}$ in Cu-Mg-Al mixed oxides}

Apart from the results above-mentioned, when using other divalent transition metals with redox properties and a proven capability to produce acetol in the glycerol hydrogenolysis, such as nickel or cobalt $[35,36,46,47]$, the results also revealed the need of using copper 
in this system (see SI, Table S3 and the explanatory text). This is in good agreement with what the majority of literature reports about glycerol transformation to propane-diols on the fact that copper is the essential metal when working with metallic mixed oxides by using a fixed-bed reactor under close related reaction conditions $[38,47]$. Thus, the study of the different $\mathrm{Cu}$ species present in the Cu-based mixed oxide materials and how they specifically interact with the glycerol to selectively produce acetol becomes crucial to understand the catalytic process and the role of $\mathrm{Cu}$ in the solid material.

\subsubsection{Effect of the oxidation state of $\mathrm{Cu}$ in $\mathrm{Cu}-\mathrm{Mg}-\mathrm{Al}$ mixed oxides}

It has been reported that the coexistence of $\mathrm{Cu}^{0}, \mathrm{Cu}^{1+}$ and $\mathrm{Cu}^{2+}$ species in a partially reduced $\mathrm{Cu}-\mathrm{Al}$ oxide catalyst is responsible for its multifunctional role, thus catalyzing, for example, the simultaneous dehydration to acetol and the hydrogenolysis (hydrogenation) to 1,2-propanediol [38]. Therefore, the effects of having different copper species in our Cu-based mixed oxides were assessed by means of a detailed XPS study.

XPS experiments were performed by using: a) $5.0 \% \mathrm{Cu}-\mathrm{HT}-4$, a fresh calcined material; b) $5.0 \% \mathrm{Cu}-\mathrm{HT}-4 \mathrm{U}$, the same material recovered after reaction; c) $5.0 \% \mathrm{Cu}-\mathrm{HT}-4 \mathrm{R}$, again the same material but this time reduced "ex situ" at $450{ }^{\circ} \mathrm{C}$ under $\mathrm{H}_{2}$ atmosphere and without having been tested in reaction; and finally d) 5.0\%Cu-HT-4R-INSITU, the same material but reduced at $450{ }^{\circ} \mathrm{C}$ under $\mathrm{H}_{2}$ atmosphere in the instrument's own cell, to accurate that sample has not had contact with atmospheric air before being analysed. The attained results of XPS measurements are shown in Figure 7 and summarized in Table 6. In addition, Figure S11 in the SI presents the XPS data attained by studying the stability (reduction) of the oxidation state of $\mathrm{Cu}$ on solid samples under measurement conditions. The results allow discarding the reduction of $\mathrm{Cu}$ species during these experiments. 
Table 6. XPS data of the Cu2 $p_{3 / 2}$ core level and the surface composition.

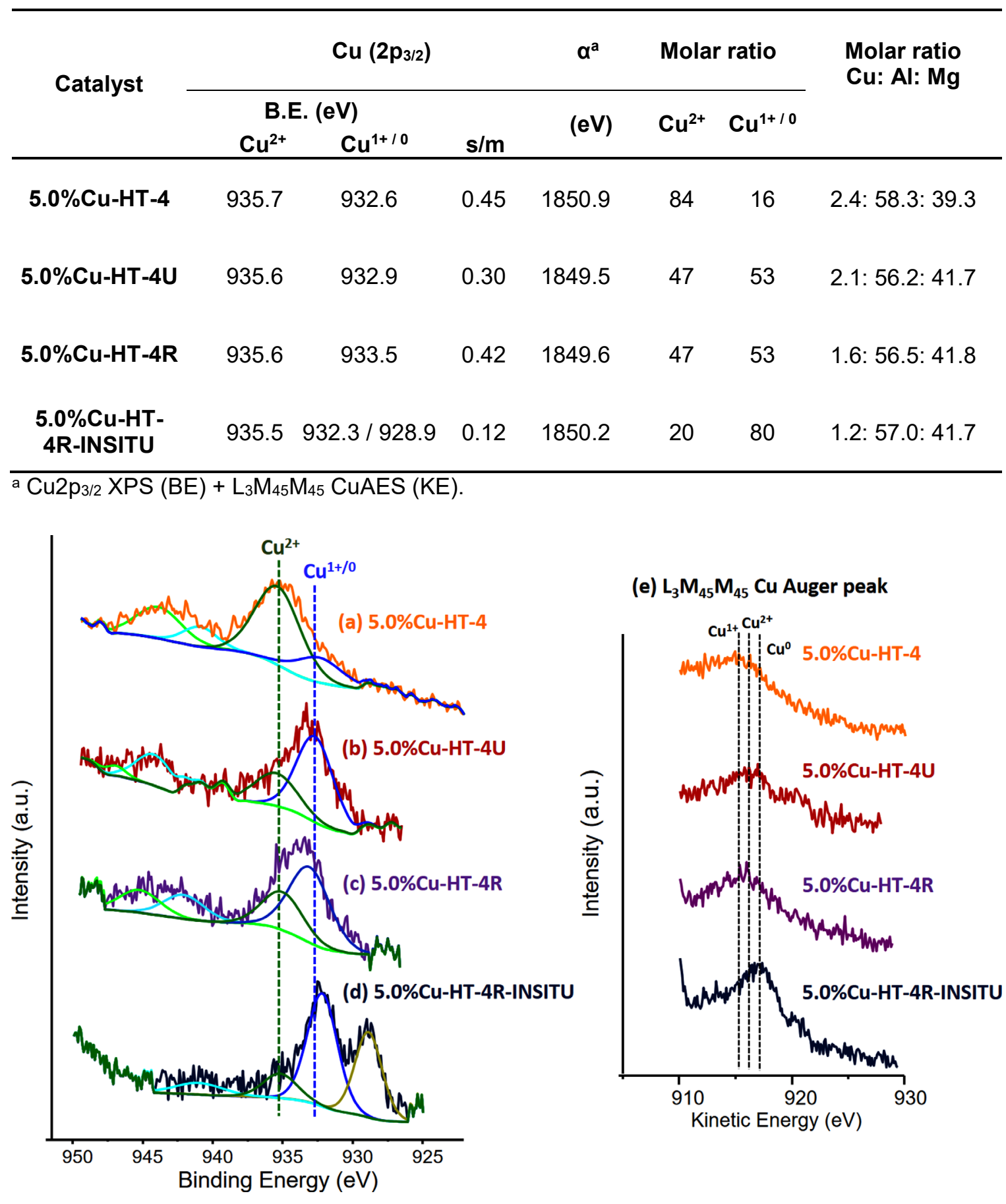

Figure 7. Cu2 $\mathrm{p}_{3 / 2}$ XPS peak of a) $5.0 \% \mathrm{Cu}-\mathrm{HT}-4$ (fresh, calcined), b) $5.0 \% \mathrm{Cu}-\mathrm{HT}-4 \mathrm{U}$ (used), c) 5.0\%Cu-HT-4R ( $\mathrm{H}_{2}$ reduced "ex situ"), d) 5.0\%Cu-HT-4R-INSITU $\left(\mathrm{H}_{2}\right.$ reduced "in situ"), e) $\mathrm{L}_{3} \mathrm{M}_{45} \mathrm{M}_{45} \mathrm{Cu}$ Auger peak for the studied Cu-Mg-Al samples. 
In the fresh sample the $\mathrm{Cu} 2 \mathrm{p}_{3 / 2}$ main peak appears at $935.7 \mathrm{eV}$ together with a shoulder at lower BE $(932.6 \mathrm{eV})$. The presence of the shake-up satellite $(\mathrm{s} / \mathrm{m}=0.45)$ and the corresponding modified Auger Parameter of $1850.9 \mathrm{eV}$ confirm the assignation as $\mathrm{Cu}^{2+}$ predominately [48], where the lower $\mathrm{BE}$ is related to a minor amount of reduced copper species $\left(\mathrm{Cu}^{1+} / \mathrm{Cu}^{0}\right)$. The high BE shift of the $\mathrm{Cu}^{2+}$ ion $(935.7 \mathrm{eV})$ is due to final state effects related to their high dispersion in the HT matrix [49]. An opposite situation is observed in the case of the used material $(5.0 \% \mathrm{Cu}-\mathrm{HT}-4 \mathrm{U})$, where the main peak appears at low BE $(932.9 \mathrm{eV})$ together with a shoulder at high BE $(935.6 \mathrm{eV})$. The lower shake-up intensity $(\mathrm{s} / \mathrm{m}=0.30)$ and the value of the modified Auger Parameter of $1849.5 \mathrm{eV}$ indicate the presence of reduced copper species $\mathrm{Cu}^{1+}$ predominately, whereas the shoulder at high-BE corresponds to $\mathrm{Cu}^{2+}$. On the other hand, in the case of the "ex situ" $\mathrm{H}_{2}$ reduced sample (5.0\%Cu-HT-4R) two peaks at $935.6 \mathrm{eV}$ and $933.5 \mathrm{eV}$ are observed, associated to $\mathrm{Cu}^{2+}$ and to reduced $\mathrm{Cu}^{1+}$, respectively. The presence of reduced copper is confirmed by the value of the modified Auger Parameter at $1849.6 \mathrm{eV}$. Finally, in the "in situ" $\mathrm{H}_{2}$ reduced sample (5.0\%Cu-HT-4R-INSITU) two main peaks corresponding to $\mathrm{Cu}$ reduced species can be distinguished at 928.9 and $932.2 \mathrm{eV}$, and also one shoulder at $935.5\left(\mathrm{Cu}^{2+}\right)$. The value of the modified Auger Parameter at $1850.2 \mathrm{eV}$ unveils the majority presence of $\mathrm{Cu}^{0}$ versus $\mathrm{Cu}^{1+}$. In addition, the splitting of the $\mathrm{Cu} 2 \mathrm{p}_{3 / 2}$ XPS peak into two components (928.9 and $932.2 \mathrm{eV}$ ) is related to differential charging of the sample because of the presence of Cu metal species in different environments and/or particle sizes. Small amounts of $\mathrm{Cu}^{2+}$ are also detected, based on the XPS component at BE of $935.5 \mathrm{eV}$ and the shake-up peak.

The presence of $\mathrm{Cu}^{1+}$ in the $5.0 \% \mathrm{Cu}-\mathrm{HT}-4 \mathrm{U}$ used catalyst evidences that the reduction of $\mathrm{Cu}^{2+}$ species present in the fresh (calcined) sample is taking place during the reaction. However, since the used catalyst has been analysed after being exposed to atmospheric air and metallic copper $\left(\mathrm{Cu}^{0}\right)$ is easily oxidized into either $\mathrm{Cu}^{1+}$ or $\mathrm{Cu}^{2+}[50]$, the extent of 
copper species reduction through this "on reaction" reduction is difficult to define. The TPR analysis of the fresh (calcined) material and the "ex situ" $\mathrm{H}_{2}$ reduced material (see Figure S12) also confirms the presence of $\mathrm{Cu}^{2+}$ species (peak at $285^{\circ} \mathrm{C}$ ) $[51,52]$ in the former (5.0\% Cu-HT-4) and segregated $\mathrm{Cu}^{2+}$ and/or $\mathrm{Cu}^{1+}$ species (peak at $190{ }^{\circ} \mathrm{C}$ ) $[53,54]$ in the later $(5.0 \% \mathrm{Cu}-\mathrm{HT}-4 \mathrm{R})$. Probably, both $\mathrm{Cu}^{0}$ and $\mathrm{Cu}^{1+}$ are present in the reduced material $5.0 \% \mathrm{Cu}-\mathrm{HT}-4 \mathrm{R}$. $\mathrm{Cu}^{0}$ would be formed during the reduction with $\mathrm{H}_{2}$ at $450{ }^{\circ} \mathrm{C}$ (see XPS Cu-HT4-R-INSITU, Figure 7d), whereas $\mathrm{Cu}^{1+}$ would result from the oxidation of $\mathrm{Cu}^{0}$ to $\mathrm{Cu}^{1+}$ in the presence of air (see XPS Cu-HT4-R, Figure 7c). And, if the used material $(5.0 \% \mathrm{Cu}-\mathrm{HT} 4 \mathrm{U})$ also suffers a reduction during the glycerol dehydration process, as it seems, this could also be applied to it.

With the aim of setting up if these reduced copper species detected in Cu-Mg-Al mixed oxides are active or not in the selective dehydration of glycerol, the $5.0 \% \mathrm{Cu}-\mathrm{HT}-4 \mathrm{R}$ ("ex situ" $\mathrm{H}_{2}$ reduced) material having mainly $\mathrm{Cu}^{1+}$ species (see XPS data, Fig. 7 and Table 6) was tested in reaction, finding very similar activity (glycerol conversion) and selectivity to acetol values to those obtained with the original $5.0 \% \mathrm{Cu}-\mathrm{HT}-4$ calcined or un-reduced material (see Figure 8). In addition, no significantly faster deactivation occurred at larger TOS for the reduced material compared to the calcined one. Another experiment with the $5.0 \% \mathrm{Cu}-\mathrm{HT}-4 \mathrm{R}$-INSITU material (reduced in the same fix-bed catalytic reactor at $450{ }^{\circ} \mathrm{C}$ under $\mathrm{H}_{2}$ atmosphere during $4 \mathrm{~h}$, prior to the reaction), having mainly $\mathrm{Cu}^{0}$ (see XPS data, Fig. 7 and Table 6), was carried out. In this case, a significant decrease in glycerol conversion was observed, falling the average value from $\approx 65 \%$ to $\approx 45 \%$ with respect to the other two samples discussed above. As for the acetol selectivity, also a lower value was obtained (from $\approx 50 \%$ to $\approx 45 \%$ in average) over this reduced sample mainly possessing $\mathrm{Cu}^{0}$ species. 

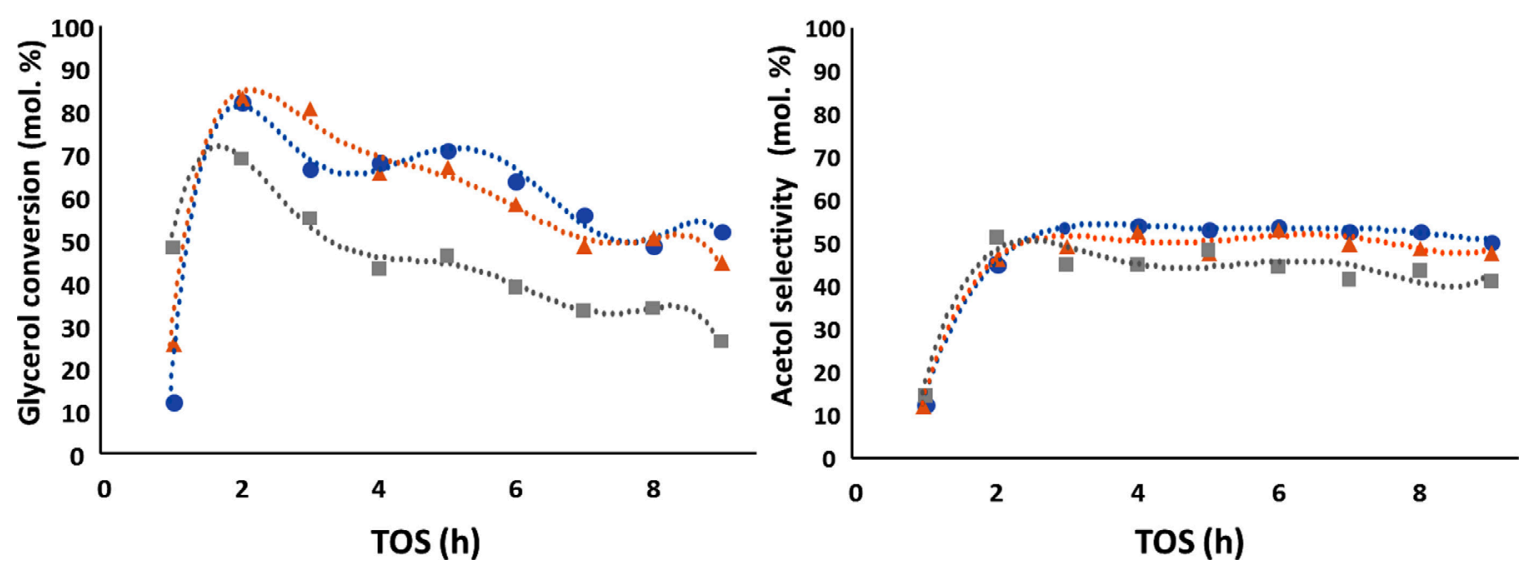

Figure 8. Glycerol conversion (a) and selectivity to acetol (b) for 5.0\%Cu-HT-4, 5.0\%CuHT-4R and 5.0\%Cu-HT-4R-INSITU materials. (Reaction conditions: Temperature $=240$ ${ }^{\circ} \mathrm{C}$, feed: $\mathrm{MeOH} / \mathrm{GLY}(90 / 10 \mathrm{w}$.), flow $=2 \mathrm{~mL} / \mathrm{h}$, catalyst: $0.5 \mathrm{~g})$.

From the results obtained up to now, it is reasonable to think that the $\mathrm{Cu}^{2+}$ species originally present in the $5.0 \% \mathrm{Cu}-\mathrm{HT}-4$ (calcined) catalyst at the beginning of the reaction are reduced "in situ" to $\mathrm{Cu}^{1+}$ and/or $\mathrm{Cu}^{0}$ species throughout the glycerol dehydration process. The experiments herein described have set $\mathrm{Cu}^{1+}$ and $\mathrm{Cu}^{2+}$ appearing to be more active for this reaction than metallic copper, being the catalyst when the $\mathrm{Cu}$ is found mainly as $\mathrm{Cu}^{0}$ much less active and slightly less selective towards acetol compared to the solids having majorly cationic Cu species.

\subsubsection{Additional tests and measurements}

In order to provide further insights into the role of copper species in the Cu-Mg-Al mixed oxides during the catalytic selective dehydration of glycerol in continuous flow fix-bed reactor, three additional experiments were carried out and the liquid and gaseous products were analyzed at the exit of the reactor. Gas composition was determined by using a 
specific GC-TCD system fitted with 3 detection lines for determination of $\mathrm{H}_{2}, \mathrm{~N}_{2}$ and light hydrocarbons, while liquid composition was determined by the standard GC-FID system (see Experimental section).

For the first experience, the reactor previously charged with $5.0 \% \mathrm{Cu}-\mathrm{HT}-4$ catalyst was fed for one hour only with absolute methanol (MeOH pre-treatment). The thus obtained results are shown in Figure $9 a$. As can be seen, $\approx 30 \%$ of methanol fed is converted in the presence of $\mathrm{Cu}-\mathrm{Mg}-\mathrm{Al}$ material (mainly containing $\mathrm{Cu}^{2+}$ species) into gaseous products, such as $\mathrm{CO}, \mathrm{CO}_{2}$, and $\mathrm{H}_{2}$, together with very low amounts of methyl-formate.

(a)

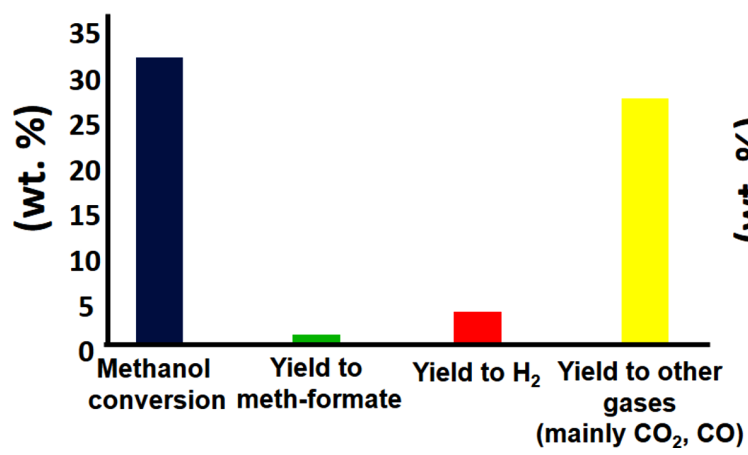

(b)

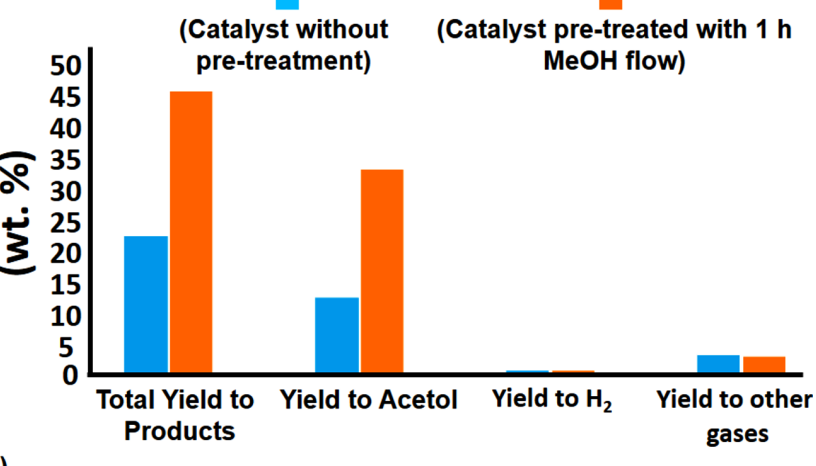

Figure 9. a) Pre-treatment test of $5.0 \% \mathrm{Cu}-\mathrm{HT}-4 \mathrm{C}$ catalyst with methanol (Reaction conditions: Feed: methanol, temperature $=240{ }^{\circ} \mathrm{C}$, flow $=2 \mathrm{~mL} / \mathrm{h}$, catalyst: $0.5 \mathrm{~g}$ ). b) Catalytic results of selective glycerol dehydration over $5.0 \% \mathrm{Cu}-\mathrm{HT}-4$ with and without methanol pre-treatment (Reaction conditions: Feed: water/glycerol (90/10 wt.), temperature $=240{ }^{\circ} \mathrm{C}$, flow $=2 \mathrm{~mL} / \mathrm{h}$, catalyst: $0.5 \mathrm{~g}$ ).

Then, the same $5.0 \% \mathrm{Cu}-\mathrm{HT}-4$ catalyst (already pre-treated with $\mathrm{MeOH}$ at $200^{\circ} \mathrm{C}$ ) was fed with a mixture of GLY/Water (10/90 in weight) during $6 \mathrm{~h}$, and the catalytic results were compared with another experiment performed by feeding a fresh $5.0 \% \mathrm{Cu}-\mathrm{HT}-4 \mathrm{C}$ catalyst (without the previous pre-treatment with methanol) with the same GLY/Water (10/90 wt.) mixture during $6 \mathrm{~h}$ as well. The attained results are depicted in Figure 9b, and they make 
clear the fact that the pre-treatment had beneficial effects on the catalytic performance. This could be attributed to the presence of either $\mathrm{Cu}(\mathrm{I})$ or $\mathrm{Cu}(0)$ instead of $\mathrm{Cu}(\mathrm{II})$ species, thanks to the hydrogen formation when feeding with $\mathrm{MeOH}$ during the catalyst's pretreatment (see Figure 9a). Thus, these copper reduced species would be more active than $\mathrm{Cu}^{2+}$ species for this reaction and, since $\mathrm{Cu}^{1+}$ has already been found to be more active than $\mathrm{Cu}^{0}$ (section 3.4.1, Figure 8), $\mathrm{Cu}^{1+}$ can be concluded as the most active species for this reaction. These evidences are in good agreement with some recent results reported by Batiot-Dupeyrat and co-workers based on catalytic results together with DFT calculations [55].

TPR measurements of the $5.0 \% \mathrm{Cu}-\mathrm{HT}-4$ calcined sample before and after pre-treatment with methanol (at $200^{\circ} \mathrm{C}$ ) unveils the oxidation of $\mathrm{Cu}(\mathrm{II})$ when comparing with the original calcined sample (Figure 10). Therefore, it is reasonable to think that the methanol feeding used throughout this work is able to make the corresponding $\mathrm{Cu}(\mathrm{II}) \rightarrow \mathrm{Cu}(\mathrm{I}), \mathrm{Cu}(0)$ transformation. In fact, during the pre-treatment with $\mathrm{MeOH}$, approximately $25 \mathrm{mmol}$ of $\mathrm{H}_{2}$ were produced, as $0.4 \mathrm{mmol}$ of copper are present in our catalyst, this quantity could be enough to reduce most of the $\mathrm{Cu}^{2+}$ species inside the catalyst. 


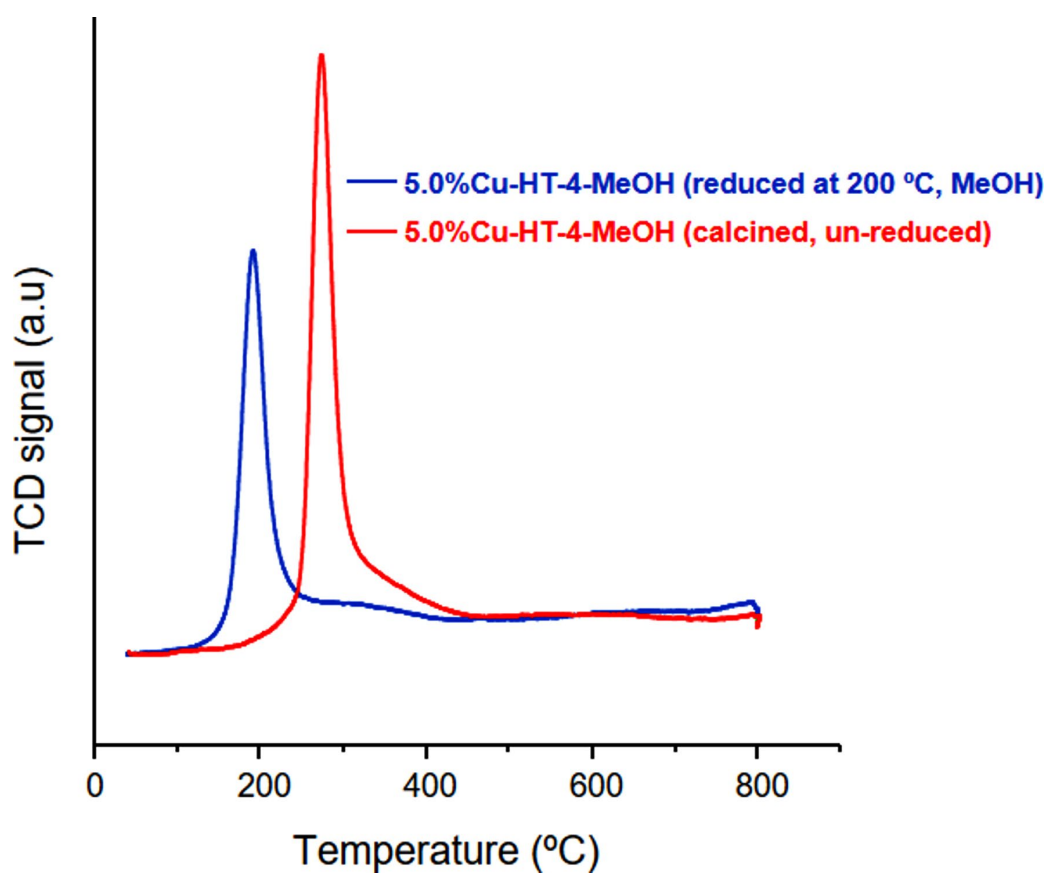

Figure 10. TPR traces for 5.0\%Cu-HT-4 (calcined, un-reduced) and 5.0\%Cu-HT-4R (calcined + reduced at $200{ }^{\circ} \mathrm{C}$ with $\mathrm{MeOH}$ ).

In summary, under the reaction conditions here employed, the $\mathrm{Cu}^{2+}$ species present in the catalyst undergo the corresponding reduction to $\mathrm{Cu}^{1+}\left(\right.$ and $\left.\mathrm{Cu}^{0}\right)$ species, thanks to the presence of $\mathrm{MeOH}$, favoring $\mathrm{Cu}^{1+}$ species the catalytic selective dehydration of glycerol to acetol. Although it is hard to distinguish between the presence of $\mathrm{Cu}^{1+}$ and $\mathrm{Cu}^{0}$ due to the oxidation behavior of copper once exposed to the air, results shown in Figure 8 point out $\mathrm{Cu}^{1+}$ as more active species to carry out the reaction than $\mathrm{Cu}^{0}$.

\subsubsection{FT-IR measurements}

In order to explain the catalytic behavior of the $5.0 \% \mathrm{Cu}-\mathrm{HT}-4$ sample, and to provide further information about the reaction mechanism and the role of copper in the reaction pathways, IR spectroscopic studies have been performed using 1,2-propanodiol as probe 
molecule instead of glycerol. The selection of 1,2-propanediol (boiling point $=214^{\circ} \mathrm{C}$ ) as probe molecule respond only to an experimental reason, since the extremely high boiling point of glycerol $\left(290^{\circ} \mathrm{C}\right)$ made impossible to properly work with it in gas phase in our FTIR system. In addition, the HT-4 (Mg/Al = 4), 5.0\%Ni-HT-4 and 5.0\%Co-HT-4 samples displaying much lower catalytic activity have also been analyzed. 1,2-propanodiol has been adsorbed at $25^{\circ} \mathrm{C}$ on all samples until saturation coverage, and then the temperature has been stepwise increased from $25^{\circ} \mathrm{C}$ to $160^{\circ} \mathrm{C}$, acquiring IR spectra at each temperature.

Gas phase 1,2 propanediol shows a complex set of IR bands in the low frequency region with maxima at $1654,1137,1079,1043,989,924$ and $839 \mathrm{~cm}^{-1}$. After adsorption at $25^{\circ} \mathrm{C}$, the IR bands corresponding to the $\mathrm{vC}-\mathrm{O}$ vibration $\left(1137,1079\right.$ and $\left.1043 \mathrm{~cm}^{-1}\right)$ are shifted to higher frequencies $\left(1143,1085\right.$ and $\left.1058 \mathrm{~cm}^{-1}\right)$ on all samples, in addition to a corresponding shift in the $\mathrm{OH}$ band of all samples $\left(3730 \mathrm{~cm}^{-1}\right)$ to lower frequency (Figure 11). Since the interaction of 1,2 propanediol is relatively strong in all cases (i.e. stable toward evacuation at $10^{-6} \mathrm{mbar}$ and $25^{\circ} \mathrm{C}$ ) the red shift of the $v \mathrm{C}-\mathrm{O}$ IR bands may correspond to an interaction with Lewis acid sites, besides that with $\mathrm{OH}$ groups. In addition, the shift in the $v \mathrm{C}-\mathrm{O}$ IR bands is the same in all samples, indicating similar adsorption sites in all samples. This fits with what has been already pointed out about the weak acid sites corresponding to $\mathrm{Al}^{3+}$ as the main responsible of the catalytic activity. Since these acid sites are present in all the studied materials (see $\mathrm{NH}_{3}$-TPD measurements, Figure $\mathrm{S} 10$ in $\mathrm{SI}$ ), they could be the main responsible of the reactant adsorption. 


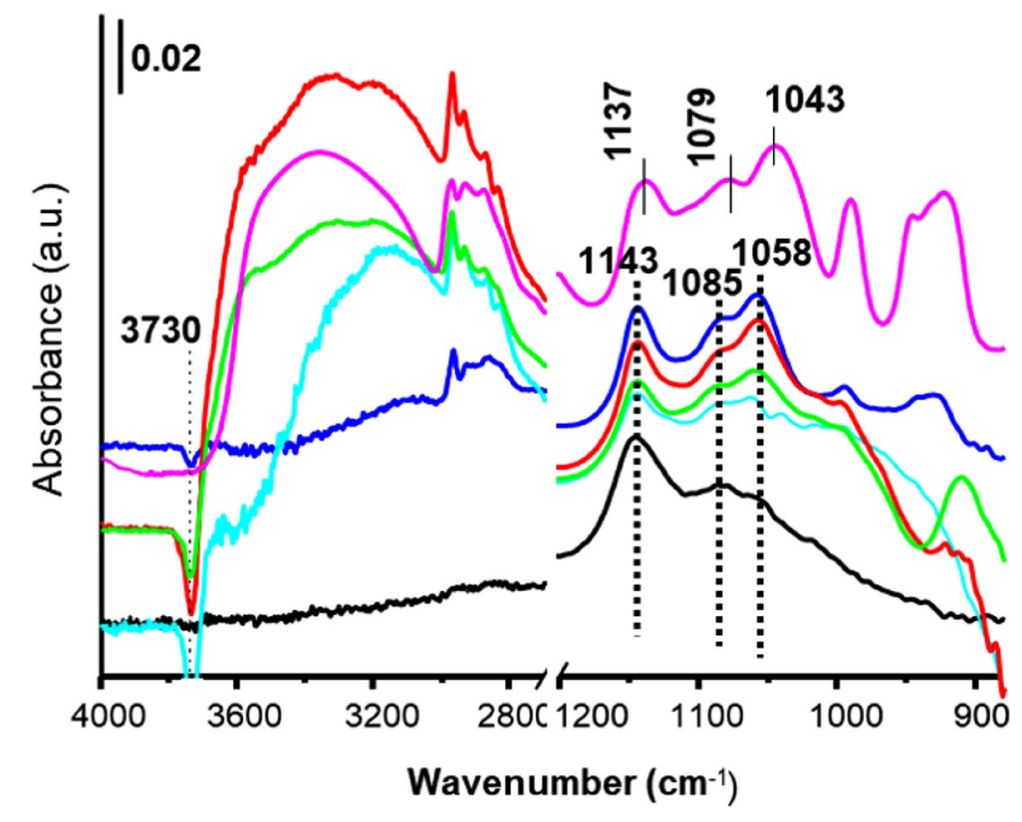

Figure 11. IR spectra of 1,2-propanediol adsorbed at $25^{\circ} \mathrm{C}$ on $5.0 \% \mathrm{Cu}-\mathrm{HT}-4$ (blue), $5.0 \% \mathrm{Ni}-\mathrm{HT}-4$ (red), 5.0\%Co-HT-4 (green), HT-4 (cyan) and 5.0\%Cu-HT-4R (ex situ $\mathrm{H}_{2}$ reduced, black). In magenta gas phase IR spectra of 1,2-propanediol as reference spectra.

Despite of this, by analyzing the evolution of the adsorbed 1,2-propanediol compound at increasing temperatures, a different behavior could be observed depending on the nature of the transition metal site ( $\mathrm{Cu}, \mathrm{Ni}$, and $\mathrm{Co})$, envisaging different reaction mechanisms and, accordingly, reaction intermediate species and reaction rates. Thus, in the 5.0\%Cu-HT-4 sample increasing reaction temperature up to $160^{\circ} \mathrm{C}$ leads to the appearance of a band at $1705 \mathrm{~cm}^{-1}$ corresponding to a carbonyl functional group, whereas under the same conditions in the $\mathrm{Ni}$ and Co based catalyst a band at $1596 \mathrm{~cm}^{-1}$ is observed corresponding to $\mathrm{C}=\mathrm{C}$ bond, while no additional band could be observed in the HT-4 sample (Figure 11). This may correspond to a different activation mode of the 1,2-propanediol, where a hydride abstraction could take place promoted by $\mathrm{Cu}$ species, whereas $\mathrm{OH}^{-}$abstraction catalyzed by Lewis acid sites takes place on $\mathrm{Ni}$ and Co catalysts. Moreover, using $\mathrm{CO}$ as a probe molecule, $\mathrm{Cu}^{1+}$ species have been evidenced in the IR studies after 1,2-propanediol 
adsorption at $160^{\circ} \mathrm{C}$ on the $5.0 \% \mathrm{Cu}-\mathrm{HT}-4$ sample (IR band at $2098 \mathrm{~cm}^{-1}$ )[56], which may be related to $\mathrm{Cu}^{2+}$ reduction by the aforementioned Cu-hydride interaction (Figure 13). In opposite, no reduced species $\mathrm{Ni}^{1+}$ nor $\mathrm{Co}^{2+/ 1+}$ have been observed in the $5.0 \% \mathrm{Ni}-\mathrm{HT}-4$ and $5.0 \%$ Co-HT-4 samples under similar conditions. This fact was fully expected considering the very low reducibility of these samples, as very low amounts of $\mathrm{Ni}^{2+}$ and $\mathrm{Co}^{3+}$ are available to be reduced at low temperatures (see TPR, Figure S13 in SI). Thus, it can be concluded that weak acid centers are important because they are 1,2-propanediol adsorption centers (see $\mathrm{NH}_{3}$-TPD, Figure $\mathrm{S} 10$ in $\mathrm{SI}$ ), and that the additional presence of reducible centers, such as $\mathrm{Cu}^{2+}$ (but not $\mathrm{Ni}^{2+}$ and $\mathrm{Co}^{3+}$ ), could favor the abstraction of $\mathrm{H}^{-}$, thereby accelerating the carbonyl group formation pathway.

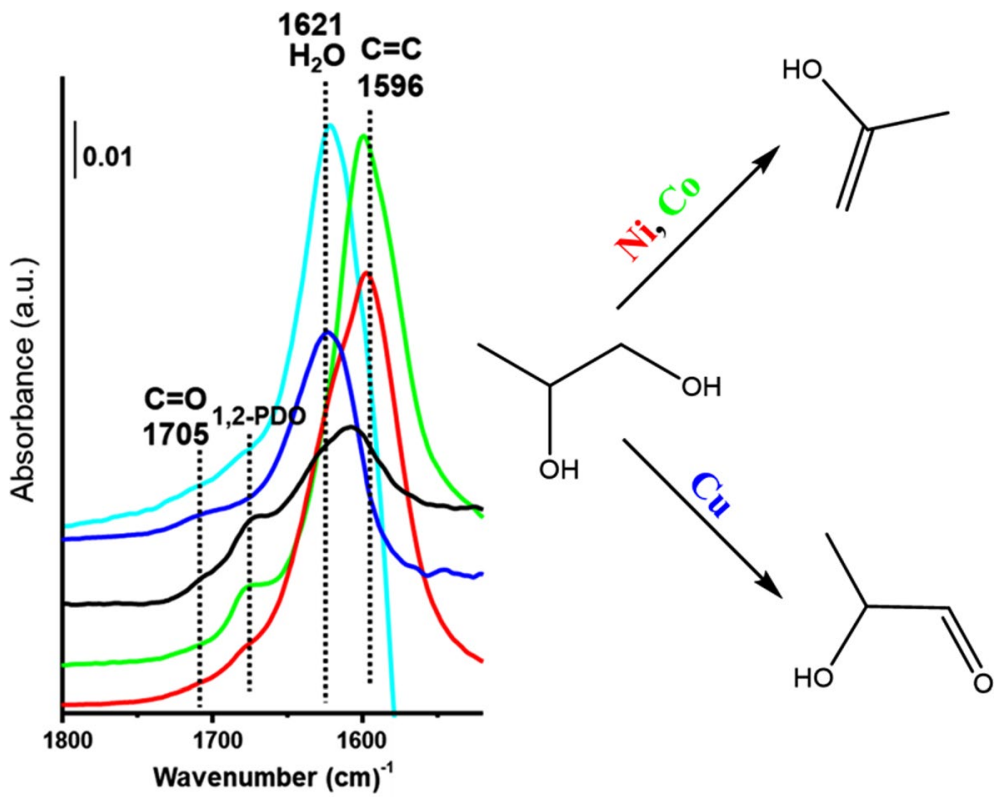

Figure 12. IR spectra of 1,2-propanediol at $160^{\circ} \mathrm{C}$ on $5.0 \% \mathrm{Cu}-\mathrm{HT}-4$ (blue), $5.0 \% \mathrm{Ni}-\mathrm{HT}-4$ (red), 5.0\%Co-HT-4 (green), HT-4 (cyan) and 5.0\%Cu-HT-4 "ex situ" $\mathrm{H}_{2}$ reduced (black).1,2-PDO: IR peak related to 1,2-propanediol. 


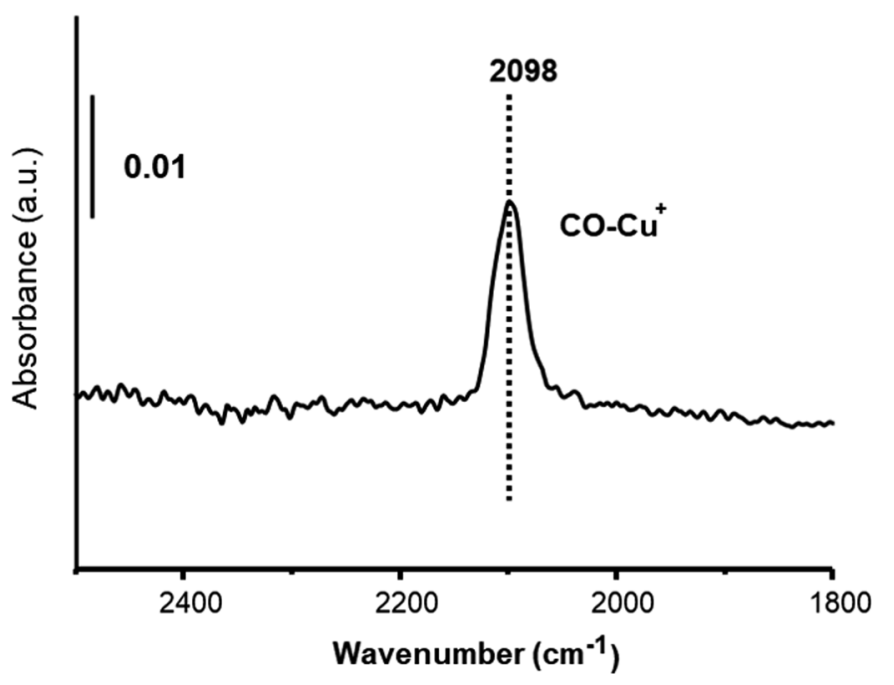

Figure 13. IR spectra of $\mathrm{CO}$ adsorption at $25^{\circ} \mathrm{C}$ as probe molecule on the $5.0 \% \mathrm{Cu}-\mathrm{HT}$ 4 sample after 1,2-propanediol adsorption and increasing temperature to $160^{\circ} \mathrm{C}$.

Once $\mathrm{Cu}^{2+}$ and $\mathrm{Cu}^{1+}$ are identified as the two main species present in the catalyst when the reaction is going on, and to assess if $\mathrm{Cu}^{2+}$ or $\mathrm{Cu}^{1+}$ are involved in the possible intermediate formation step, the $5.0 \% \mathrm{Cu}-\mathrm{HT}-4$ sample has been "ex situ" reduced in $\mathrm{H}_{2}$ flow (containing mainly $\mathrm{Cu}^{1+}$, see XPS data of $5.0 \% \mathrm{Cu}-\mathrm{HT}-4 \mathrm{R}$ in Figure 7 ) and analyzed in the IR study. As seen in the Cu-based non-reduced sample, a band at $1705 \mathrm{~cm}^{-1}$ due to the presence of carbonyl group has been observed in the 1,2-propanediol temperature dependent reaction profile. Nevertheless, the onset of carbonyl group formation appears at a slightly lower temperature, i.e. $120^{\circ} \mathrm{C}$, in the "ex situ" reduced sample versus $160^{\circ} \mathrm{C}$ in the calcined sample (see Figure $\mathrm{S} 14$ in $\mathrm{SI}$ ). Thus, while both $\mathrm{Cu}^{2+}$ and $\mathrm{Cu}^{1+}$ can be considered as active sites in the $5.0 \% \mathrm{Cu}-\mathrm{HT}-4$ sample, a slightly higher reactivity could be observed for $\mathrm{Cu}^{1+}$, which agrees on the improvement already seen when reducing the Cu-containing catalyst with $\mathrm{MeOH}$ at $240^{\circ} \mathrm{C}$ (see section 3.5.2). It is important to remark based on the IR data that the enhanced catalytic activity in the glycerol dehydration observed with $5.0 \% \mathrm{Cu}-\mathrm{HT}-4$ sample can be ascribed to the specific role of copper versus 
other transition metals to promote the carbonyl group formation pathway at the beginning of the process.

However, despite displaying different reaction mechanisms, this cannot explain the markedly lower activity of 5.0\%Co-HT-4 and 5.0\%Ni-HT-4 catalysts. Another aspect which could influence the catalytic activity is the interaction strength of the reaction products with the catalyst surface, in a way that a stronger interaction would result in a fast catalyst deactivation. Thus, and in order to analyze the interaction strength of the reaction products, hydroxyacetone (or acetol) has been adsorbed on the $5.0 \% \mathrm{Cu}-\mathrm{HT}-4$ and $5.0 \% \mathrm{Ni}-\mathrm{HT}-4$ samples and followed by FT-IR spectroscopic measurements. As shown in Figure 14, hydroxyacetone interacts on both catalysts, although the interaction is lower on the $5.0 \% \mathrm{Cu}-\mathrm{HT}-4$ sample and stronger on the $5.0 \% \mathrm{Ni}-\mathrm{HT}-4$ sample, probably because of the higher density of acid sites in this sample (see $\mathrm{NH}_{3}$-TPD, Table $\mathrm{S} 2$ in $\mathrm{SI}$ ).

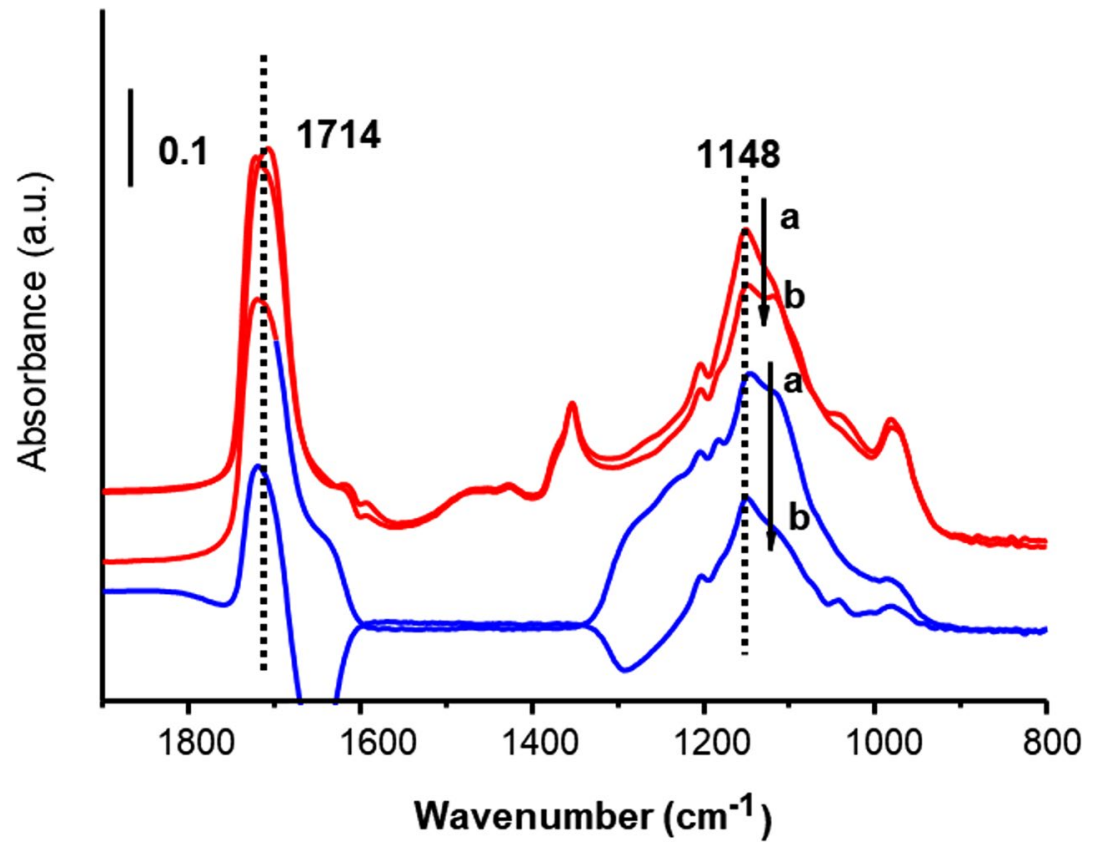

Figure 14. IR spectra of hydroxyacetone adsorbed at $25^{\circ} \mathrm{C}$ on $5.0 \% \mathrm{Cu}-\mathrm{HT}-4$ (blue) and $5.0 \% \mathrm{Ni}-\mathrm{HT}-4$ (red) (a), and after evacuation at $25^{\circ} \mathrm{C}$ for $5 \mathrm{~min}(\mathrm{~b})$. 
Summarizing, it can be inferred that weak acid sites are relevant for adsorption of 1,2propanediol, and the presence of specific copper sites in the Cu-HT sample could favor hydride abstraction in the first step of reaction. Moreover, $\mathrm{Cu}^{1+}$ species show a higher reactivity compared to $\mathrm{Cu}^{2+}$, and since $\mathrm{Cu}^{2+}$ species are reduced in the first state of the reaction due to the presence of methanol, we can assess and confirm $\mathrm{Cu}^{1+}$ as active sites in the glycerol dehydration reaction over $5.0 \% \mathrm{Cu}-\mathrm{HT}-4$ catalyst. Moreover, the desorption of reaction products is enhanced in the $5.0 \% \mathrm{Cu}-\mathrm{HT}-4$ sample compared to the $5.0 \% \mathrm{Ni}$ HT-4 and 5.0\%Co-HT-4 materials. This could be related to the different distribution of acidbase sites in both Co- and $\mathrm{Ni}$-based samples (see $\mathrm{NH}_{3}$-TPD measurements, Table $\mathrm{S} 10$ in SI) that could have too acid density, thus making problematic acetol to leave the catalytic surface. Thus, the essential role of copper species together with the higher interaction of the products on the Co- and Ni-based catalysts may explain the markedly higher catalytic activity observed with the Cu-containing catalyst.

\subsubsection{Proposed mechanism}

The foregoing results indicated that $\mathrm{Cu}$ is essential to achieve good conversion and selectivity to acetol, mainly due to the formation of an intermediate possessing a carbonyl group at the beginning of the process. In this sense, glyceraldehyde should be the intermediate reaction, following the results getting by the FT-IR study. In Scheme 3 a possible reaction pathway is shown. In order to clarify, even more, the role of $\mathrm{Cu}$ and to elucidate some insights of the mechanism, catalytic activity tests of acetol formation with a low percent of glyceraldehyde into the starting feed were carried out. 


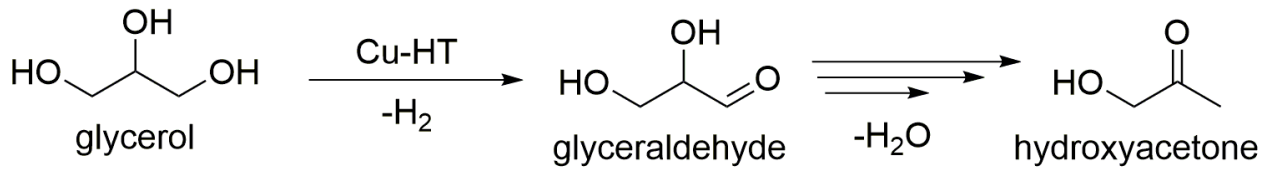

Scheme 3. Proposed reaction pathway for acetol formation over Cu-HT catalyst.

This reaction was performed over the most active material that was $5.0 \% \mathrm{Cu}-\mathrm{HT}-4$ so far, under similar conditions used before. They were followed by ${ }^{13} \mathrm{C}$ NMR at short reaction time, 45 min, observing the presence of a low amount of glyceraldehyde (see Figure S21 in $\mathrm{SI}$ ). Because of the glyceraldehyde nature that gives a very high reactivity in that reaction medium, it was impossible to isolate or accumulate more quantity of glyceraldehyde during reaction; therefore, ${ }^{1} \mathrm{H}$ NMR data were unclear.

Experiments in continuous flow carried out with the less active catalyst Co-HT showed an improvement in the yield towards acetol when the fixed bed reactor was fed with the mixture of glycerol $+0.45 \mathrm{wt} \%$ glyceraldehyde (Figure 15). This improvement has the same percentage value as the amount introduced on the feed: $0.45 \%$. In these cases, it was necessary to use a small amount of water to dissolve the glyceraldehyde in the initial mixture.

These results gave us a useful proof about the mechanism of the reaction: Co is unable to activate the $\mathrm{C}-\mathrm{OH}$ bond of glycerol towards the formation of glyceraldehyde, the intermediate to acetol. However, skipping the first step, Co-HT was able to transform glyceraldehyde to acetol. 


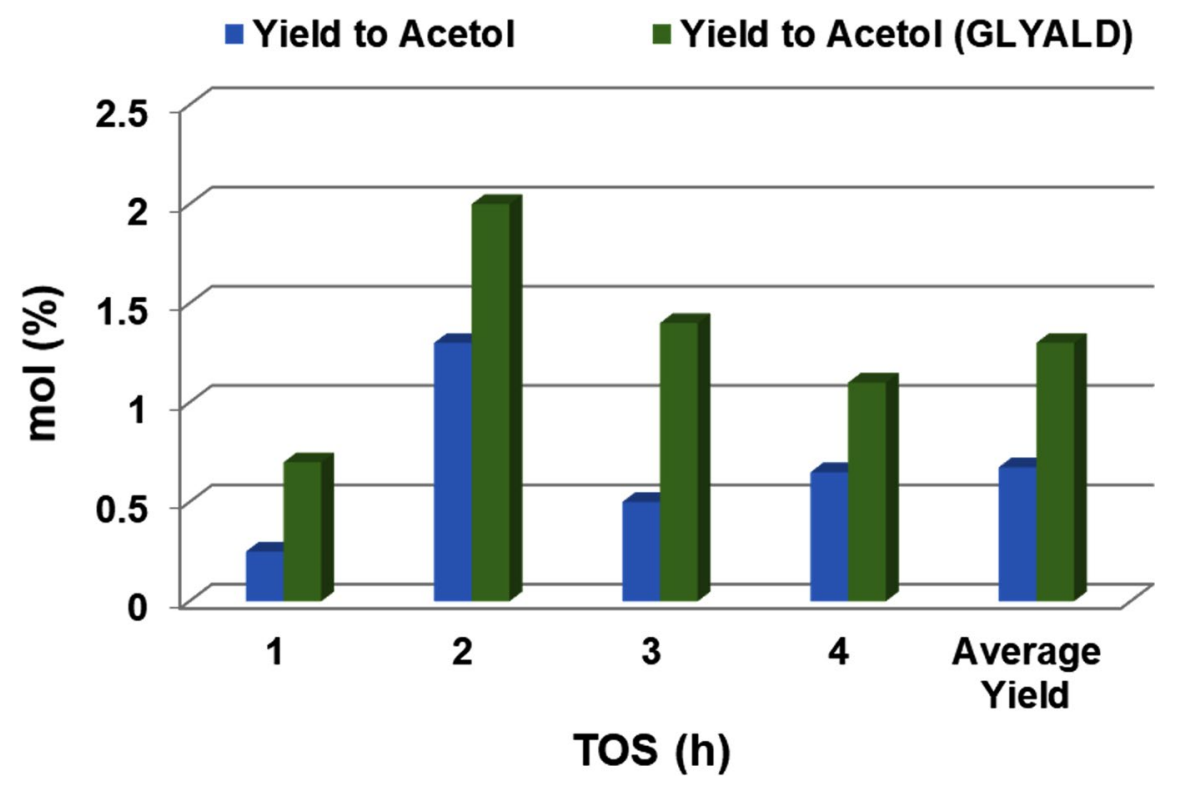

Figure 15. Catalytic results of selective glycerol dehydration over 5.0\%Co-HT-4 with (orange) and without (blue) glyceraldehyde co-feed (Reaction conditions: Feed: methanol/glycerol/glyceraldehyde/water $(87.8 / 9.5 / 0.45 / 2.2 \mathrm{wt}$.$) , temperature =240{ }^{\circ} \mathrm{C}$, flow $=2 \mathrm{~mL} / \mathrm{h}$, catalyst: $0.5 \mathrm{~g}$ ).

\subsection{Effect of the amount of $\mathrm{Cu}$ in $\mathrm{Cu}$-based catalysts}

Once the adequate Cu-Mg-Al mixed oxide with the optimal Mg/Al molar ratio was stablished as the best catalyst for the selective dehydration of glycerol to acetol, the effect of the amount of $\mathrm{Cu}$ in these materials was studied. $\mathrm{Cu}$ loading was varied from 0.0 to $12.0 \mathrm{wt} \%$, finding out that, although the selectivity to acetol is barely affected when increasing the quantity of copper, the more copper the solid contains, the higher both conversion and yield to acetol are attained. Nonetheless, this is only true until reaching Cu loading of 10wt\% (see Figure 16, and Table S4 in SI). From this amount of copper onwards, no further increase is observed for the glycerol conversion and the selectivity to acetol. Thus, a mixed oxide containing $10.0 \mathrm{wt} \%$ of copper would correspond to the optimal composition. The $10.0 \% \mathrm{Cu}-\mathrm{HT}-4$ catalyst kept a good compromise between glycerol conversion and acetol selectivity and, more importantly, it provided the best catalytic 
stability during 9 hours of reaction with practically no variation in the selectivity to acetol $(\approx 55 \%$, see Figure S15 in SI).

Comparison of the acidity and basicity data obtained by means of TPD analysis of both $5.0 \% \mathrm{Cu}-\mathrm{HT}-4$ and $10.0 \% \mathrm{Cu}-\mathrm{HT}-4$ calcined samples (see Table S5, in SI) show that the introduction of more copper into the structure does not affect significantly the amount and force of the active acid-basic centers. In fact, the two Cu-based materials exhibit almost the same acid/basic sites distribution, being slightly more acid and less basic the one containing lower amounts of copper (5.0\%Cu-HT-4 sample). Therefore, we can associate higher activity observed for $10.0 \% \mathrm{Cu}-\mathrm{HT}-4$ catalyst with increasing quantities of copper, as no effect of this greater amount of copper in the acid-basic properties of our materials was observed. In this sense, it was noticed that the more copper the material has, the more reducible it is and, therefore, a higher amount of copper is available to carry out the reaction. Nevertheless, once the $10 \mathrm{wt} \%$ of $\mathrm{Cu}$ is surpassed, part of the copper needs higher temperatures to be reduced (see Figure $\mathrm{S} 16 \mathrm{a}, \mathrm{SI}$ ), thereby showing more difficulties to take part in the reaction. The position of this TPR peak, together with the $\mathrm{CuO}_{x}$ nanoparticles seen for the material $12.0 \% \mathrm{Cu}-\mathrm{HT}-4$ in the HR-TEM measurements (Figure $\mathrm{S} 16 \mathrm{~b}, \mathrm{SI}$ ) made us thing about large aggregates of $\mathrm{CuO}_{x}$ as the responsible of this behavior [54]. 
AVERAGE GLYCEROL CONVERSION

AVERAGE ACETOL SELECTIVITY

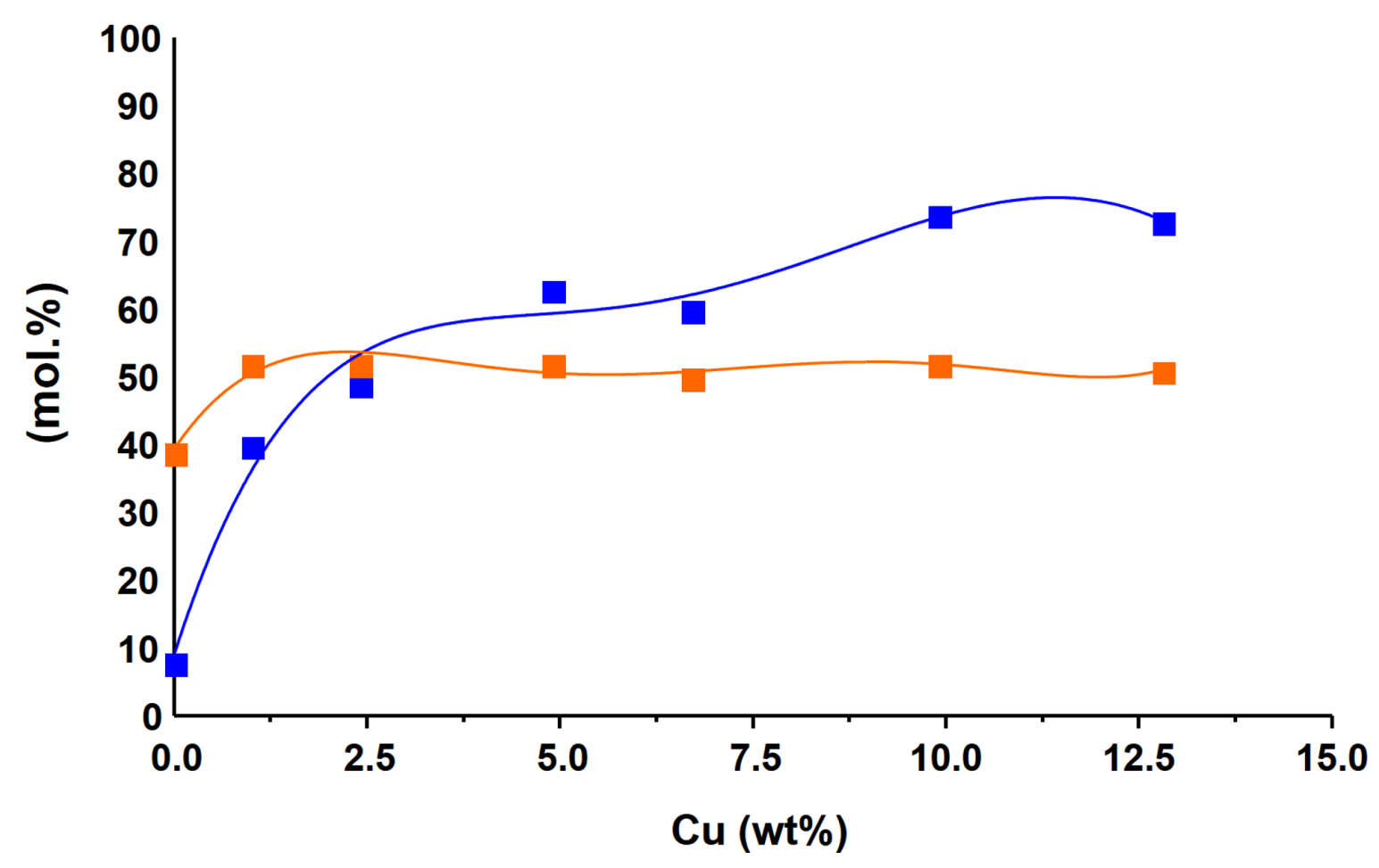

Figure 16. Average glycerol conversion and average acetol selectivity for Cu-Mg-Al calcined materials with different Cu contents during TOS $=1-9 \mathrm{~h}$ (Reaction conditions: feed $=$ methanol/glycerol (90/10 in weight), flow $=2 \mathrm{ml} / \mathrm{h}$, with $0.5 \mathrm{~g}$ of catalyst at $240{ }^{\circ} \mathrm{C}$ ).

\subsection{Importance of the use of $\mathrm{MeOH}$ as solvent}

Results up to now attained make necessary to remark that the choice and use of methanol as solvent for the selective dehydration of glycerol is a key parameter. Methanol is helping to reduce $\mathrm{Cu}^{2+}$ to $\mathrm{Cu}^{1+}$, which has already been pointed out as the most active species in this process (see Sections 3.5.1 and 3.5.2). Thus, the presence of methanol facilitates the reaction occurrence. In this sense, several reactions for the selective dehydration of glycerol to acetol were performed to study the effects of the inclusion of water in the feed. Water was added to the GLY/MeOH mixture to evaluate if it could eventually replace, at least partially, the use of $\mathrm{MeOH}$ as solvent. Figure $\mathrm{S} 18$ summarizes the glycerol 
conversion results for different water additions to the system. The presence of added water resulted in a decrease in the amount of glycerol converted. It was also observed that the introduction of water had a significant effect on the catalyst stability. In conclusion, when the activity of the catalyst reaches a maximum in almost all cases, the overall yield of the reaction significantly decreases as soon as there is even a small quantity of water in the reaction medium.

This phenomenon could be explained not only because of the total or partial absence of methanol, but also taking into account the rehydration of the hydrotalcite-type material when water is introduced into the reaction media, water molecules could block acid centers needed for the first glycerol adsorption [57]. Nevertheless, the formation of the corresponding Cu-Mg-Al hydrotalcite phase was not detected, even for the reaction carried out in pure water (see Figure S19 in SI). Then, other possibility could be the effect that water could exert on the thermodynamic equilibrium.

\subsection{Re-usability}

The $10.0 \% \mathrm{Cu}-\mathrm{HT}-4$ catalyst showed high catalytic activity accompanied with good selectivity to acetol in the selective dehydration of glycerol in continuous flow fixed bed reactor, although some deactivation was observed with time on stream. At this point, the question is if the Cu-Mg-Al material could be used several times in the reaction, for example by introducing regeneration cycles in-between reactions. To address this issue, catalyst re-cycles were carried out by washing the catalyst used in the reaction with $\mathrm{MeOH}$, and then regenerating it under the same calcination conditions used for the fresh material (before its $1^{\text {st }}$ use). Five consecutive re-uses of the $10 \% \mathrm{Cu}-\mathrm{HT}-4 \mathrm{C}$ catalyst with the preceding catalyst regenerations in each case were performed under standard reactions 
conditions for the selective glycerol dehydration and the attained results are given in Figure 17. In general, both glycerol conversion and selectivity to acetol values remain practically unaltered during the five consecutive catalytic re-uses.

The issue of possible leaching of metallic species (i.e. $\mathrm{Cu}, \mathrm{Mg}$ and $\mathrm{Al}$ ) together with the deposition of carbonaceous compounds during the catalyst re-cycling tests was assessed by means of different comparative analysis of the catalysts before and after re-uses. Thus, thermogravimetry (TGA) and elemental (EA) analysis, together with ICP and surface area measurements of $5.0 \% \mathrm{Cu}-\mathrm{HT}-4$ and $10.0 \% \mathrm{Cu}-\mathrm{HT}-4$ re-used materials reveal that our $\mathrm{Cu}-$ Mg-Al materials are mainly deactivated by carbonaceous matter deposition, this making possible the recovering of the initial catalytic performance by means of a calcination process (see Tables S6 and S7 in SI). Any significant metal leaching was detected for both $5.0 \% \mathrm{Cu}-\mathrm{HT}-4$ and $10.0 \% \mathrm{Cu}-\mathrm{HT}-4$ catalysts after several re-uses, while after a primary surface area loss during the first use the surface area values stabilize around 150 $\mathrm{m}^{2} / \mathrm{g}$ (Table S7 in SI). Besides that, it is necessary to point out that the reduction $\mathrm{Cu}^{2+} \rightarrow$ $\mathrm{Cu}^{1+} / \mathrm{Cu}^{0}$ already observed during the reaction does not affect the catalytic performance as $\mathrm{Cu}^{1+}$ are the most active species, as it has been already discussed in previous sections. Furthermore, the rehydration of the calcined hydrotalcite, due to the extensively described "memory effect" [57], could also have a role in the catalytic deactivation. However, a retrotopotactic transformation when feeding the reactor with a mixture containing small amount of water (see Figure S19) was not noticed, even though when water is generated throughout the reaction. The only structural difference observed after the reaction is the formation of a very small amount of $\mathrm{CuO}$, probably growing from the mixed oxide phase and sintering during the reaction (see Figure S20). Nevertheless, this effect does not affect the re-uses of the material. All these observations let us to conclude that the carbonaceous 
compounds deposition on the solid surface could be considered, at this stage, as the main cause of catalyst deactivation in this process.

Summarizing, Cu-Mg-Al materials have demonstrated to be highly active, selective, and also re-usable in the selective dehydration of glycerol in a continuous flow fixed bed reactor. Besides that, the catalysts remained active after several re-uses by introducing regeneration cycles in-between reactions and preserved their chemical and structural properties at least after five consecutive re-uses.

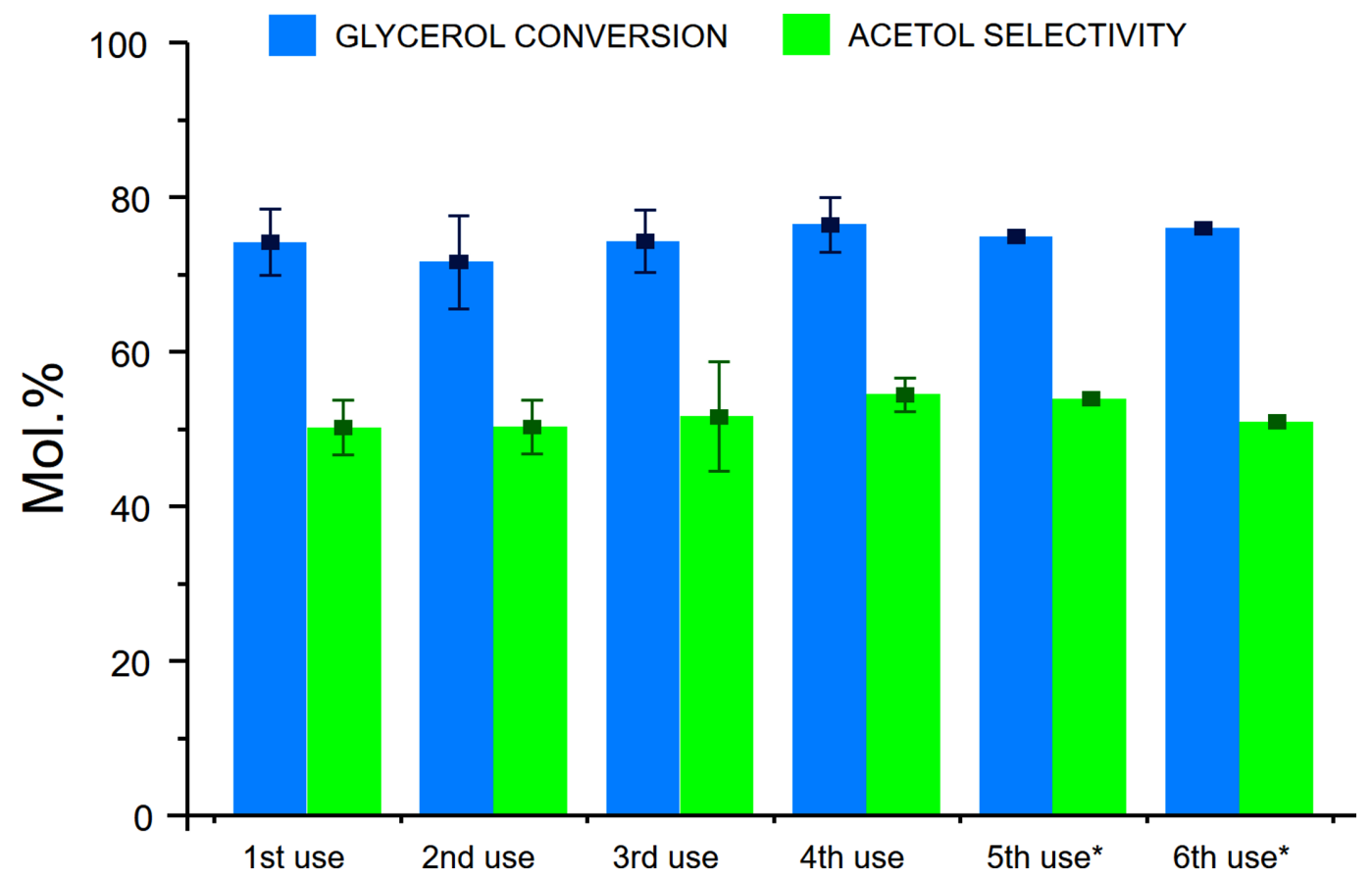

Figure 17. Glycerol conversion and acetol selectivity accumulative data during reusability tests of $10.0 \% \mathrm{Cu}-\mathrm{HT}-4$ catalyst (Average values of four repetitions). Reaction conditions: feed $=\mathrm{MeOH} / \mathrm{GLY}(90 / 10$ in weight $)$, flow $=2 \mathrm{ml} / \mathrm{h}$, with $0.5 \mathrm{~g}$ of catalyst at $240{ }^{\circ} \mathrm{C}$. ${ }^{*}$ For uses 5th and 6th only one experiment was carried out, therefore no error bars are presented. 


\section{Conclusions}

This research indicates that waste by-product glycerol from biodiesel production can be transformed into acetol by using environmentally friendly Cu-based mixed oxides derived from hydrotalcites as catalysts. Additionally, the reaction is carried out in a continuous flow fix-bed reactor, which could be scaled up from an industrial point of view. Concretely, the $10.0 \% \mathrm{Cu}-\mathrm{HT}-4$ catalyst offered the best results for glycerol conversion $(\approx 80 \%)$ and acetol selectivity ( $\approx 60 \%)$, being stable for $9 \mathrm{~h}$. This type of catalysts showed similar results (yield $\approx 40 \%$ ) when comparing with other materials with similar copper loadings, such as the recently described $\mathrm{Cu}-\mathrm{MgF}_{2}$. However, more importantly, the here optimized catalyst successfully addressed the relevant reusability issue. Thus, the catalyst remains active after several re-uses by introducing regeneration cycles in-between reactions and preserving their chemical and structural properties at least after two consecutive re-uses. Together with the development of a new alternative system to produce acetol from glycerol, interesting contributions to understand the reaction mechanism have been done. The experiments carried out to evaluate the effect on the catalytic performance of copper have pointed out this metal is essential to perform the glycerol dehydration to acetol with a high reaction rate. Probably, the preferred formation of a $\mathrm{C}=\mathrm{O}$ containing intermediate makes the difference between $\mathrm{Cu}$ and $\mathrm{Co}$ or $\mathrm{Ni}$. In this sense, $\mathrm{Cu}^{1+}$ has been concluded as the most active $\mathrm{Cu}$ species present in the catalyst, these species being formed at the beginning of the reaction by reduction of $\mathrm{Cu}^{2+}$ species. However, minor contributions to the reaction of the other two Cu-species $\left(\mathrm{Cu}^{0}\right.$ and $\left.\mathrm{Cu}^{2+}\right)$ cannot be discarded. As far as the acid-base sites role is concerned, glycerol adsorption takes place on weak acid centers and then, once copper has interacted with the molecule and the intermediate is formed, and acid-base pair interaction would be responsible for the final generation of acetol. 


\section{Acknowledgments}

Financial support by Spanish Government (CTQ-2015-67592, PGC2018-097277-B-100 and SEV-2016-0683) and PhosAgro/UNESCO/IUPAC Partnership (Proj. 139) is gratefully acknowledged. J.M. also thanks Spanish Government (CTQ-2015-67592) for his FPI fellowship.

\section{References}

[1] BP Statistical Review of World Energy, \#BPstats. 40 (2015). bp.com/statisticalreview.

[2] M. Stöcker, Angew. Chem. Int. Ed. 47(48) (2008) 9200-9211.

[3] G.W. Huber, S. Iborra, A. Corma, Chem Rev. 106 (2006) 4044-4098.

[4] G.W. Huber, A. Corma, Angew. Chem. Int. Ed. 46 (2007) 7184-7201.

[5] J.N. Chheda, G.W. Huber, J.A. Dumesic, Angew. Chem. Int. Ed. 46 (2007) 7164-7183.

[6] A. Demirbas, Energy Convers. Manag. 50 (2009) 2239-2249.

[7] A.L. Moreira, J.M. Dias, M.F. Almeida, M.C. Alvim-Ferraz, Energy Fuels 24 (2010) 5717-5721.

[8] J. Costa, M. Almeida, M. Alvim-Ferraz, J. Dias, Energy Convers Manag. 74 (2013) 1723.

[9] J.M. Dias, M.C. Alvim-Ferraz, M.F. Almeida, Bioresour. Technol. 100 (2009) 63556361.

[10] S.C. D’Angelo, A. Dall'Ara, C. Mondelli, J. Pérez-Ramírez, S. Papadokonstantakis, ACS Sust. Chem. Eng. 6 (2018) 16563-16572.

[11] G.M. Lari, G. Pastore, M. Haus, Y. Ding, S. Papadokonstantakis, C. Mondelli, J. Pérez-Ramírez, Energy Environ. Sci. 11 (2018) 1012-1029.

[12] D.T. Johnson, K.A. Taconi, Environ. Prog. 26 (2007) 338-348. 
[13] C.C. Zhou, J.N. Beltramini, Y. Fan, G.M. Lu, Chem. Soc. Rev. 37 (2008) 527-549.

[14] T. Werpy, G. Petersen, A. Aden, J. Bozell, J. Holladay, J. White, A. Manheim. Top value-added chemicals from biomass, Volume 1-Results of screening for potential candidates from sugars and synthesis gas, in Report of U.S. DOE, Energy Efficiency and Renewable Energy, Biomass, 2004.

[15] M.J. Climent, A. Corma, P. De Frutos, S. Iborra, M. Noy, A. Velty, P. Concepción, J. Catal. 269 (2010) 140-149.

[16] C. Vieville, J. Yoo, S. Pelet, Z. Mouloungui, Catal. Lett. 56 (1998) 245-247.

[17] R.R. Soares, D.A. Simonetti, J.A. Dumesic. Angew. Chem. 118 (2006) 4086-4089.

[18] N. Rahmat, A.Z. Abdullah, A.R. Mohamed, Renew. Sust. Energ. Rev. 14 (2010) 9871000.

[19] B. List, J. Am. Chem. Soc. 122 (2000) 9336-9337.

[20] W. Notz, B. List, J. Am. Chem. Soc. 122 (2000) 7386-7387.

[21] M.A. Dasari, P. Kiatsimkul, W.R. Sutterlin, G.J. Suppes, Appl. Catal. A:Gen. 281 (2005) 225-231.

[22] C. Chiu, M.A. Dasari, G.J. Suppes, W.R. Sutterlin, AIChE J. 52 (2006) 3543-3548.

[23] T.P. Braga, N. Essayem, S. Prakash, A. Valentini, J. Braz. Chem. Soc. 27 (2016) 2361-2371.

[24] S. Sato, M. Akiyama, R. Takahashi, T. Hara, K. Inui, M. Yokota, Appl. Catal. A:Gen. 347 (2008) 186-191.

[25] M. Velasquez, A. Santamaria, C. Batiot-Dupeyrat, Appl. Catal. B:Environ. 160 (2014) 606-613.

[26] A. Talebian-Kiakalaieh, N.A.S. Amin, H. Hezaveh, Renew. Sust. Energ. Rev. 40 (2014) 28-59.

[27] M. Pagliaro, M. Rossi, Chem. Sus. Chem. 1 (2008) 653-653. 
[28] A.K. Kinage, P.P. Upare, P. Kasinathan, Y.K. Hwang, J. Chang, Catal. Comm. 11 (2010) 620-623.

[29] D.C. Carvalho, L.G. Pinheiro, A. Campos, E.R.C. Millet, F.F. de Sousa, J.M. Filho, G.D. Saraiva, E.C. da Silva Filho, M.G. Fonseca, A.C. Oliveira, Appl. Catal. A:Gen. 471 (2014) 39-49.

[30] W.T. Reichle, Solid State Ion. 22 (1986) 135-141.

[31] D. Tichit, B. Coq, Cattech. 7 (2003) 206-217.

[32] F. Cavani, F. Trifirò, A. Vaccari, Catal. Today. 11 (1991) 173-301.

[33] J. Di Cosimo, V. Díez, M. Xu, E. Iglesia, C. Apesteguía, J. Catal. 178 (1998) 499-510.

[34] B.F. Sels, D.E. De Vos, P.A. Jacobs, Cat. Rev. 43 (2001) 443-488.

[35] R.L. Manfro, T.P. Pires, N.F. Ribeiro, M.M. Souza, Catal. Sci. Technol. 3 (2013) 12781287.

[36] M. Araque, L.M. Martínez, J.C. Vargas, M.A. Centeno, A.C. Roger, Appl. Catal. B:Environ. 125 (2012) 556- 566.

[37] A. Bienholz, H. Hofmann, P. Claus, Appl. Catal. A:Gen. 391(2011) 153-157.

[38] R.B. Mane, C.V Rode. Green. Chem. 14(10) (2012) 2780-2789.

[39] N. Blanch-Raga, A. E. Palomares, J. Martínez-Triguero, G. Fetter, P. Bosch.Ind. Eng. Chem. Res. 52 (2013) 15772-15779.

[40] J.Y. Shen, M. Tu, C. Hu, J. Solid State Chem. 137 (1998) 295-301.

[41] D. Yuan, X. Li, Q. Zhao, J. Zhao, S. Liu, M. Tadé, Appl. Catal. A:Gen. 451 (2013) 176183.

[42] M. Trombetta, G. Ramis, G. Busca, B. Montanari, A. Vaccari, Langmuir 13 (1997) 4628-4637.

[43] M.D. Romero, J.A. Calles, M.A. Ocaña, J.M. Gómez, Microp. Mesop. Mater. 111 (2008) 243-253. 
[44] I. Popescu, N. Tanchoux, D. Tichit, I.C. Marcu, Appl. Catal. A: Gen. 538 (2017) 8190.

[45] P. Lauriol-Garbay, J. Millet, S. Loridant, V. Bellière-Baca, P. Rey, J. Catal. 280 (2011) $68-76$

[46] S. Mészáros, J. Halász, Z. Kónya, P. Sipos, I. Pálinkó, Appl. Clay Sci. 80 (2013) 245248.

[47] X. Guo, Y. Li, W. Song, W. Shen, Catal. Letters 141 (2011) 1458-1463.

[48] V.A. Naumkin, A. Kraut-Vass, S.W. Gaarenstroom, C.J. Powell, NIST standard reference database 20 , version 4.1. https://srdata.nist.gov/xps/WagnerPlot.aspx. [49] W. Grünert, N.W. Hayes, R.W. Joyner, E.S. Shpiro, M.R.H. Siddiqui, G.N. Baeva, J. Phys. Chem. 98 (1994) 10832-10846

[50] P. Keil, D. Lützenkirchen-Hecht, R. Frahm, AIP Conf. Proc. 882 (2007) 490-492.

[51] L. Chmielarz, P. Kuśtrowski, A. Rafalska-Łasocha, R. Dziembaj, Thermochim. Acta 395 (2002) 225-236.

[52] S. Kannan, A. Dubey, H. Knozinger, J. Catal. 231 (2005) 381-392.

[53] G. Fierro, M. Lojacono, M. Inversi, P. Porta, R. Lavecchia, F. Cioci, J. Catal. 148 (1994) 709-721.

[54] A. Alejandre , F. Medina , P. Salagre , X. Correig and J. E. Sueiras, Chem. Mater., 11 (1999), 939.

[55] S. Célerier, S. Morisset, I. Batonneau-Gener, T. Belin, K. Younes, C. Batiot-Dupeyrat, Appl. Catal. A:Gen. 557 (2018) 135-144

[56] K. Hadjiivanov, G.N. Vayssilov, Adv. Catal. 47 (2002) 307-511

[57] S. Miyata, Clays Clay Miner. 28 (1980) 50-56.

[58] A. A. Davydov, A. A. Budneva, React. Kinet. Catal. Lett., 25 (1983) 121.

[59] S. Bordiga, C. Pazé, G. Berlier, D. Scarano, G. Spoto, A. Zecchina, C. Lamberti, Catal. Today, 70 (2001) 91-105. 


\section{Figure Captions}

Figure 1. a) XRD patterns of as-synthesized Cu-based hydrotalcites with different $M^{\prime \prime} / M^{\prime \prime \prime}$ ratios (the "s" at the end of the name indicates a material analysed just after the synthesis). b) XRD patterns of Cu-based hydrotalcite-derived mixed oxides with different $\mathrm{M}^{\prime \prime} / \mathrm{M}^{\prime \prime \prime}$ ratios.

Figure 2. Figure 2. HR-TEM (1) and STEM (2) images of (a) $5.0 \% \mathrm{Cu}-\mathrm{HT}-4$, (b) $10.0 \% \mathrm{Cu}$ HT-4, (c) $12.0 \%$ Cu-HT-4. (•) Copper detected by EDS mapping.

Figure 3. a) Glycerol conversion and selectivity to acetol with TOS under the optimal reaction conditions over the $5.0 \% \mathrm{Cu}-\mathrm{HT}-4$ catalyst b) Product distribution and carbon balance: a Carbon balance calculated with the total amount of products quantified during reaction, and ${ }^{b}$ Carbon balance calculated including also the carbonaceous matter deposited on catalytic surface and the gas products coming from glycerol. (Reaction conditions: feed: $\mathrm{MeOH} / \mathrm{GLY}=90 / 10 \mathrm{wt}$, flow $=2 \mathrm{~mL} / \mathrm{h}$, temperature $=240^{\circ} \mathrm{C}$, catalyst $=$ $0.5 \mathrm{~g}$ )

Figure 4. Glycerol conversion, selectivity and yield to acetol in the selective dehydration of glycerol over $5.0 \% \mathrm{Cu}-\mathrm{HT}$ catalysts with different $(\mathrm{Cu}+\mathrm{Mg}) / \mathrm{Al}$ molar ratios at TOS $=4 \mathrm{~h}$. (Reaction conditions: feed: $\mathrm{MeOH} / \mathrm{GLY}=90 / 10 \mathrm{wt}$, flow $=2 \mathrm{~mL} / \mathrm{h}$, temperature $=240^{\circ} \mathrm{C}$, catalyst $=0.5 \mathrm{~g}$ ).

Figure 5. Average glycerol conversion and selectivity to acetol in the selective dehydration of glycerol over $5.0 \% \mathrm{Cu}-\mathrm{HT}$ catalysts with different $(\mathrm{Cu}+\mathrm{Mg}) / \mathrm{Al}$ molar ratios during TOS $=1-9 \mathrm{~h}$. (Reaction conditions: feed: $\mathrm{MeOH} / \mathrm{GLY}=90 / 10 \mathrm{wt}$., flow $=2 \mathrm{~mL} / \mathrm{h}$, temperature $=$ $240^{\circ} \mathrm{C}$, catalyst $=0.5 \mathrm{~g}$ ).

Figure 6. $\mathrm{NH}_{3}$-TPD (a) and $\mathrm{CO}_{2}$-TPD (b) profiles of Cu-Mg-Al hydrotalcite-derived mixed oxides with different $\mathrm{M}^{\prime \prime} / \mathrm{M}^{\prime \prime \prime}$ ratios.

Figure 7. Cu2 $\mathrm{p}_{3 / 2}$ XPS peak of a) $5.0 \% \mathrm{Cu}-\mathrm{HT}-4$ (fresh, calcined), b) $5.0 \% \mathrm{Cu}-\mathrm{HT}-4 \mathrm{U}$ (used), c) 5.0\%Cu-HT-4R ( $\mathrm{H}_{2}$ reduced "ex situ"), d) 5.0\%Cu-HT-4R-INSITU ( $\mathrm{H}_{2}$ reduced "in situ"), e) $\mathrm{L}_{3} \mathrm{M}_{45} \mathrm{M}_{45} \mathrm{Cu}$ Auger peak for the studied Cu-Mg-Al samples. 
Figure 8. Glycerol conversion (a) and selectivity to acetol (b) for 5.0\%Cu-HT-4, 5.0\%CuHT-4R and 5.0\%Cu-HT-4R-INSITU materials. (Reaction conditions: Temperature $=240$ ${ }^{\circ} \mathrm{C}$, feed: $\mathrm{MeOH} / \mathrm{GLY}(90 / 10 \mathrm{w}$.), flow = 2mL/h, catalyst: $0.5 \mathrm{~g})$

Figure 9. a) Pre-treatment test of $5.0 \% \mathrm{Cu}-\mathrm{HT}-4 \mathrm{C}$ catalyst with methanol (Reaction conditions: Feed: methanol, temperature $=240{ }^{\circ} \mathrm{C}$, flow $=2 \mathrm{~mL} / \mathrm{h}$, catalyst: $0.5 \mathrm{~g}$ ). b) Catalytic results of selective glycerol dehydration over $5.0 \% \mathrm{Cu}-\mathrm{HT}-4$ with and without methanol pre-treatment (Reaction conditions: Feed: water/glycerol (90/10 wt.), temperature $=240^{\circ} \mathrm{C}$, flow $=2 \mathrm{~mL} / \mathrm{h}$, catalyst: $0.5 \mathrm{~g}$ ).

Figure 10. TPR traces for 5.0\%Cu-HT-4 (calcined, un-reduced) and 5.0\%Cu-HT-4R (calcined + reduced at $200{ }^{\circ} \mathrm{C}$ with $\mathrm{MeOH}$ ).

Figure 11. IR spectra of 1,2-propanediol adsorbed at $25^{\circ} \mathrm{C}$ on $5.0 \% \mathrm{Cu}-\mathrm{HT}-4$ (blue), $5.0 \% \mathrm{Ni}-\mathrm{HT}-4$ (red), 5.0\%Co-HT-4 (green), HT-4 (cyan) and 5.0\%Cu-HT-4R (ex situ $\mathrm{H}_{2}$ reduced, black). In magenta gas phase IR spectra of 1,2-propanediol as reference spectra.

Figure 12. IR spectra of 1,2-propanediol at $160^{\circ} \mathrm{C}$ on $5.0 \% \mathrm{Cu}-\mathrm{HT}-4$ (blue), $5.0 \% \mathrm{Ni}-\mathrm{HT}-4$ (red), 5.0\%Co-HT-4 (green), HT-4 (cyan) and 5.0\%Cu-HT-4 "ex situ" $\mathrm{H}_{2}$ reduced (black).1,2-PDO: IR peak related to 1,2-propanediol.

Figure 13. IR spectra of $\mathrm{CO}$ adsorption at $25^{\circ} \mathrm{C}$ as probe molecule on the $5.0 \% \mathrm{Cu}-\mathrm{HT}-4$ sample after 1,2-propanediol adsorption and increasing temperature to $160^{\circ} \mathrm{C}$.

Figure 14. IR spectra of hydroxyacetone adsorbed at $25^{\circ} \mathrm{C}$ on $5.0 \% \mathrm{Cu}-\mathrm{HT}-4$ (blue) and $5.0 \% \mathrm{Ni}-\mathrm{HT}-4$ (red) (a), and after evacuation at $25^{\circ} \mathrm{C}$ for $5 \mathrm{~min}(\mathrm{~b})$.

Figure 15. Catalytic results of selective glycerol dehydration over 5.0\%Co-HT-4 with (orange) and without (blue) glyceraldehyde co-feed (Reaction conditions: Feed: methanol/glycerol/glyceraldehyde/water (87.8/9.5/0.45/2.2 wt.), temperature $=240{ }^{\circ} \mathrm{C}$, flow $=2 \mathrm{~mL} / \mathrm{h}$, catalyst: $0.5 \mathrm{~g}$ ).

Figure 16. Average glycerol conversion and average acetol selectivity for Cu-Mg-Al calcined materials with different Cu contents during TOS $=1-9 \mathrm{~h}$ (Reaction conditions: feed $=$ methanol/glycerol $(90 / 10$ in weight $)$, flow $=2 \mathrm{ml} / \mathrm{h}$, with $0.5 \mathrm{~g}$ of catalyst at $\left.240{ }^{\circ} \mathrm{C}\right)$. 
Figure 17. Glycerol conversion and acetol selectivity accumulative data during reusability tests of $10.0 \% \mathrm{Cu}-\mathrm{HT}-4$ catalyst. Reaction conditions: feed $=\mathrm{MeOH} / \mathrm{GLY}$ (90/10 in weight), flow $=2 \mathrm{ml} / \mathrm{h}$, with $0.5 \mathrm{~g}$ of catalyst at $240^{\circ} \mathrm{C}$. 


\section{SUPPORTING INFORMATION}

\section{Continuous catalytic process for the selective dehydration of glycerol over $\mathrm{Cu}$ - based mixed oxide}

Jaime Mazaríoa, Patricia Concepciónª, María Venturaa, Marcelo E. Domine*a

a Instituto de Tecnología Química (UPV-CSIC). Universitat Politècnica de València. Consejo Superior de Investigaciones Científicas. Avda. de los Naranjos s/n, 46022, Valencia, Spain.

\section{$\underline{\text { XRD Measurements }}$}
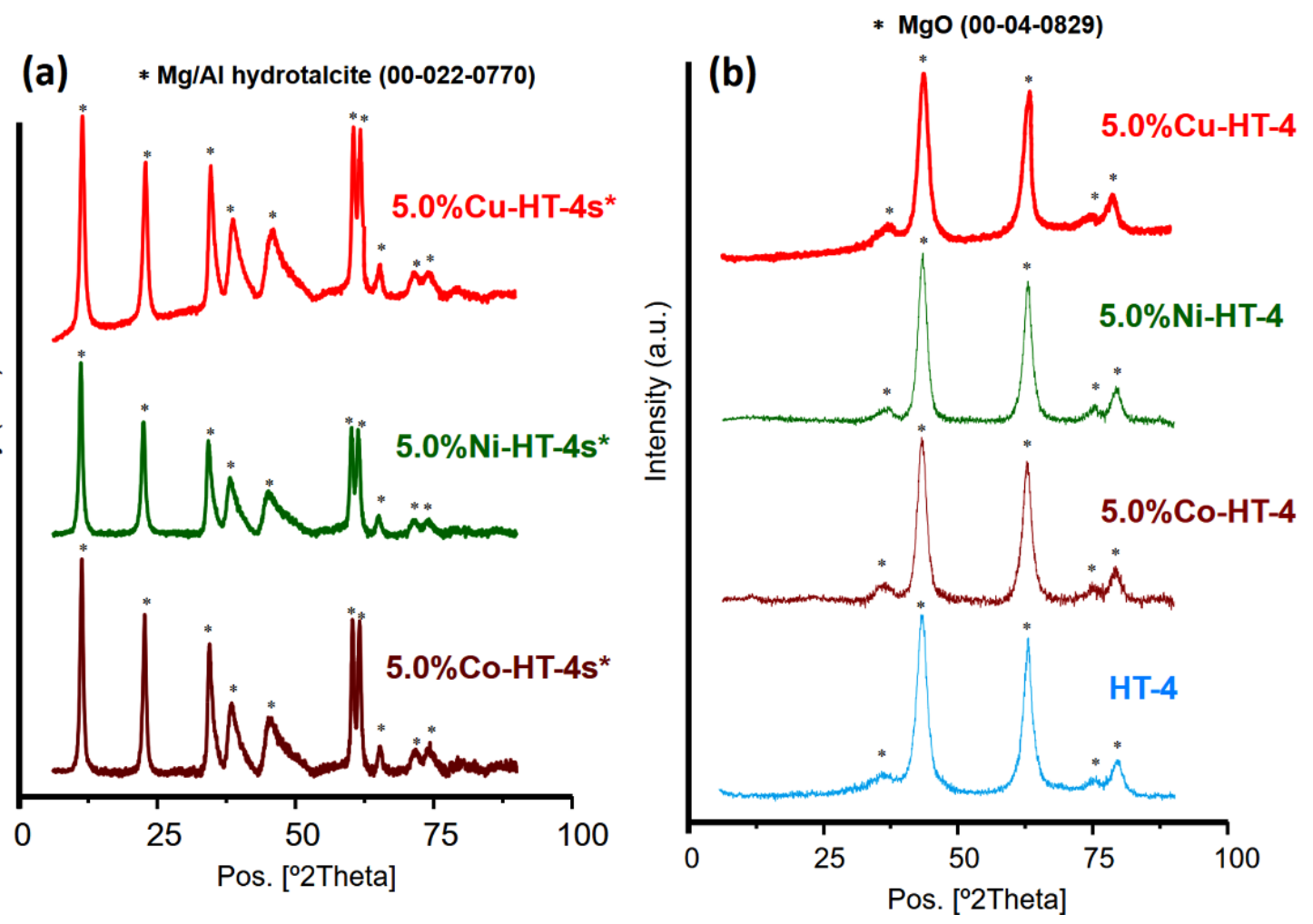

Figure S1. a) XRD patterns of as-synthesized hydrotalcites containing different transition metals. (the " $\mathrm{s}$ " at the end of the name indicates a material analyzed just after the synthesis). b) XRD patterns of hydrotalcite-derived mixed oxides containing different transition metals. $\left(^{*}\right)$ : Background corrected to avoid strong fluorescence effects. 

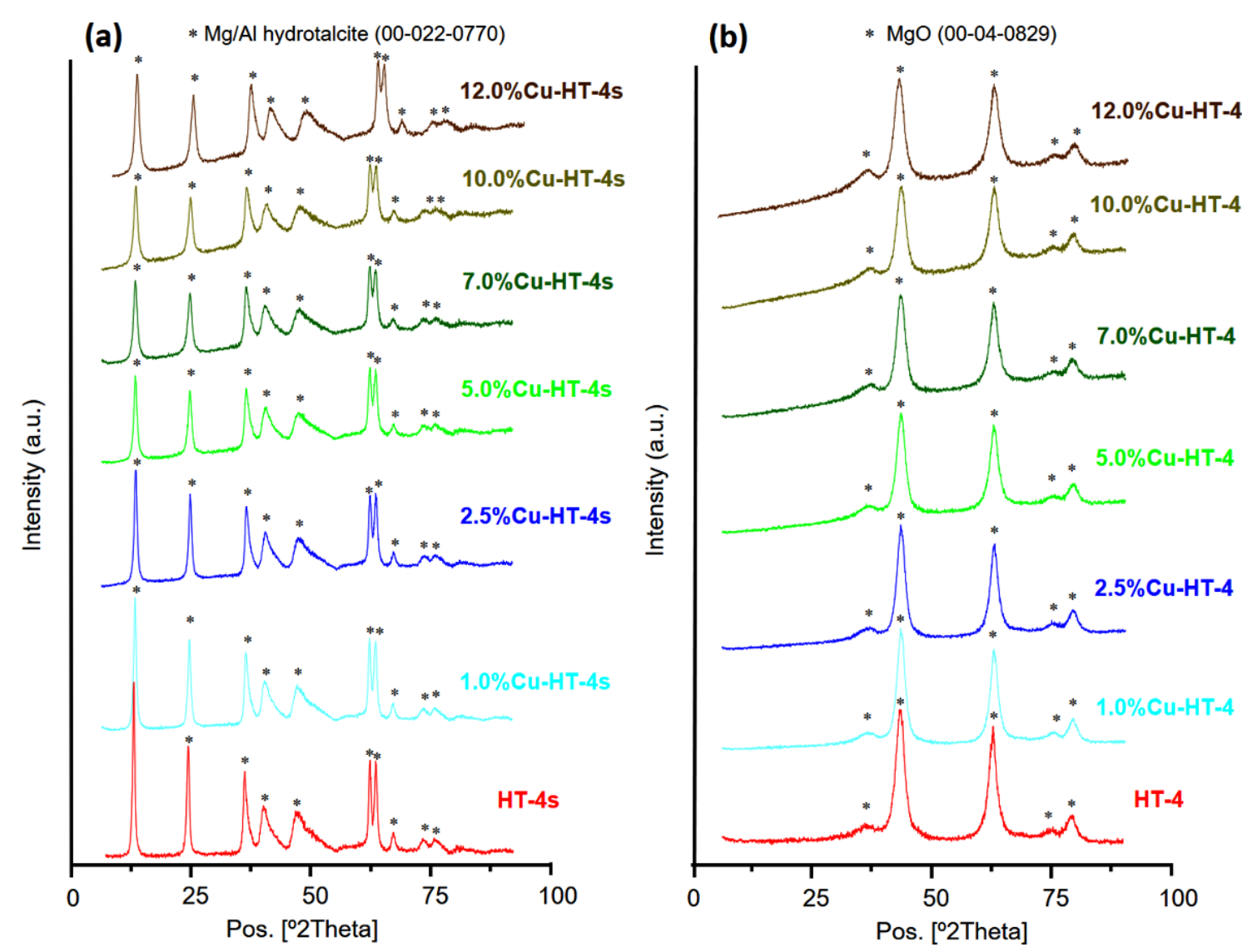

Figure S2. a) XRD patterns of as-synthesized hydrotalcites (s) containing different copper loadings. b) XRD patterns of hydrotalcite-derived mixed oxides containing different copper loadings.

\section{Study of the dilution degree effect in fixed-bed catalytic reactor}

Regarding the dilution degree of feed, a clear decrease in the glycerol conversion was observed by decreasing the $\mathrm{MeOH} / \mathrm{GLY}$ (methanol/glycerol) ratio from $95 / 5$ to $50 / 50$, this means increasing the glycerol concentration in the feed (as expected). At the same time, some small increase in the selectivity to acetol (and consequently in the acetol yield) was achieved when decreasing $\mathrm{MeOH} / \mathrm{GLY}$ weight ratio from 95:5 to 85:15 or even $75: 25$, this fact mainly occurring at short time on streams (TOS $=3 \mathrm{~h}$ ). These significant differences in acetol selectivity appeared at short TOS were practically not observed when the reaction reaches TOS $=5 \mathrm{~h}$. In fact, acetol yields at TOS $=5 \mathrm{~h}$ calculated for different $\mathrm{MeOH} / \mathrm{GLY}$ ratios in the feed (from $95 / 5$ to $85 / 15$ ) were quite similar and close to $35 \%$. More interestingly, beneficial effects on catalyst stability were observed when 
increasing the quantity of methanol in the feed (see Table S1). Experiments with streams containing less than $20 \mathrm{wt} \%$ of glycerol allowed the catalyst to be working up to $8 \mathrm{~h}$ keeping acceptable values of conversion, with selectivity levels to acetol higher than $52 \%$.

Table S1. Catalytic results on the selective dehydration of glycerol in a continuous flow fix-bed reactor over 5\%Cu-HT-4 catalyst with different methanol/glycerol (MeOH/GLY) ratios.

\begin{tabular}{|c|c|c|c|c|c|c|}
\hline \multirow{2}{*}{$\begin{array}{c}\text { MeOH / } \\
\text { GLY } \\
\text { ratio } \\
\text { (wt\%) }\end{array}$} & \multicolumn{2}{|c|}{ TOS $=3 \mathrm{~h}$} & \multicolumn{2}{|c|}{ TOS $=5 \mathrm{~h}$} & \multicolumn{2}{|c|}{ TOS $=8 \mathrm{~h}$} \\
\hline & $\begin{array}{c}\text { GLY } \\
\text { conversion } \\
\text { (\%Mol.) }\end{array}$ & $\begin{array}{l}\text { Select. } \\
\text { to acetol } \\
\text { (\%Mol.) }\end{array}$ & $\begin{array}{c}\text { GLY } \\
\text { conversion } \\
\text { (\%Mol.) }\end{array}$ & $\begin{array}{l}\text { Select. } \\
\text { to acetol } \\
\text { (\%Mol.) }\end{array}$ & $\begin{array}{c}\text { GLY } \\
\text { conversion } \\
\text { (\%Mol.) }\end{array}$ & $\begin{array}{c}\text { Select. to } \\
\text { acetol } \\
\text { (\%Mol.) }\end{array}$ \\
\hline $95 / 5$ & 87.3 & 34.1 & 71.6 & 49.0 & 44.4 & 58.7 \\
\hline $90 / 10$ & 66.6 & 53.4 & 71.1 & 53.3 & 48.8 & 52.9 \\
\hline $85 / 15$ & 65.5 & 52.0 & 62.9 & 59.3 & 12.1 & 51.5 \\
\hline $75 / 25$ & 50.2 & 67.0 & 38.3 & 59.1 & - & - \\
\hline $50 / 50$ & 37.0 & 52.4 & 23.3 & 45.1 & - & - \\
\hline
\end{tabular}




\section{Study of the temperature effect in fixed-bed catalytic reactor}

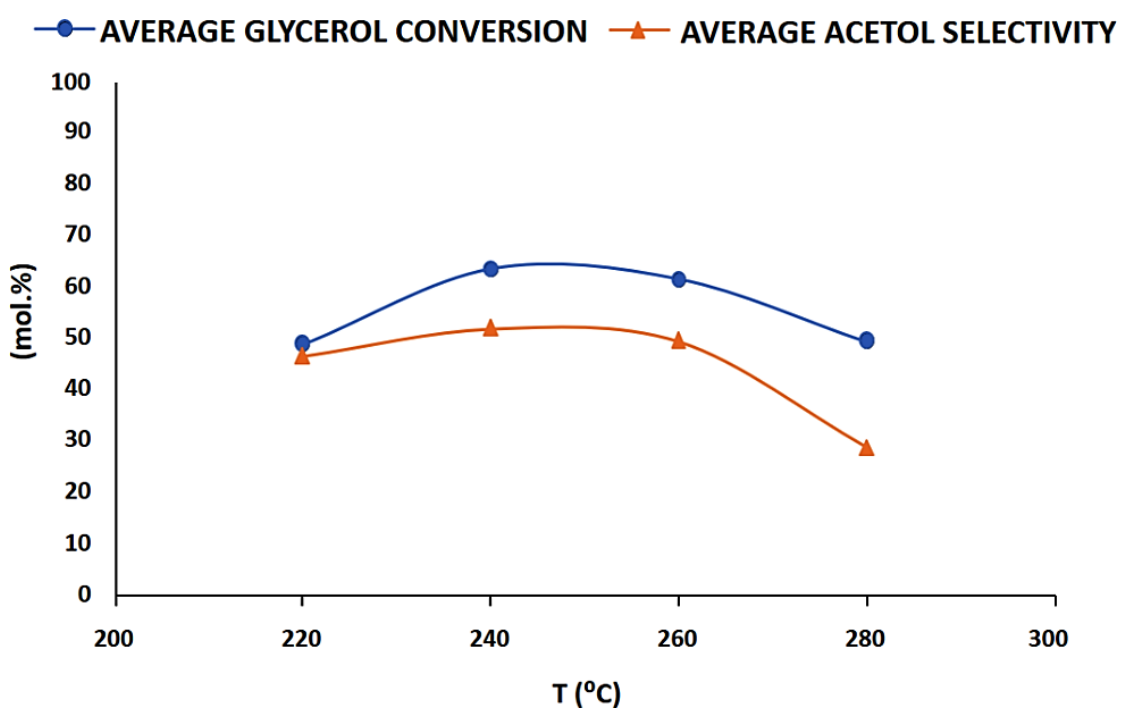

Figure S3. Effect of temperature in the selective dehydration of glycerol over $5.0 \% \mathrm{Cu}$ HT-4 catalyst. Average data obtained during process (Reaction conditions: feed: $\mathrm{MeOH} / \mathrm{GLY}=90 / 10 \mathrm{wt}$., flow $=2 \mathrm{~mL} / \mathrm{h}$, catalyst $=0.5 \mathrm{~g}, \mathrm{TOS}=1-9 \mathrm{~h}$ ).

\section{Internal and external diffusion studies in fixed-bed catalytic reactor}

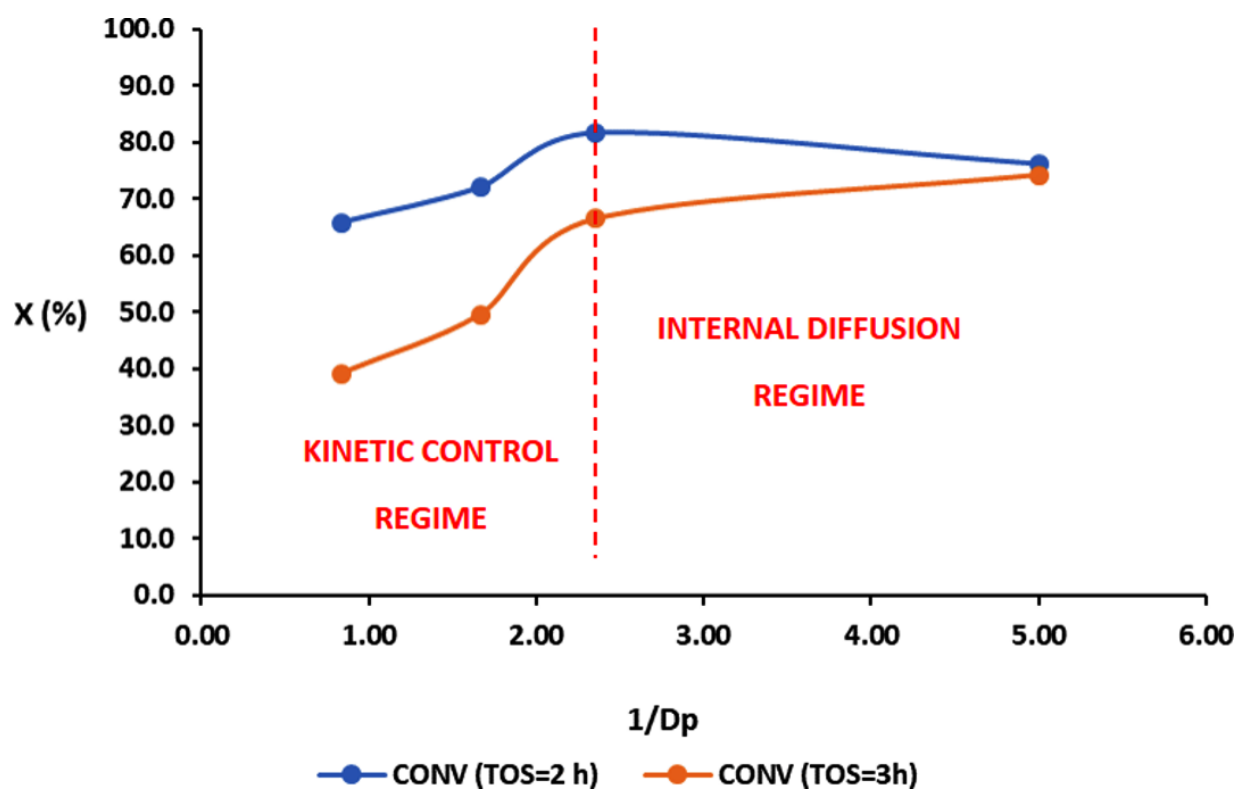

Figure S4. Internal diffusion study. Temperature $=240^{\circ} \mathrm{C}$, feed: methanol/glycerol (90/10 wt.), flow $=2 \mathrm{~mL} / \mathrm{h}$, catalyst: $0.5 \mathrm{~g}, 5.0 \% \mathrm{Cu}-\mathrm{HT}-4$. 


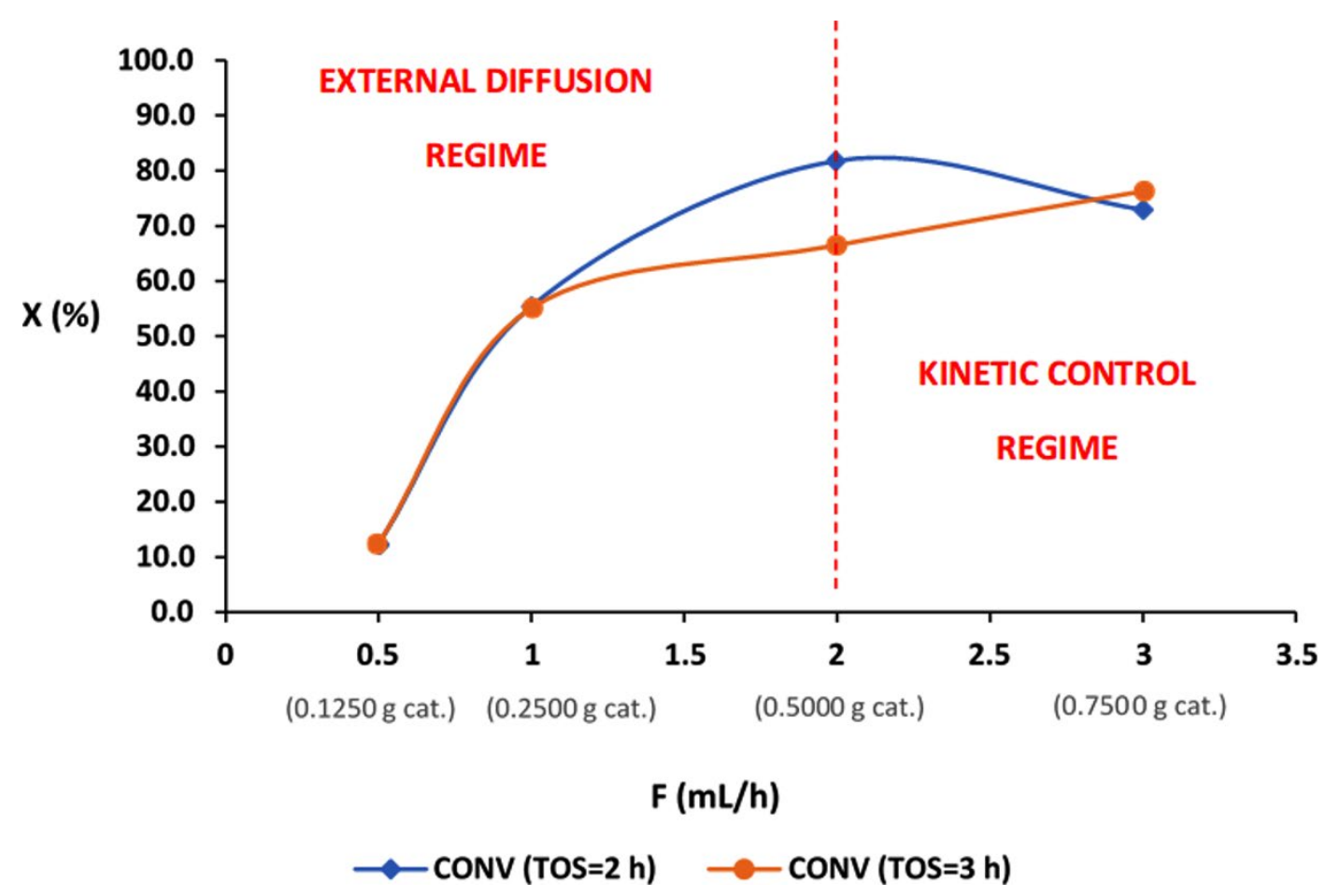

Figure S5. External diffusion study. Temperature $=240{ }^{\circ} \mathrm{C}$, feed: methanol/glycerol (90/10 wt.), catalyst: $0.5 \mathrm{~g}, 5.0 \% \mathrm{Cu}-\mathrm{HT}-4$, particle size $=0.425-0.600 \mathrm{~mm}$. 


\section{Other catalyst characterization studies}
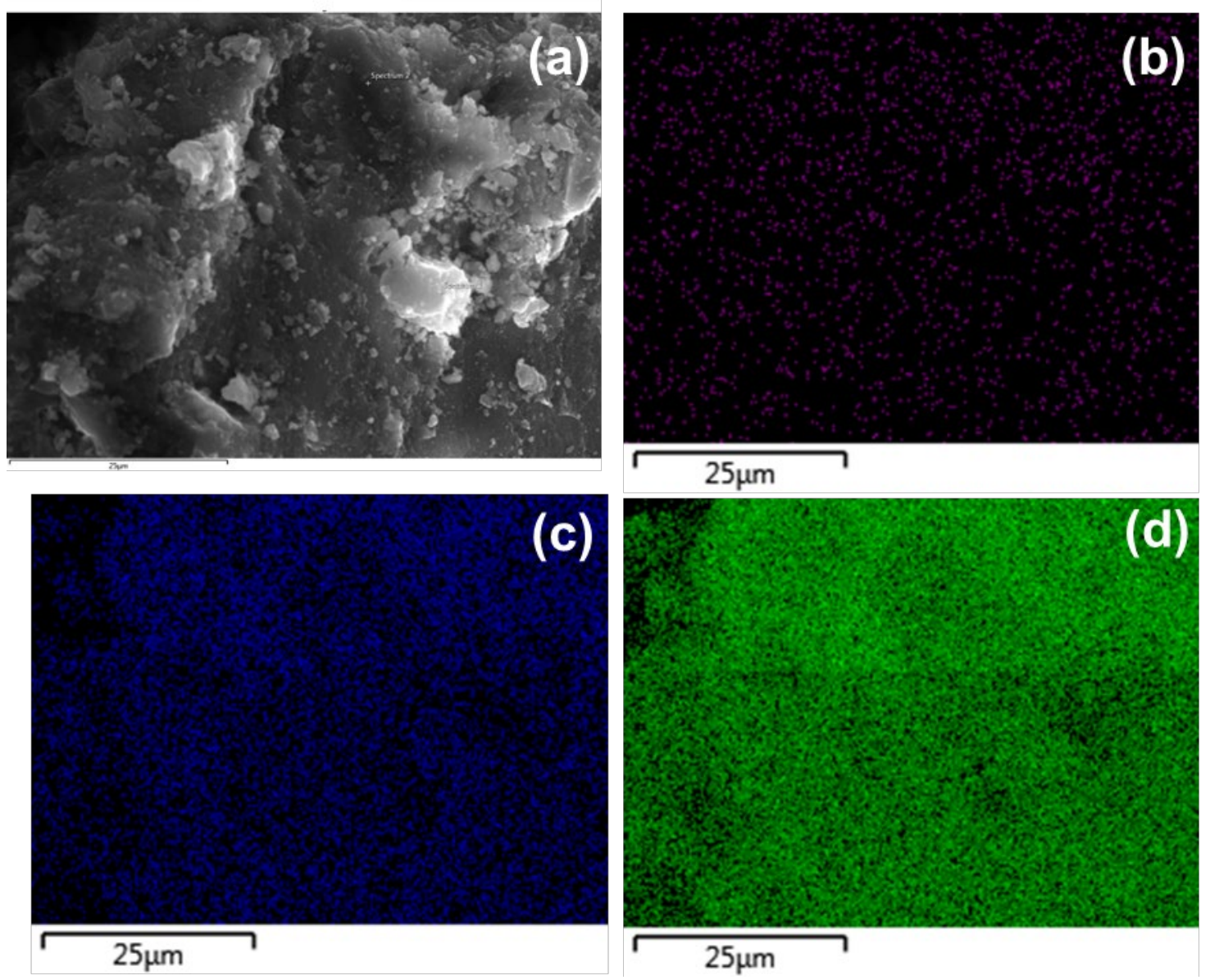

Figure S6. SEM image (a) and $\mathrm{Cu}(\mathrm{b}), \mathrm{Al}(\mathrm{c})$ and $\mathrm{Mg}(\mathrm{d})$ EDS mapping of 5.0\%Cu-HT-4 material. 

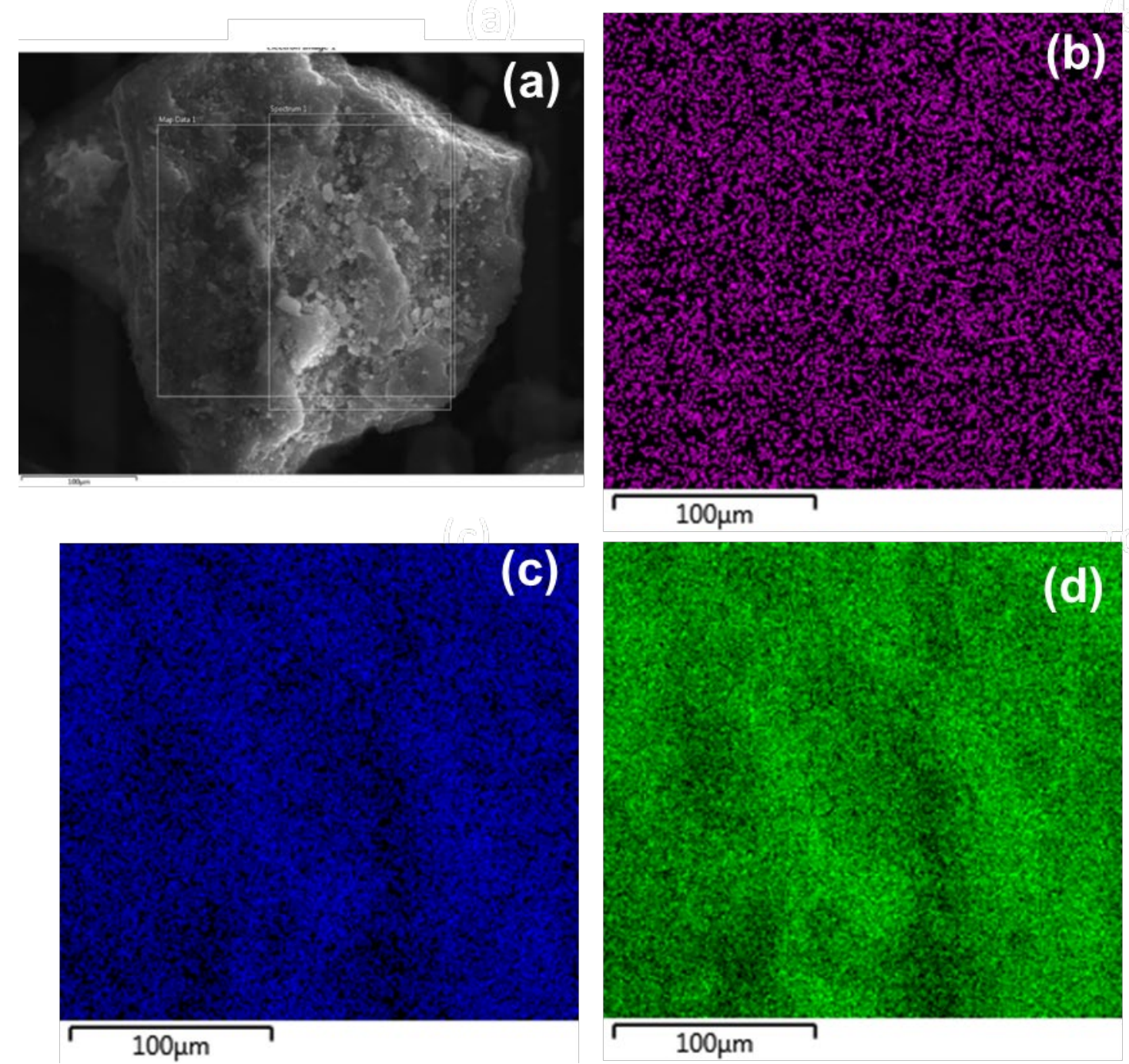

Figure S7. SEM image (a) and $\mathrm{Cu}(\mathrm{b}), \mathrm{Al}(\mathrm{c})$ and $\mathrm{Mg}(\mathrm{d})$ EDS mapping of $10.0 \% \mathrm{Cu}$ HT-4 material. 

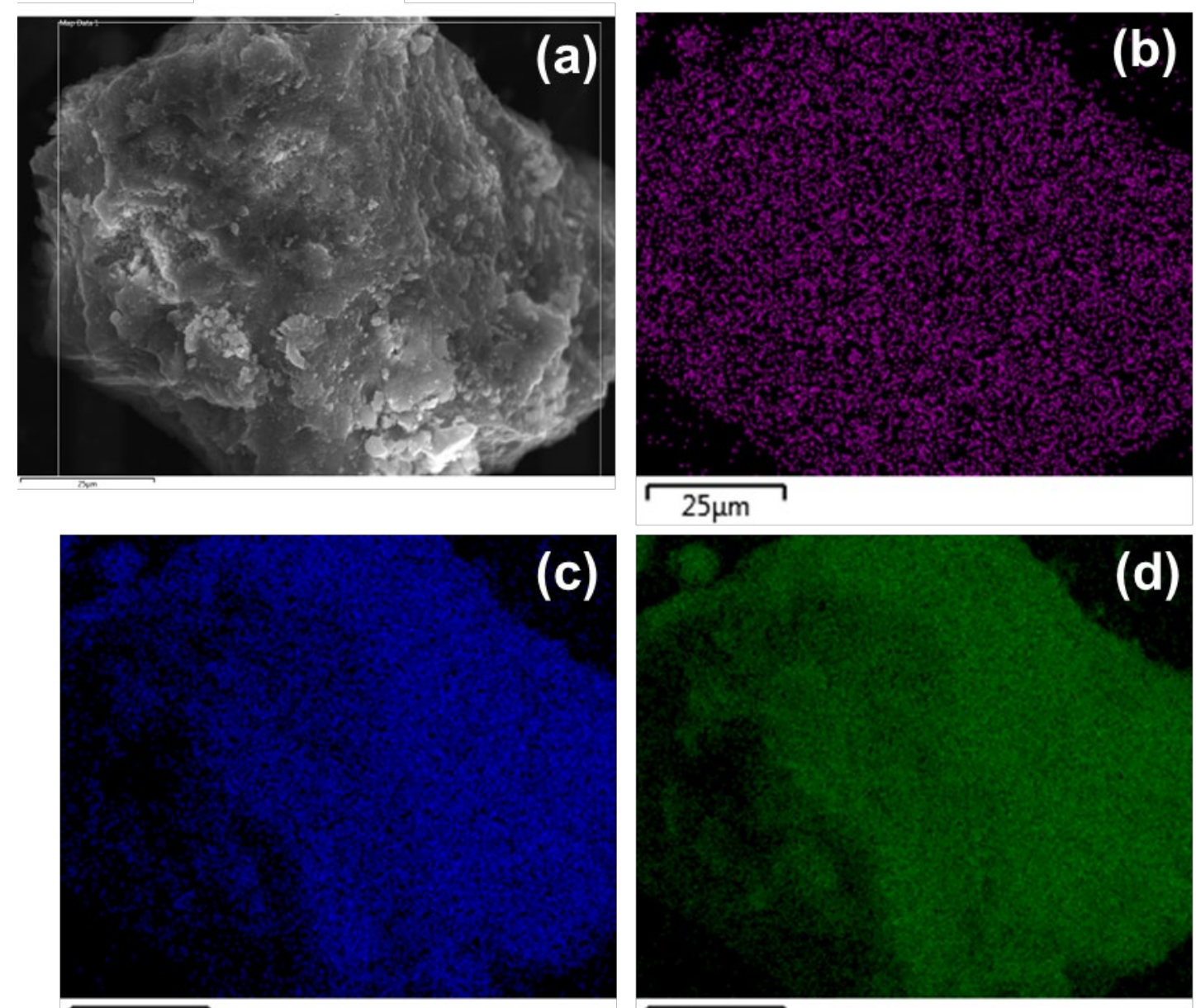

$25 \mu \mathrm{m}$

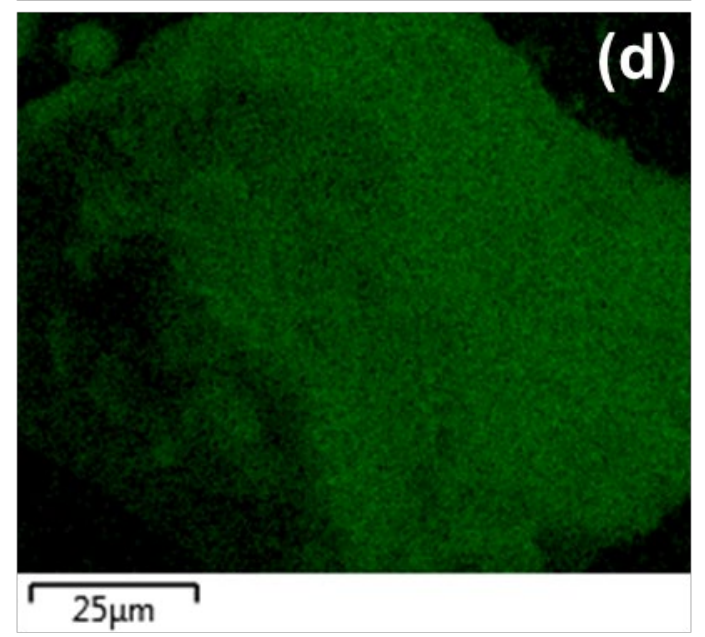

Figure S8. SEM image (a) and $\mathrm{Cu}(\mathrm{b}), \mathrm{Al}(\mathrm{c})$ and $\mathrm{Mg}(\mathrm{d})$ EDS mapping of $12.0 \% \mathrm{Cu}-\mathrm{HT}-$ 4 material.

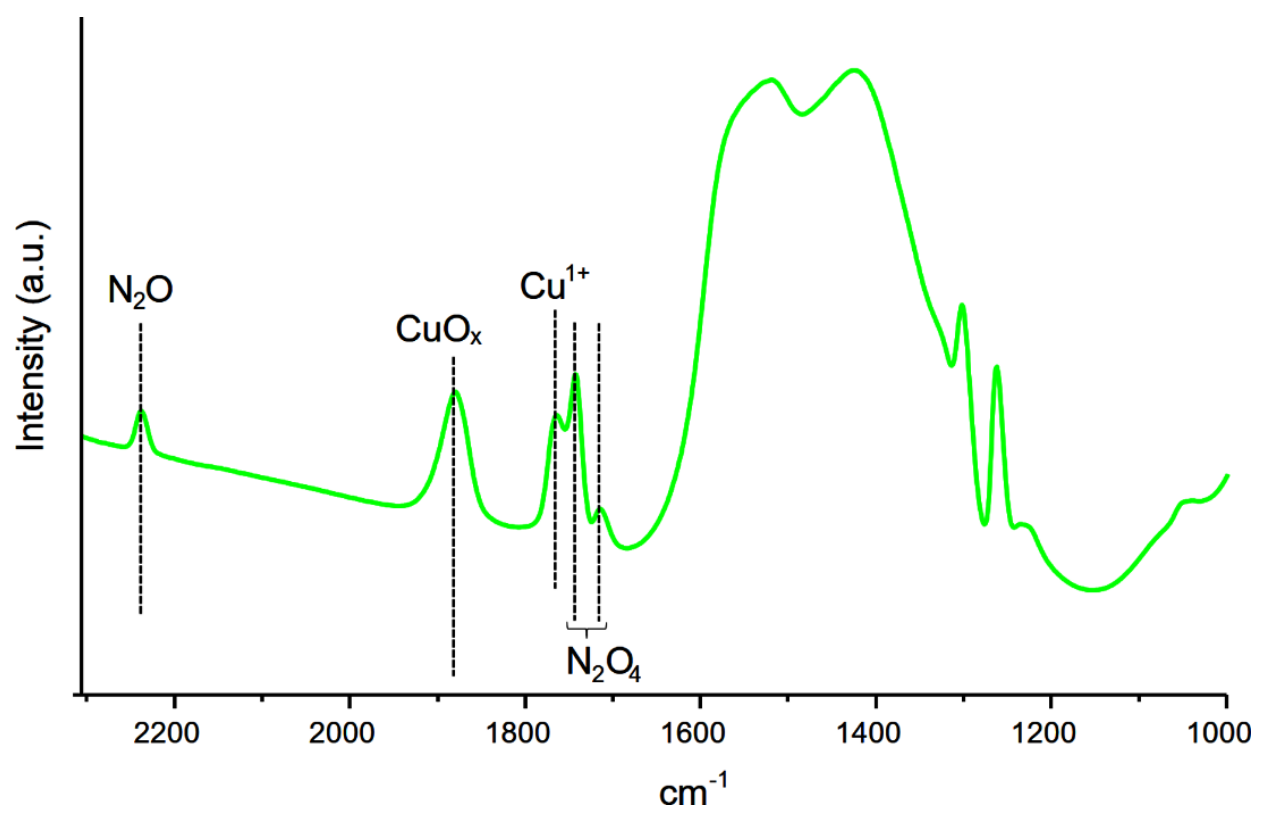

Figure S9. NO adsorption FTIR spectra on 5.0\%Cu-HT-4 material. Interpretation according to references $[1,2]$. 


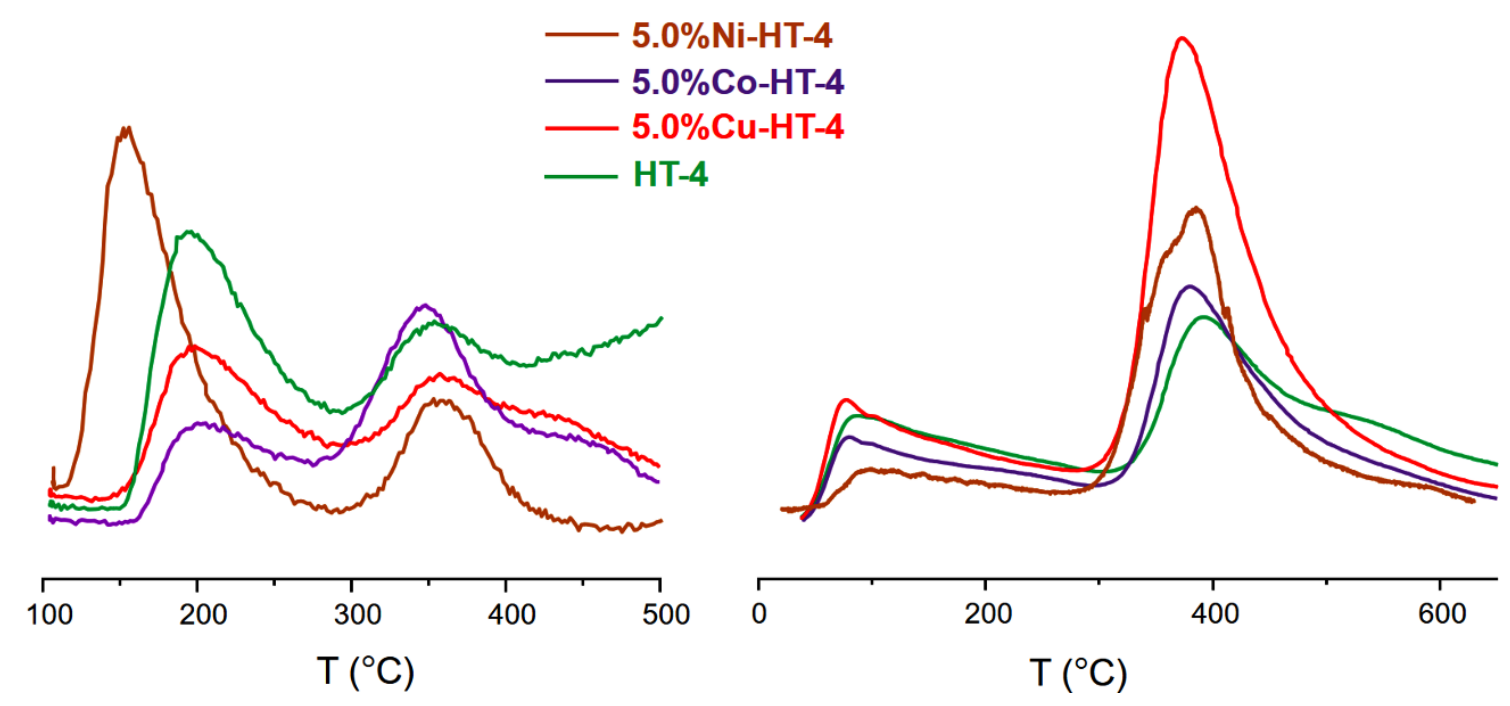

Figure S10. TPD-NH $\mathrm{NH}_{3}(\mathrm{a})$ and TPD- $\mathrm{CO}_{2}$ (b) profiles of Mg-Al hydrotalcite-derived mixed oxide pure and with different transition metals. Note: Baseline drift in HT-4 sample due to $\mathrm{NO}_{\mathrm{x}}$ formation $\left(\mathrm{T} \geq 450^{\circ} \mathrm{C}\right)$.

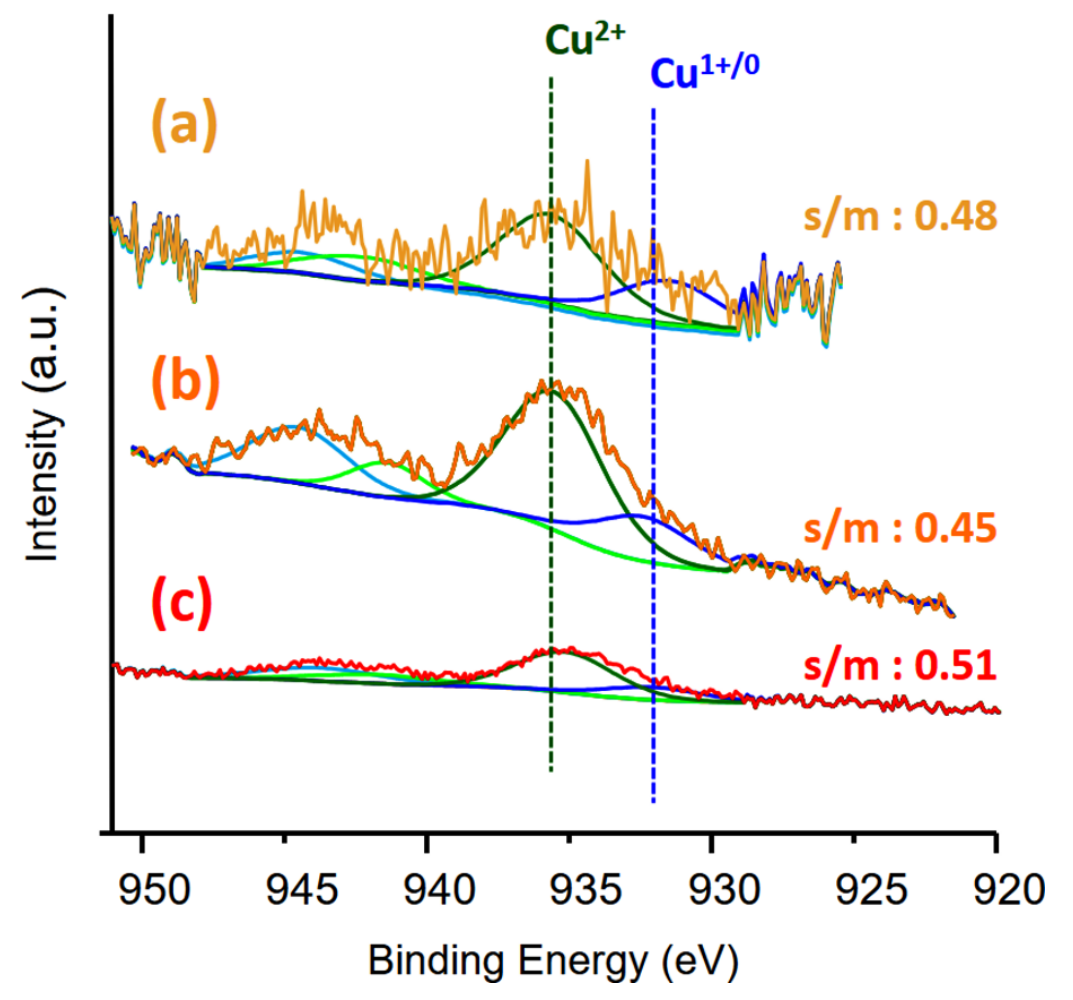

Figure S11. Cu2 $\mathrm{p}_{3 / 2}$ XPS peak of a) $5.0 \% \mathrm{Cu}-\mathrm{HT}-4$ (Mg anode, 1 scan), b) $5.0 \% \mathrm{Cu}-\mathrm{HT}$ 4 (Mg anode, 25 scans), c) 5.0\%Cu-HT-4 (Al anode after overall acquisition, 25 scans). 


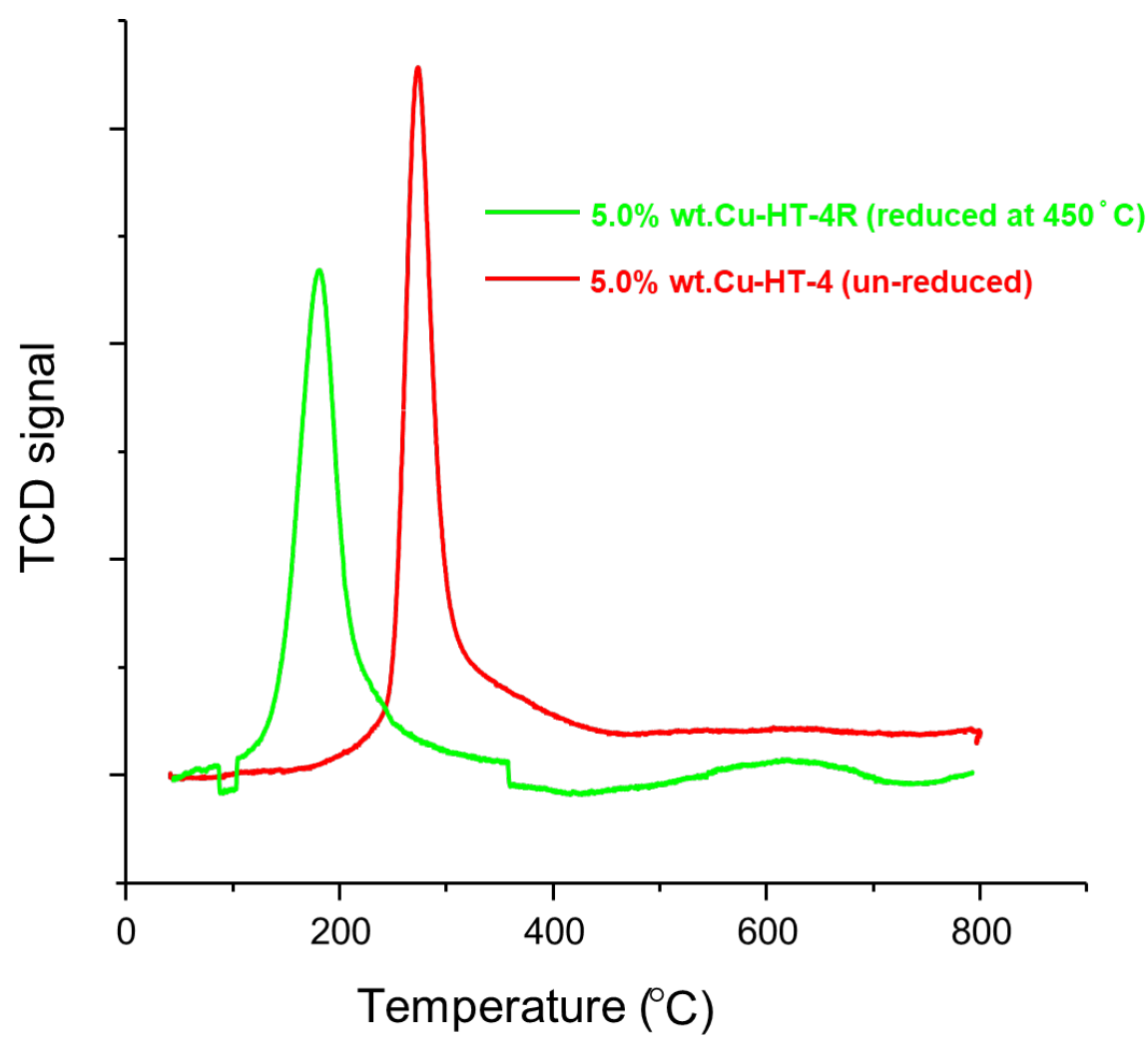

Figure S12. TPR traces for 5.0\%Cu-HT-4C (fresh, calcined) and 5.0\%Cu-HT-4R (calcined + reduced at $450^{\circ} \mathrm{C}$ under $\mathrm{H}_{2}$ atmosphere) samples.

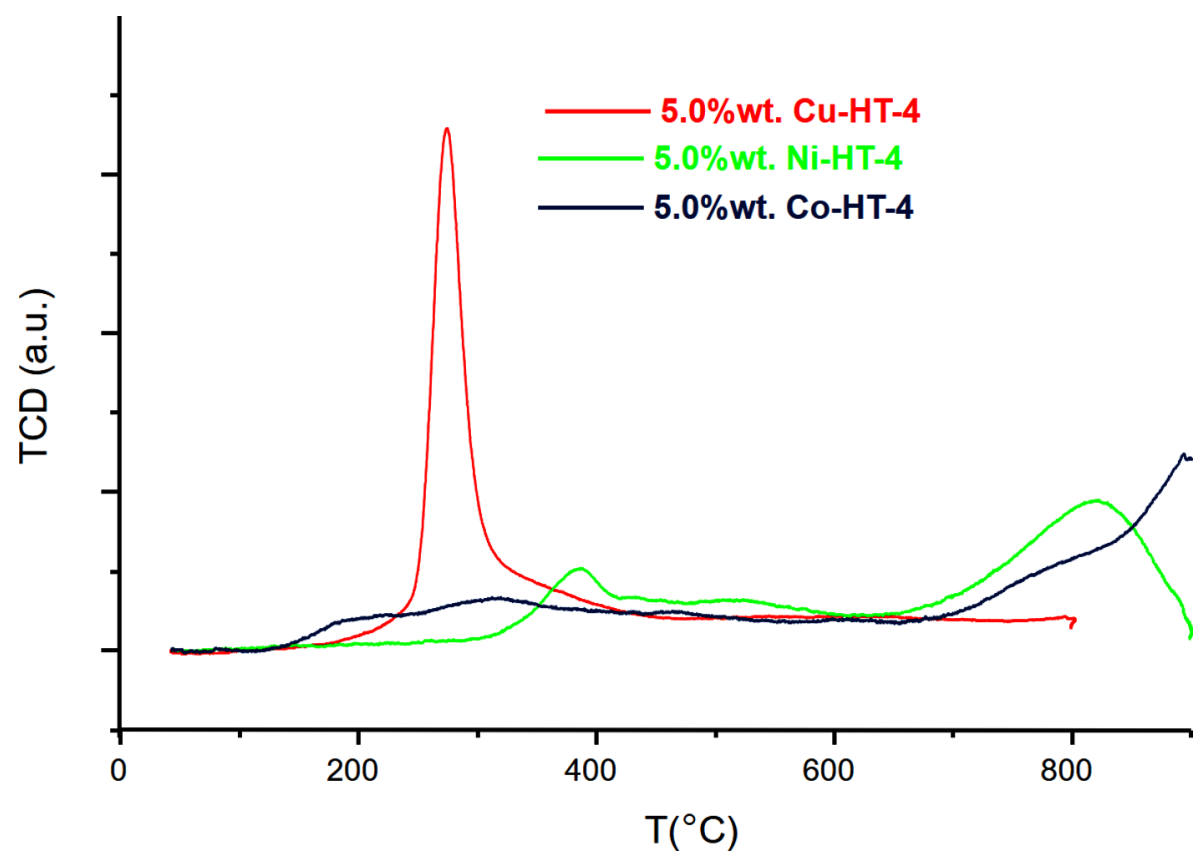

Figure S13. TPR traces for 5.0\%Cu-HT-4 (red), 5.0\%Co-HT-4 (blue) and 5.0\%Ni-HT-4 (green) samples. 
Table S2. Quantitative data for temperature programmed desorption ( $\mathrm{NH}_{3}$-TPD- and $\mathrm{CO}_{2}$-TPD) of Mg-Al HT-derived (HT-4) pure material and with the incorporation of different $\mathrm{Cu}$, $\mathrm{Co}$ and $\mathrm{Ni}$ metals.

\begin{tabular}{ccccc}
\hline Catalyst & $\begin{array}{c}\text { Acid site } \\
\text { density } \\
(\boldsymbol{\mu m o l / g})\end{array}$ & $\begin{array}{c}\text { Basic } \\
\text { site } \\
\text { density } \\
(\boldsymbol{\mu} \text { mol/g) }\end{array}$ & $\begin{array}{c}\text { Acid sites } \\
\text { (weak/medium) }\end{array}$ & $\begin{array}{c}\text { Basic sites } \\
\text { (weak/medium) }\end{array}$ \\
\hline $\mathbf{5 . 0 \% C u - H T - 4}$ & 87 & 159 & $42: 58$ & $21: 79$ \\
$\mathbf{5 . 0 \% C o - H T - 4}$ & 165 & 198 & $26: 74$ & $28: 72$ \\
$\mathbf{5 . 0 \% N i - H T - 4}$ & 115 & 290 & $74: 26$ & $18: 82$ \\
HT-4 & 139 & 245 & $56: 44$ & $31: 69$ \\
\hline
\end{tabular}

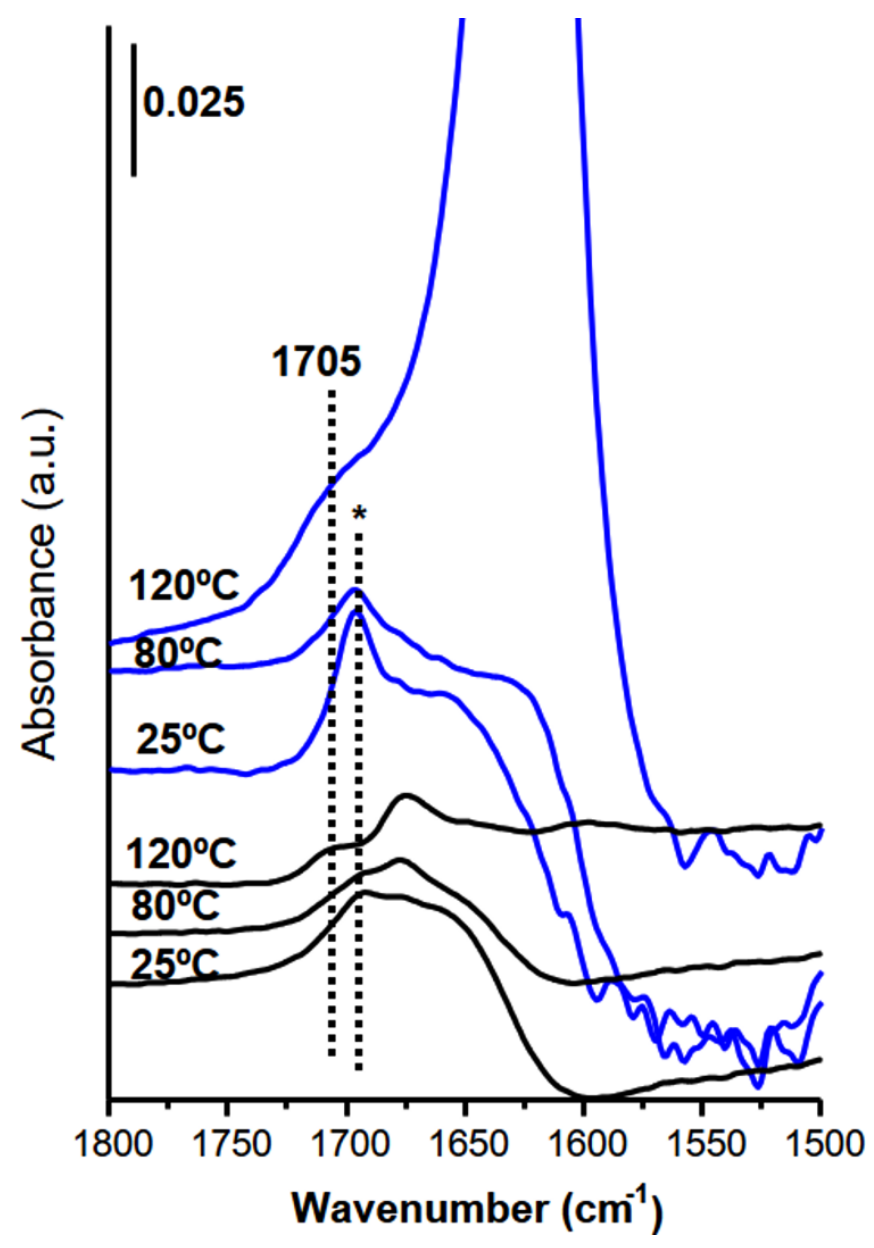

Figure S14. FT-IR spectra of 1,2 -propanediol at $25^{\circ} \mathrm{C}, 80^{\circ} \mathrm{C}$ and $160^{\circ} \mathrm{C}$ on $5.0 \% \mathrm{Cu}$ $\mathrm{HT}-4$ (blue) and 5.0\% Cu-HT-4 "ex situ" $\mathrm{H}_{2}$ reduced (black).1,2PDO: IR peak related to 1,2 propanediol. 


\section{Comparison between $\mathrm{Cu}-$, $\mathrm{Ni}-$ and Co-based catalysts}

The feasibility of using other divalent transition metals with redox properties and a proven capability to produce acetol in the glycerol hydrogenolysis, such as nickel or cobalt $[3,4]$ was explored. For that, $5.0 \% \mathrm{Ni}-\mathrm{HT}-4$ and $5.0 \% \mathrm{Co}-\mathrm{HT}-4$ materials were prepared, calcined and tested in the selective dehydration of glycerol in continuous flow fixed-bed reactor (at $240^{\circ} \mathrm{C}$ and TOS $=9 \mathrm{~h}$ ), always comparing with the $5.0 \% \mathrm{Cu}$ HT-4 catalyst. The attained catalytic results for these three analogous samples are summarized in Table 6. The experiments performed using $5.0 \% \mathrm{Ni}-\mathrm{HT}-4$ and $5.0 \% \mathrm{Co}-$ HT-4 hydrotalcite-derived mixed oxides clearly revealed the need of using copper in this system. Very low glycerol conversions with poor selectivities to acetol were achieved with both Co- and Ni-based catalysts (in the case of Ni-HT-4, negligible amounts of acetol were detected). Nonetheless, some goods results in terms of glycerol conversion to either acetol or 1,2-propanediol described in the literature for materials containing these transition metals have been reported $[5,6]$. These results could be explained in terms of the highly larger contact times in a batch reactor system, as opposed to the shorter contact times in a fixed bed reactor, which could allow Co and $\mathrm{Ni}$ to interact with the glycerol molecule in the same way as $\mathrm{Cu}$ does in our system. In addition, the presence of $\mathrm{H}_{2}$ in the reaction system could also help to increase $\mathrm{Ni}$ and Co reactivity. In any case, majority of literature reports about glycerol transformation to propane-diols agree on the fact that copper is the essential metal when working with metallic mixed oxides by using a fixed-bed reactor $[6,7]$.

Table S3. Catalytic activity data for hydrotalcite-derived mixed oxides containing different transitions metals.

\begin{tabular}{|c|c|c|}
\hline Catalyst & $\begin{array}{c}\text { Glycerol conversion } \\
\text { (\%Mol.) }\end{array}$ & $\begin{array}{l}\text { Selectivity to acetol } \\
\text { (\%Mol.) }\end{array}$ \\
\hline $5.0 \% \mathrm{Cu}-\mathrm{HT}-4$ & 74.4 & 51.3 \\
\hline $5.0 \%$ Co-HT-4 & 5.6 & 16.5 \\
\hline $5.0 \% \mathrm{Ni}-\mathrm{HT}-4$ & $<5.0$ & - \\
\hline
\end{tabular}




\section{Effect of $\mathrm{Cu}$ loading on catalytic activity}

Table S4. Catalytic performance of Cu-Mg-Al mixed oxides with different Cu contents in the selective dehydration of glycerol to acetol.

\begin{tabular}{cccc}
\hline Catalyst & $\begin{array}{c}\text { Cu content (wt\%) } \\
\text { [measured by } \\
\text { ICP] }\end{array}$ & $\begin{array}{c}\text { Glycerol conversion } \\
\text { (\%Mol.) }\end{array}$ & $\begin{array}{c}\text { Selectivity to acetol } \\
\text { (\%Mol.) }\end{array}$ \\
\hline HT-4 & - & 7.8 & 41.5 \\
$\mathbf{1 . 0 \% C u - H T - 4}$ & 1.0 & 44.1 & 46.8 \\
$\mathbf{2 . 5 \% C u - H T - 4}$ & 2.4 & 50.3 & 55.4 \\
$\mathbf{5 . 0 \% C u - H T - 4}$ & 4.9 & 68.3 & 54.6 \\
$\mathbf{7 . 0 \% C u - H T - 4}$ & 6.7 & 73.8 & 53.4 \\
$\mathbf{1 0 . 0 \% C u - H T - 4}$ & 9.9 & 86.4 & 58.0 \\
$\mathbf{1 2 . 0 \% C u - H T - 4}$ & 12.8 & 85.3 & 48.1 \\
\hline
\end{tabular}

Reaction conditions: feed $=\mathrm{MeOH} / \mathrm{GLY}(90 / 10 \mathrm{in}$ weight), flow $=2 \mathrm{ml} / \mathrm{h}$, with $0.5 \mathrm{~g}$ of catalyst at $240^{\circ} \mathrm{C}$, results at TOS $=4 \mathrm{~h}$.

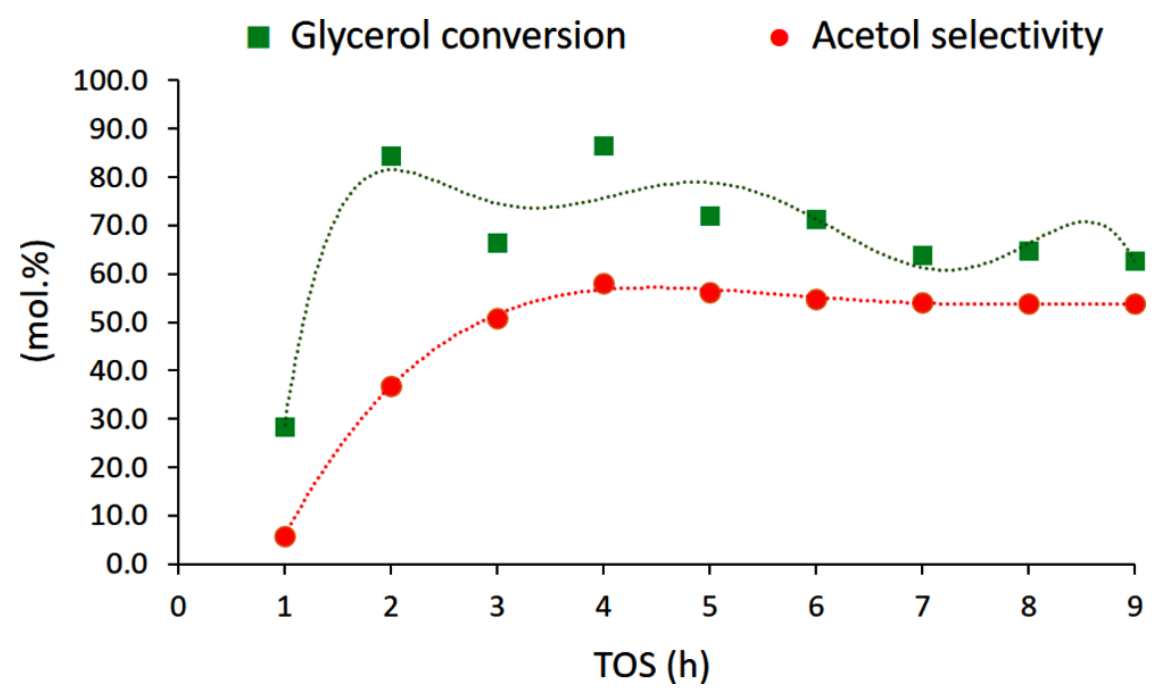

Figure S15. Catalytic performance of $10.0 \% \mathrm{Cu}-\mathrm{HT}-4$ in the selective dehydration of glycerol to acetol [Reaction conditions: feed $=\mathrm{MeOH} / \mathrm{GLY}$ (90/10 in weight), flow $=2$ $\mathrm{ml} / \mathrm{h}$, with $0.5 \mathrm{~g}$ of catalyst at $240^{\circ} \mathrm{C}$ ]. 

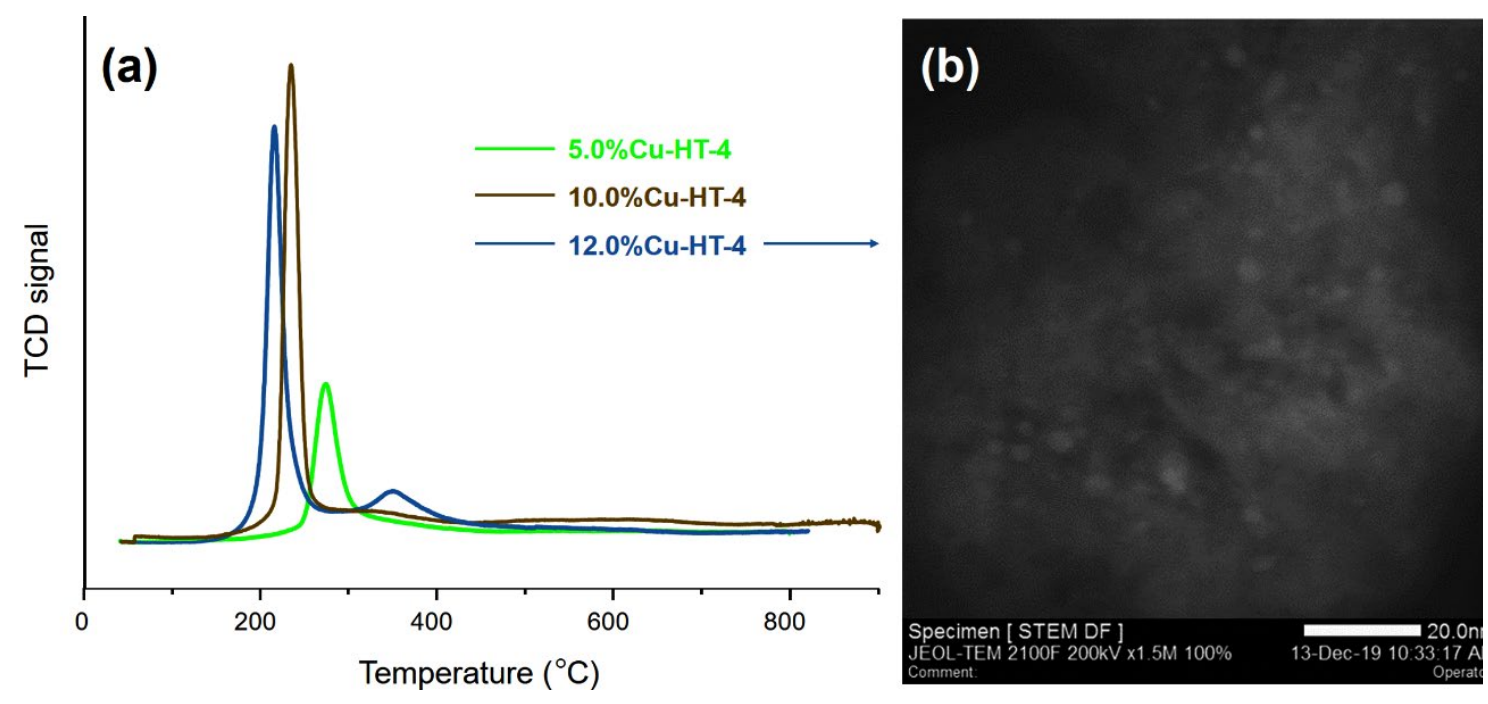

Figure S16. (a) TPR traces for $5.0 \% \mathrm{Cu}-\mathrm{HT}-4$ (green), $10.0 \% \mathrm{Cu}-\mathrm{HT}-4$ (brown) and $12.0 \% \mathrm{Cu}-\mathrm{HT}-4$ (blue) samples. (b) $\mathrm{CuO}_{x}$ nanoparticles seen in HR-TEM for $12.0 \% \mathrm{Cu}$ $\mathrm{HT}-4$ material.
(a) $\mathrm{TPD}-\mathrm{NH}_{3}$
(b) $\mathrm{TPD}-\mathrm{CO}_{2}$

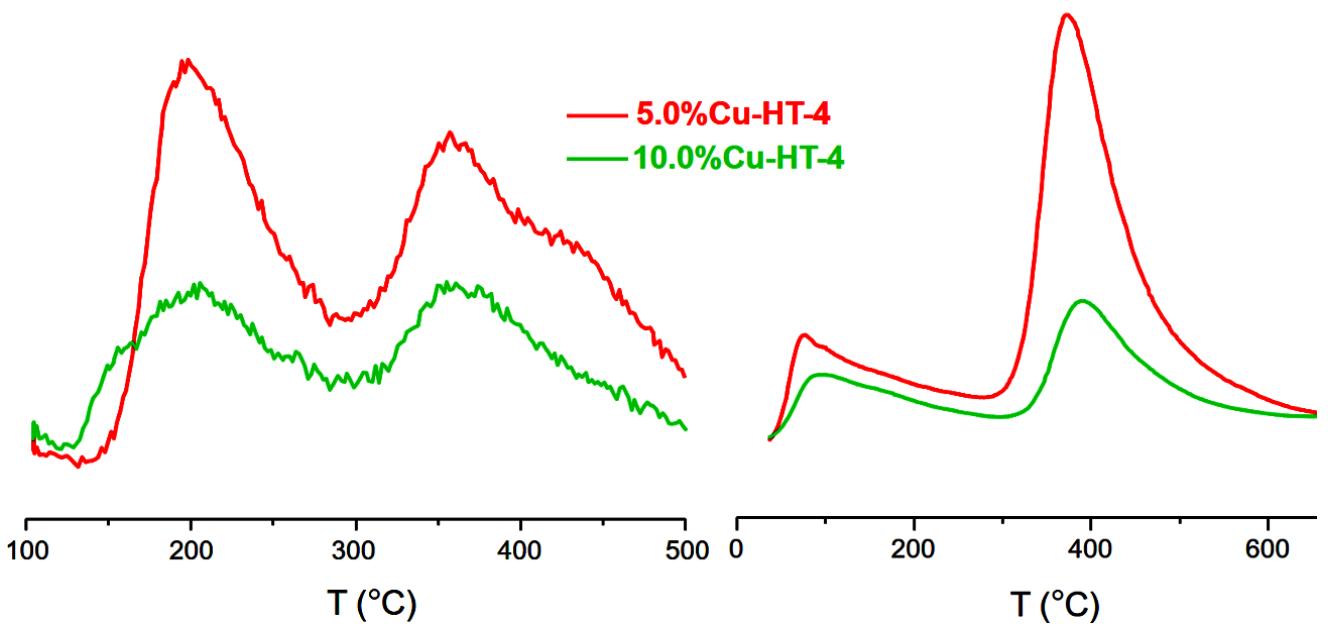

Figure S17. $\mathrm{NH}_{3}$-TPD (a) and $\mathrm{CO}_{2}$-TPD (b) profiles of Cu-Mg-Al hydrotalcite-derived mixed oxides with different $\mathrm{Cu}$ contents.

Table S5. Quantitative data for temperature programmed desorption $\left(\mathrm{NH}_{3}\right.$-TPD- and $\mathrm{CO}_{2}$-TPD) of $5.0 \% \mathrm{Cu}-\mathrm{HT}-4 \mathrm{C}$ and $10.0 \% \mathrm{Cu}-\mathrm{HT}-4 \mathrm{C}$ calcined materials.

\begin{tabular}{ccccc}
\hline Catalyst & $\begin{array}{c}\text { Acid site } \\
\text { density } \\
(\boldsymbol{\mu m o l} / \mathbf{g})\end{array}$ & $\begin{array}{c}\text { Basic site } \\
\text { density } \\
(\boldsymbol{\mu m o l} / \mathrm{g})\end{array}$ & $\begin{array}{c}\text { Acid peaks } \\
\text { (weak/strong) }\end{array}$ & $\begin{array}{c}\text { Basic peaks } \\
\text { (weak/medium) }\end{array}$ \\
\hline $\mathbf{5 . 0 \% C u - H T - 4 C}$ & 87 & 159 & $42: 58$ & $21: 79$ \\
$\mathbf{1 0 . 0 \% C u - H T - 4 C}$ & 80 & 165 & $45: 55$ & $33: 67$ \\
\hline
\end{tabular}




\section{Effect of introducing water}

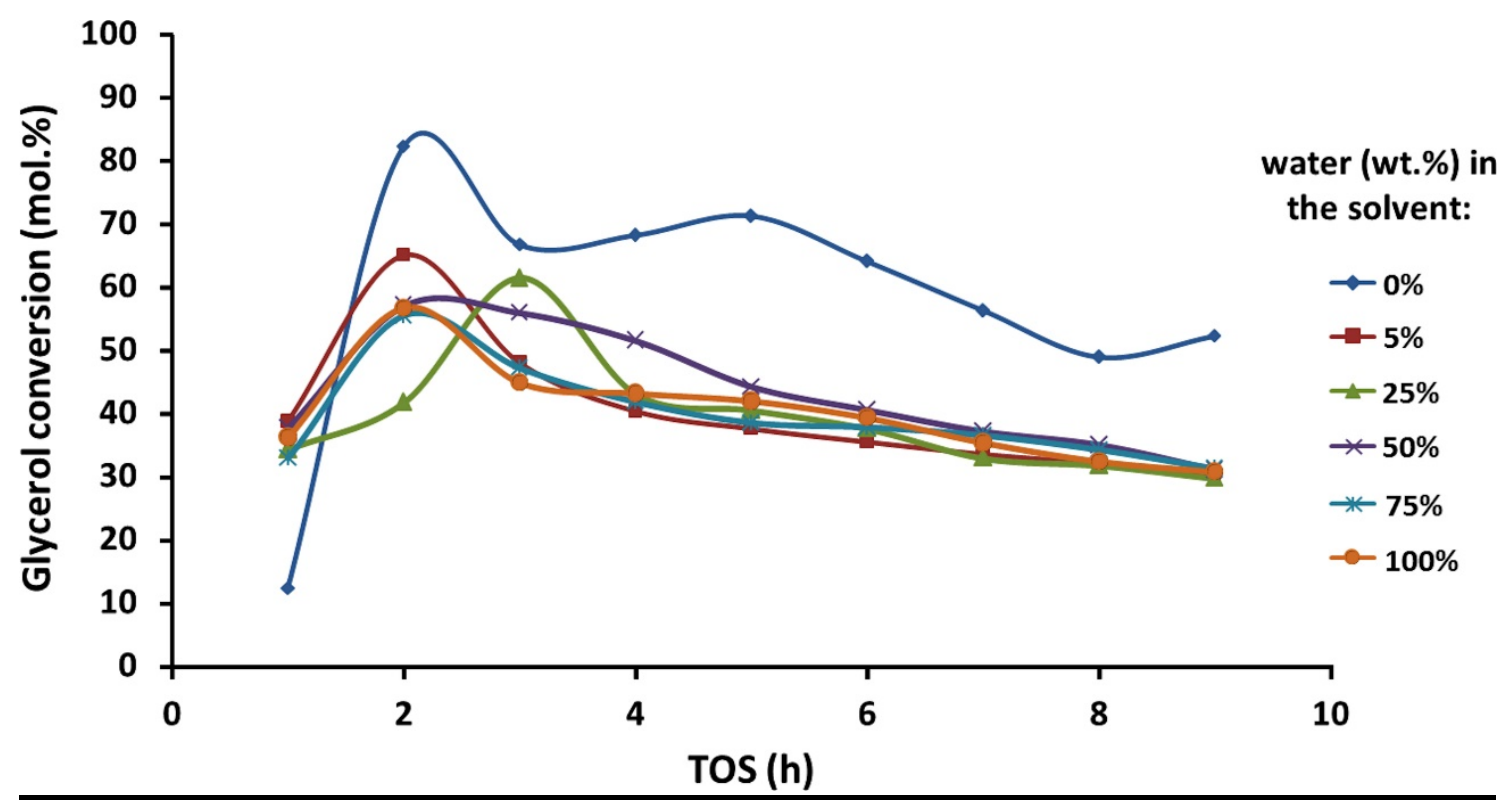

Figure S18. Glycerol conversion over $5.0 \% \mathrm{Cu}-\mathrm{HT}-4 \mathrm{C}$ calcined material by feeding the reactor with different $\mathrm{MeOH} / \mathrm{H}_{2} \mathrm{O}$ ratios (Reaction conditions: Temperature $=240{ }^{\circ} \mathrm{C}$, flow $=2 \mathrm{~mL} / \mathrm{h}$, catalyst: $0.5 \mathrm{~g}$ ).

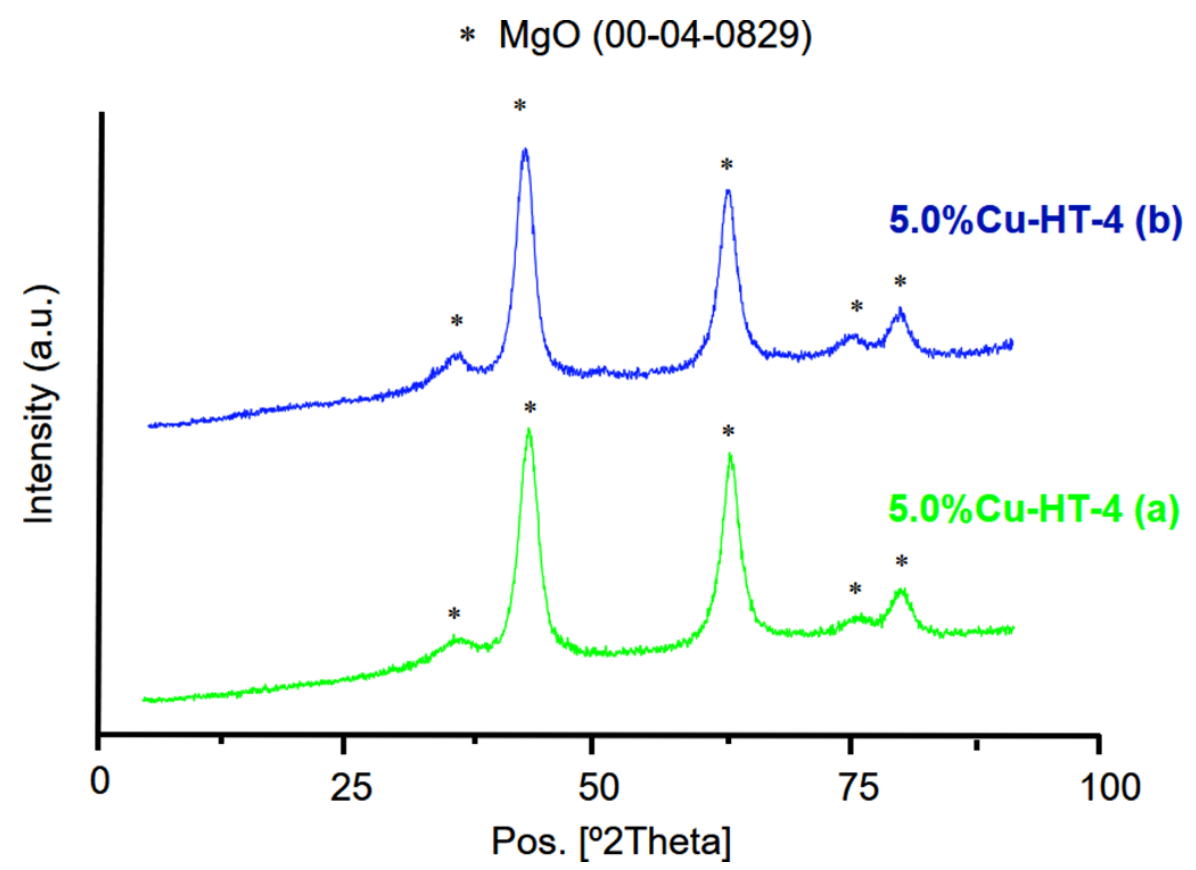

Figure S19. XRD patterns of 5.0\%Cu-HT-4 materials. (green): Material after having been used in catalytic reaction (feed of $\mathrm{MeOH} / \mathrm{GLY}=90: 10 \mathrm{wt}$.)., (blue): Material after having been used in catalytic reaction (feed of $\mathrm{H}_{2} \mathrm{O} / \mathrm{GLY}=90: 10$ wt.). 


\section{Catalysts recycling studies}

* $\mathrm{MgO}(00-04-0829)$ - $\mathrm{CuO}(00-002-1040)$ - $\mathrm{SiC}(00-002-1462)$
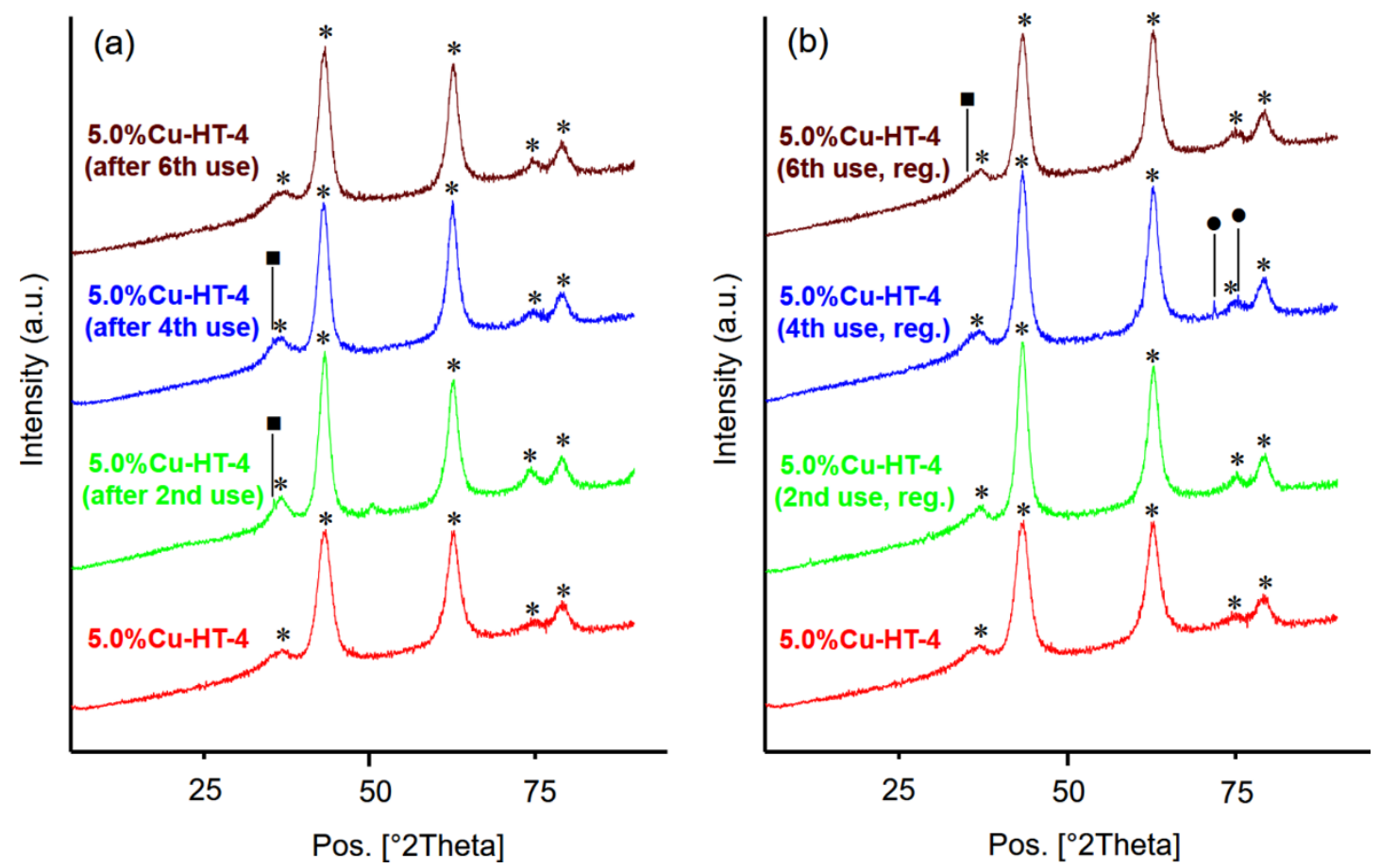

Figure S20. XRD patterns of $5.0 \% \mathrm{Cu}-\mathrm{HT}-4$ materials. (a): Materials after having been used in catalytic reaction (b): Materials after having been used in catalytic reaction and regenerated.

Table S6. Results of elemental and thermogravimetric analysis of $\mathrm{Cu}-\mathrm{Mg}-\mathrm{Al}$ materials after reaction and further regeneration $\left(550^{\circ} \mathrm{C}, 6 \mathrm{~h}\right.$, air).

\begin{tabular}{ccc}
\hline Catalyst & $\%$ C/ After reaction & $\%$ C/ After regeneration \\
\hline $\mathbf{5 . 0} \%$ Cu-HT-4 & $12.1\left(22.3^{\mathrm{a}}\right)$ & 1.6 \\
$\mathbf{1 0 . 0 \% C u - H T - 4}$ & $16.2\left(27.3^{\mathrm{a}}\right)$ & 1.5 \\
\hline a Total amount of carbonaceous matter on the catalytic surface (measured by TGA $)$
\end{tabular}

a Total amount of carbonaceous matter on the catalytic surface (measured by TGA).

Table S7. Surface area and metallic content evolution over several catalytic cycles of Cu-Mg-Al materials.

\begin{tabular}{cccccccccc}
\hline & \multicolumn{3}{c}{ Surface Area $\left.\mathbf{( m}^{2} / \mathbf{g}\right)$} & \multicolumn{2}{c}{$\mathbf{C u}(\mathbf{w t} \%)^{\mathbf{a}}$} & \multicolumn{2}{c}{$\mathbf{M g}(\mathbf{w t} \%)^{\mathbf{a}}$} & \multicolumn{2}{c}{$\mathbf{A l}(\mathbf{w t} \%)^{\mathbf{a}}$} \\
Catalyst & $\begin{array}{c}\text { Before } \\
\text { reaction }\end{array}$ & $\begin{array}{c}\text { After 1 } \\
\text { reaction }\end{array}$ & $\begin{array}{c}\text { After 2 } \\
\text { reactions }\end{array}$ & $\begin{array}{c}\text { Before } \\
\text { used }\end{array}$ & $\begin{array}{c}\text { After } \\
\text { used }\end{array}$ & $\begin{array}{c}\text { Before } \\
\text { used }\end{array}$ & $\begin{array}{c}\text { After } \\
\text { used }\end{array}$ & $\begin{array}{c}\text { Before } \\
\text { used }\end{array}$ & $\begin{array}{c}\text { After } \\
\text { used }\end{array}$ \\
\hline $\mathbf{5 . 0 \% C u - H T - 4}$ & 205 & 172 & - & 4.73 & 4.72 & 43.90 & 42.10 & 12.05 & 11.89 \\
$\mathbf{1 0 . 0 \% C u - H T - 4}$ & 192 & 153 & 150 & 9.90 & 9.61 & 41.72 & 39.69 & 12.09 & 11.73
\end{tabular}

a Before reaction and after $24 \mathrm{~h}$ on continuous stream for Cu-HT-4 type catalysts. 


\section{Other measurements}

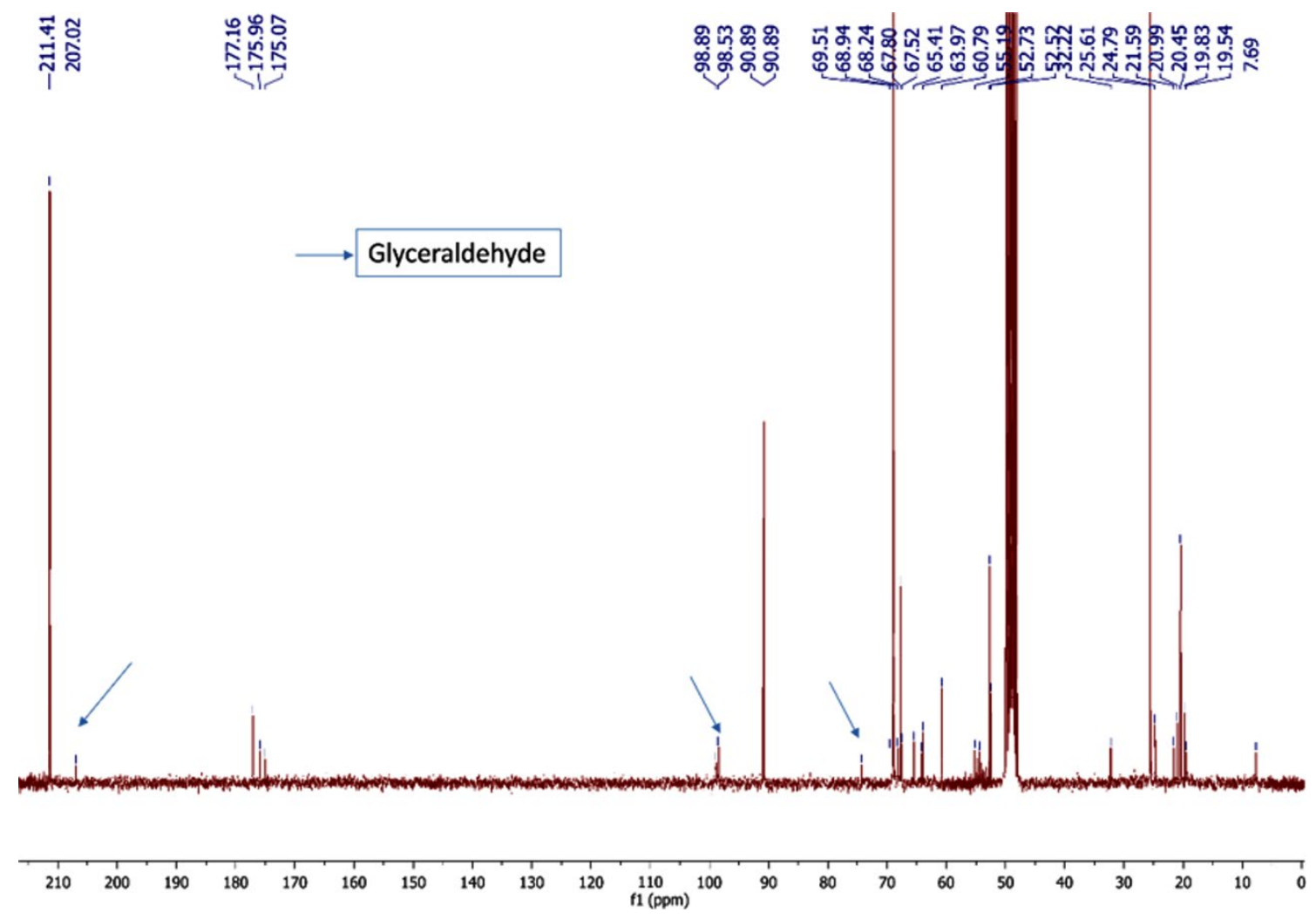

Figure S21. ${ }^{13} \mathrm{C}$ NMR of the selective glycerol dehydration over $5.0 \% \mathrm{Cu}-\mathrm{HT}-4$ with a mixture of glycerol+glyceraldehyde feed at $45 \mathrm{~min}$. (Reaction conditions: Feed: water/glycerol/glyceraldehyde $/ \mathrm{H}_{2} \mathrm{O}(87.8 / 9.5 / 0.43 / 2.2$ wt. $)$, temperature $=240{ }^{\circ} \mathrm{C}$, flow $=$ $2 \mathrm{~mL} / \mathrm{h}, 0.5 \mathrm{~g} 5.0 \% \mathrm{Cu}-\mathrm{HT}-4)$.

\section{Effect of aging conditions during the synthesis of $\mathrm{Cu}$-based HT-derived materials}

Our research group and several colleagues of our Institute have extensively studied this hydrotalcite-derived system over the last decades [8-10]. In this sense, the aging conditions as well as the $\mathrm{pH}$ after completing the addition of metallic precursors are well optimized to maximize both, the yield of the synthesis, i.e. the effectiveness of the coprecipitation, and those features resulting in the desired catalytic properties, i.e. surface area, crystalline structure, metals incorporation. Nonetheless, three more synthesis were carried out in order to address the referee's concern.

First and second syntheses refer to a hydrotalcite compositionally equivalent to $5.0 \% \mathrm{Cu}$ $\mathrm{HT}-4$ s prepared by aging at two different temperatures: $90{ }^{\circ} \mathrm{C}(5.0 \% \mathrm{Cu}-\mathrm{HT}-4 \mathrm{~s}-90)$ and 


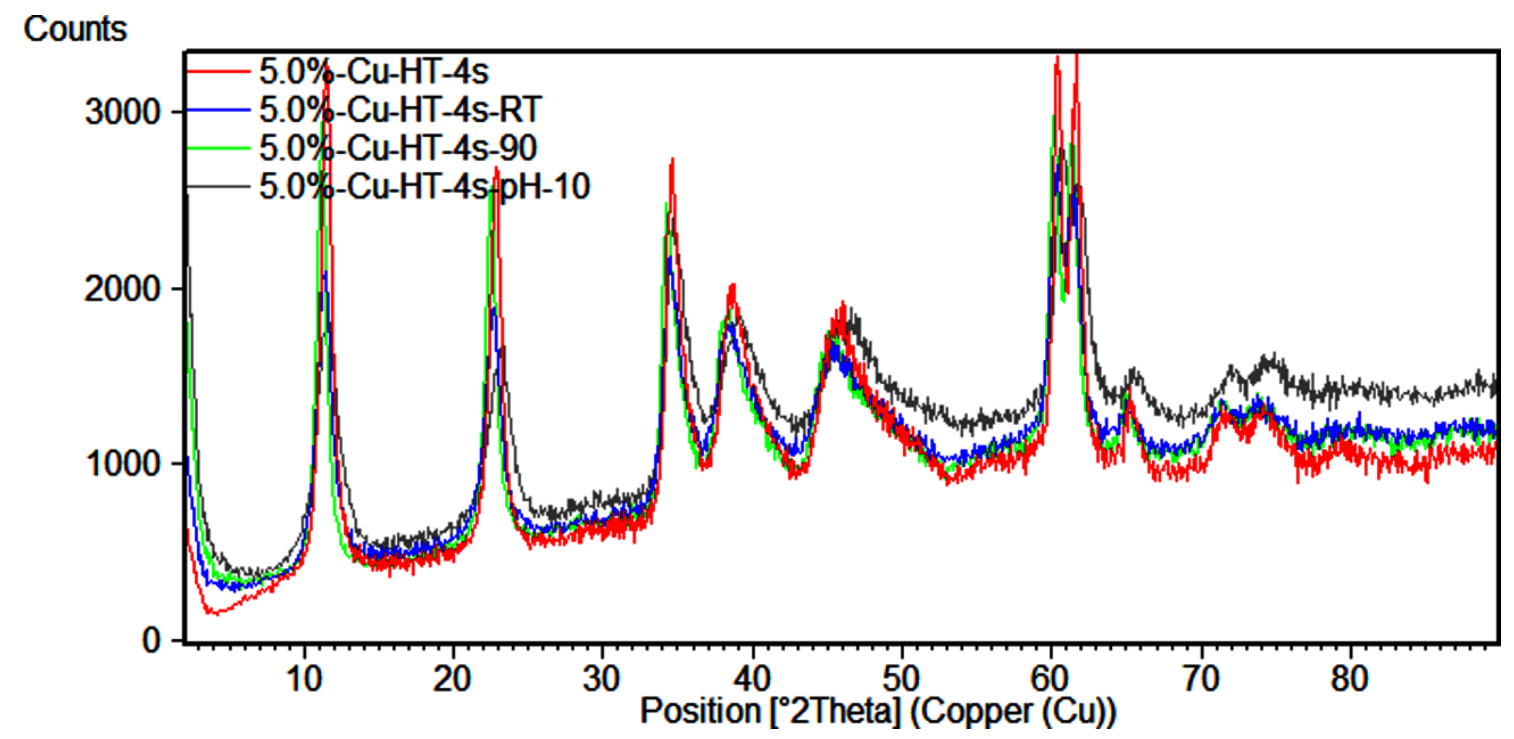

Figure S22. XRD patterns of as-synthesized Cu-based hydrotalcites with different aging conditions (the "s" at the end of the name indicates a material analysed just after the synthesis).

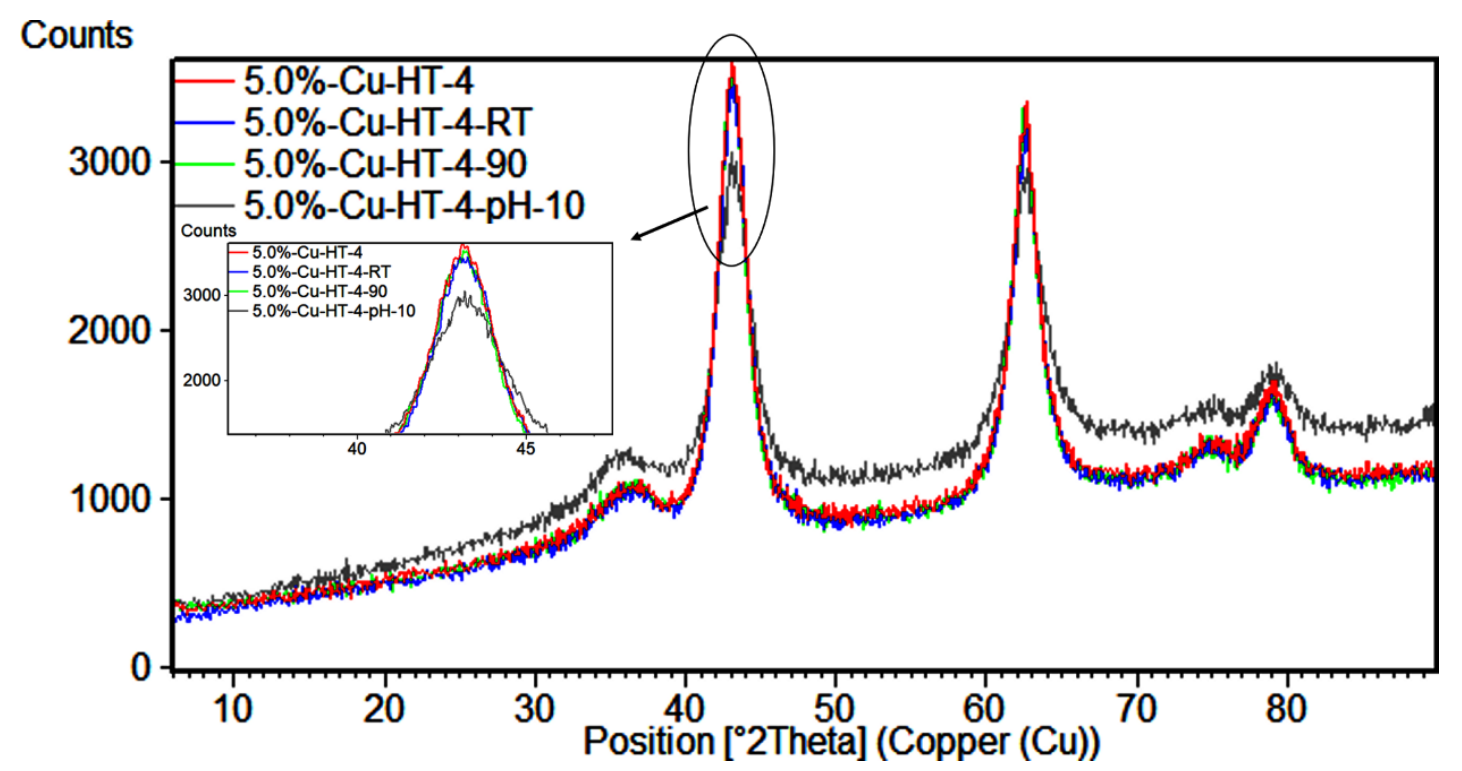

Figure S23. XRD patterns of Cu-based hydrotalcite-derived mixed oxides with different aging conditions.

Finally, and trying to further differentiate between the Cu-based HT-derived materials aged at $\mathrm{pH} \approx 14$, catalytic tests for selective dehydration of glycerol to acetol were performed for 5.0\%Cu-HT-4 (again), 5.0\%Cu-HT-4-AMB and 5.0\%Cu-HT-4-90. The results in Table S9 indicate a very similar catalytic performance in all cases, slightly standing out the reference material $5.0 \% \mathrm{Cu}-\mathrm{HT}-4$, whose aging conditions have been used throughout the whole work. 
Table S9. Catalytic activity data for hydrotalcite-derived mixed oxides with different aging temperatures.

\begin{tabular}{cccc}
\hline Catalyst & $\begin{array}{c}\text { Glycerol conversion } \\
(\% M o l .)\end{array}$ & $\begin{array}{c}\text { Selectivity to acetol } \\
(\% \text { Mol. })\end{array}$ & $\begin{array}{c}\text { Yield to acetol } \\
(\text { Mol. \% })\end{array}$ \\
\hline $5.0 \%$ Cu-HT-4 & 64 & 53 & 33 \\
$5.0 \%$ Cu-HT-4-AMB & 61 & 52 & 32 \\
$5.0 \%$ Cu-HT-4-90 & 67 & 48 & 32
\end{tabular}

Reaction conditions: Temperature $=240^{\circ} \mathrm{C}$, feed: $\mathrm{MeOH} / \mathrm{GLY}(90: 10 \mathrm{w}$.$) , flow =2 \mathrm{~mL} / \mathrm{h}$, catalyst: $0.5 \mathrm{~g}, \mathrm{TOS}=0-9 \mathrm{~h}$.

In summary, the aging conditions selected for Cu-based hydrotalcite-type materials here investigated, such as $\mathrm{pH} \approx 14$ and temperature $=60^{\circ} \mathrm{C}$ seem to be the required ones to maximize the yield of the synthesis and to attain a maximum level of acetol yield, respectively. Since crystallinity, composition and surface area of the three materials prepared at $\mathrm{pH} \approx 14$ are quite similar, the explanation of this catalytic result seems not to be straightforward. Nonetheless, as the differences are very subtle and the optimal conditions found here are in good agreement with most of the synthesis conditions described all over the literature, we have not considered within the scope of this paper to fully explain this possible small influence of the aging conditions on the catalytic performance.

\section{Selection of $\mathrm{MeOH}$ as solvent}

There were several reasons for choosing methanol as solvent. First, against the possibility of using water, it is well known that mixed oxides derived from hydrotalcites tend to suffer the so-called "memory effect" [12]. This means they undergo a retrotransformation to the corresponding hydrotalcite in the presence of considerable amounts of water. On the other hand, as the intended reaction is a dehydration, it was reasonable to avoid the presence of water in the reaction media as much as possible in order to prevent any additional thermodynamic constraint. The results presented in Figure $\mathrm{S} 18$ supports the avoidance of water as solvent.

Considering the above-mentioned facts, short chain alcohols such as methanol $(\mathrm{MeOH})$, ethanol $(\mathrm{EtOH})$ or isopropanol $(\mathrm{i}-\mathrm{prOH})$ were the best alternatives in terms of their miscibility with glycerol. Isopropanol was quickly discarded as it has been already reported that, in the presence of copper, many reactions such as decomposition [13] or 
dehydrogenation [14] can occur. Then, $\mathrm{EtOH}$ and $\mathrm{MeOH}$ were tried in a preliminary test. Form results of Table S10, EtOH was discarded due to the lower conversion attained with this alcohol as solvent. Then, $\mathrm{MeOH}$ was selected as solvent for the catalytic dehydration of glycerol studied in this work.

Table S10. Catalytic activity of hydrotalcite-derived Cu-Mg-Al mixed oxide with different solvents.

\begin{tabular}{ccc}
\hline Solvent & GLY conversion $^{\mathrm{a}}$ & Selectivity to acetol $^{\mathrm{a}}$ \\
\hline MeOH & 64.1 & 52.2 \\
EtOH & 49.6 & 49.4
\end{tabular}

a: Average glycerol conversion and selectivity to acetol during TOS $=1-9 \mathrm{~h}$ with $5.0 \% \mathrm{Cu}$ HT-4s as catalyst. (Reaction conditions: feed: solvent $/ G L Y=90 / 10$ wt., flow $=2 \mathrm{~mL} / \mathrm{h}$, temperature $=240^{\circ} \mathrm{C}$, catalyst $=0.5 \mathrm{~g}$ )

\section{References:}

[1] A.A. Davydov, A.A. Budneva, React. Kinet. Catal. Lett., 25 (1983) 121.

[2] S. Bordiga, C. Pazé, G. Berlier, D. Scarano, G. Spoto, A. Zecchina, C. Lamberti, Catal. Today, 70 (2001) 91-105.

[3] R.L. Manfro, T.P. Pires, N.F. Ribeiro, M.M. Souza, Catal. Sci. Technol. 3 (2013) 12781287.

[4] M. Araque, L.M. Martínez, J.C. Vargas, M.A. Centeno, A.C. Roger, Appl. Catal. B:Environ. 125 (2012) 556- 566.

[5] P. Lauriol-Garbay, J. Millet, S. Loridant, V. Bellière-Baca, P. Rey, J. Catal. 280 (2011) 68-76.

[6] S. Mészáros, J. Halász, Z. Kónya, P. Sipos, I. Pálinkó, Appl. Clay Sci. 80 (2013) 245248.

[7] R.B. Mane, C.V Rode. Green. Chem. 14(10) (2012) 2780-2789.

[8] A. Corma, A.E. Palomares, F. Rey, F. Márquez, J. Catal. 170 (1997) 140-149.

[9] F. Márquez, A.E. Palomares, F. Rey, A. Corma, J. Mater. Chem. 11 (2001) 16751680.

[10] N. Blanch-Raga, A. E. Palomares, J. Martínez-Triguero, G. Fetter, P. Bosch., Ind. Eng. Chem. Res. 52 (2013) 15772-15779.

[11] J.M. Oh, S.H. Hwang, J.H. Choy, Solid State Ion. 151 (2002) 285-291.

[12] A.A. Davydov, A.A. Budneva, React. Kinet. Catal. Lett., 25 (1983) 121.

[13] F. Pepe, C. Angeletti, S. De Rossi, M.L. Jacono, J. Catal. 91(1) (1985) 69-77.

[14] R.M. Rioux, M.A. Vannice, J. Catal. 216 (1-2) (2003) 362-376. 